Juliana Regueira Abath

Formação de Portfólio sob Incerteza de uma Empresa de Produção e Refino de Petróleo

Dissertação apresentada como requisito parcial para obtenção do grau de Mestre pelo Programa de Pósgraduação em Engenharia de Produção, do Departamento de Engenharia Industrial da PUC-Rio.

Orientador: Prof. Bruno Fânzeres dos Santos

Co-Orientador: Prof. Davi Michel Valladão

Rio de Janeiro

agosto de 2020 


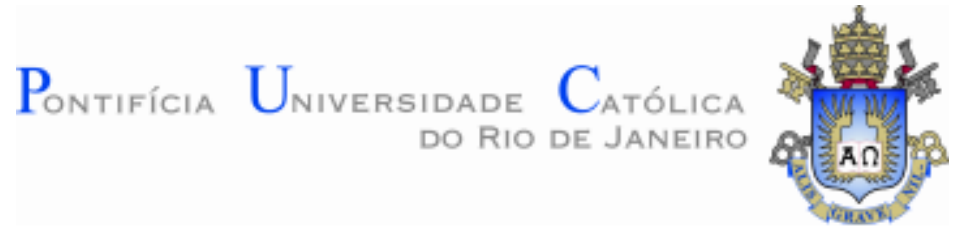

Juliana Regueira Abath

\section{Formação de Portfólio sob Incerteza de uma Empresa de Produção e Refino de Petróleo}

Dissertação apresentada como requisito parcial para obtenção do grau de Mestre pelo Programa de Pós-graduação em Engenharia de Produção da PUC-Rio. Aprovada pela Comissão Examinadora abaixo.

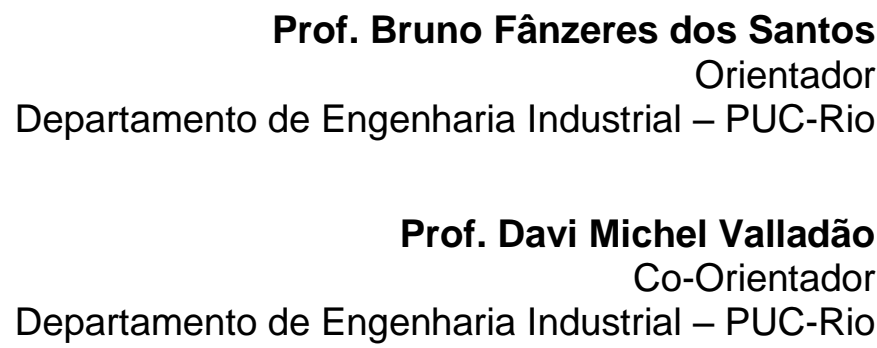

Prof. Silvio Hamacher

Departamento de Engenharia Industrial - PUC-Rio

Dr. Yuri Gama Lopes

Petrobras

Rio de Janeiro, 13 de agosto de 2020 
Todos os direitos reservados. É proibida a reprodução total ou parcial do trabalho sem autorização da universidade, da autora e do orientador.

\section{Juliana Regueira Abath}

Graduou-se em Engenharia de Produção na UFPE (Universidade Federal de Pernambuco) em 2011. É engenheira de produção na Petrobras desde 2012, atuando atualmente na área de estratégia, com ênfase em gestão do portfólio de E\&P.

Ficha Catalográfica

Abath, Juliana Regueira

Formação de portfólio sob incerteza de uma empresa de produção e refino de petróleo / Juliana Regueira Abath ; orientador: Bruno Fânzeres dos Santos ; co-orientador: Davi Michel Valladão. - 2020.

67 f. : il. color. ; $30 \mathrm{~cm}$

Dissertação (mestrado)-Pontifícia Universidade Católica do Rio de Janeiro, Departamento de Engenharia Industrial, 2020. Inclui bibliografia

1. Engenharia Industrial - Teses. 2. Gerenciamento de risco. 3. Portfólio de projetos. 4. Programação estocástica multi estágios. 5. Conditional value-at-risk. 6. Movimento de reversão a média. I. Santos, Bruno Fânzeres dos. II. Valladão, Davi Michel. III. Pontifícia Universidade Católica do Rio de Janeiro. Departamento de Engenharia Industrial. IV. Título.

CDD: 658.5 


\section{Agradecimentos}

Agradeço a todos que me ajudaram e me deram apoio durante esse período em que me dediquei ao mestrado, em especial ao meu marido Vinícius e a minha família.

Ao meu orientador Bruno Fanzeres, meu agradecimento por seu profissionalismo e dedicação que me ajudaram bastante na construção desse trabalho.

A Petrobras, por incentivar a capacitação dos seus funcionários, com destaque aos meus gerentes José Jorge de Moraes e Pedro Bruni.

A todos do departamento de Engenharia Industrial da PUC-Rio, pela cordialidade e organização.

Por fim, agradeço ao CNPq e à PUC-Rio, pela oportunidade e auxílios concedidos, sem os quais este trabalho não poderia ter sido realizado.

O presente trabalho foi realizado com apoio da Coordenação de Aperfeiçoamento de Pessoal de Nível Superior - Brasil (CAPES) - Código de Financiamento 001. 


\title{
Resumo
}

\begin{abstract}
Abath, Juliana Regueira; dos Santos, Bruno Fânzeres. Formação de Portfólio sob Incerteza de uma Empresa de Produção e Refino de Petróleo. Rio de Janeiro, 2020. 67p. Dissertação de Mestrado Departamento de Engenharia Industrial, Pontifícia Universidade Católica do Rio de Janeiro.
\end{abstract}

A formação do portfólio de uma empresa de Petróleo envolve complexas decisões devido ao ambiente de incertezas e é de extrema importância na definição do futuro estratégico da empresa. Recentemente, a otimização de um portfólio de ativos de exploração e produção de petróleo vem sendo amplamente tratada na literatura, entretanto observa-se uma escassez de trabalhos que consideram a otimização do portfólio de refino. Este trabalho tem por objetivo propor um modelo de formação de portfólio para empresas do setor de óleo e gás, que possuem atividades tanto no segmento de exploração e produção (upstream) quanto no segmento de refino (downstream), levando em conta a integração entre ambos. Assim como nos modelos tradicionais, os preços do barril de petróleo e a produtividade dos campos serão tratadas como incertezas. $\mathrm{O}$ modelo proposto utilizará técnicas de programação estocástica com aversão a risco, medido pelo CVaR (Conditional Value-at-Risk). A fim de validar a metodologia proposta, um estudo de caso baseado em uma empresa de óleo e gás será apresentado. A aplicação numérica indicou que o modelo que otimiza o portfólio conjunto de upstream e downstream apresenta resultado da função objetivo até $28 \%$ superior ao modelo usualmente tratado na literatura que trata apenas do portfólio de upstream.

\section{Palavras-chave}

Gerenciamento de risco; portfólio de projetos; programação estocástica multi estágios; Conditional Value-at-Risk; movimento de reversão a média. 


\section{Abstract}

Abath, Juliana Regueira; dos Santos, Bruno Fânzeres (Advisor). Portfolio Selection of an Oil and Gas Company Under Uncertainty. Rio de Janeiro, 2020. 67p. Dissertação de Mestrado - Departamento de Engenharia Industrial, Pontifícia Universidade Católica do Rio de Janeiro.

The portfolio allocation of an Oil and Gas company involves complex decisions within an uncertain environment and is extremely important in defining the firm's economical and financial future behavior. Recently, the portfolio selection problem for oil exploration and production (E\&P) projects has been widely treated in the literature, however, few studies consider the optimization of the combined upstream and downstream portfolio. The purpose of this work is to propose a portfolio selection model for oil and gas companies, which operates both in exploration and production (upstream) and in refining (downstream), considering the integration between them. Crude oil prices and fields' performance are the main uncertainties of the problem. The proposed model makes use of risk aversion stochastic programming techniques, measured by CVaR (conditional value at risk). To validate the proposed methodology a case study based on an Oil Company will be presented. The numerical application indicates that the model considering both upstream and downstream portfolio presents objective function results $28 \%$ higher than the model usually used in the literature that only optimizes the upstream portfolio.

\section{Keywords}

Risk management; portfolio selection; stochastic programming; conditional value-at-risk; mean reversion model. 


\section{Sumário}

1. Introdução 10

1.1._Objetivo e Contribuições 14

1.2. Revisão da Literatura 15

1.2.1. Segmento de E\&P 15

1.2.2._Segmento do Refino 16

2. Caracterização das Incertezas 18

2.1._Preços de Petróleo 18

2.2._Produção do E\&P 19

3. Modelo de Formação de Portfólio 23

4. Experimentos Numéricos 29

4.1_Dados do estudo numérico 29

4.2. Exemplo llustrativo 33

4.2.1 Sensibilidades ao preço do petróleo 34

4.2.2 Sensibilidades a demanda interna 35

4.2.3 Sensibilidades combinadas $\quad 37$

4.3. Estudo de caso pré-COVID 40

4.3.1. Resultados do Caso Base 40

4.3.2. Sensibilidade 2: perfil de risco 42

4.3.3. Análise comparativa das estratégias de portfolio 44

4.4. Estudo de caso pós-COVID 48

5. Conclusões $\quad 57$

6. Sugestão para Trabalhos Futuros 59

7. Referências Bibliográficas $\quad 60$

8. Anexol 64 


\section{Índice de Figuras}

Figura 1 - Lucro operacional das principais companhias de petróleo por setor

Figura 2 - Lucro operacional da Petrobras por segmento 13

Figura 3 - Preços históricos do petróleo (referência WTI) 18

Figura 4 - Cenários de taxa de declínio 21

Figura 5 - llustração do problema de uma empresa de petróleo 23

Figura 6 - cenários de preços de petróleo gerados a partir do MRM 31

Figura 7 - distribuição dos preços em $\mathrm{t}=1 \mathrm{e} t=12$

Figura 8 - Cenários de preços de petróleo convergindo para US\$ $30 / \mathrm{bbl}$

Figura 9 - Cenários de produção dos campos 33

Figura 10 - Decisão ótima para alto preço de petróleo 37

Figura 11 - Decisão ótima para preço de US\$90/bbl, demanda 20\% menor e custo de exportação de $20 \%$

Figura 12 - Decisão ótima para preço de US $\$ 30 / b b l$

Figura 13 - Decisão ótima para preço de US\$30/bbl e demanda $20 \%$ menor

Figura 14 - Decisão ótima para preço de US\$30/bbl, e demanda $20 \%$ menor e custo de exportação de $20 \%$

Figura 15 - Decisão ótima para o caso base

Figura 16 - Histograma dos lucros do E\&P e do refino 41

Figura 17 - Distribuição acumulada dos lucros do E\&P e do refino 41

Figura 18 - Decisões ótimas no E\&P frente ao parâmetro $\lambda$

Figura 19 - Decisões ótimas no refino frente ao parâmetro $\lambda$

Figura 20 - Resultado, soma dos lucros do E\&P e refino e CVaR para variações do $\lambda$

Figura 21 - Lucro esperado do E\&P e do refino e lucro operacional do E\&P

Figura 22 - Histograma dos resultados para $\lambda=0,2$ e $\lambda=0,8$

Figura 23 - histograma dos resultados para $\lambda=0$ e $\lambda=0,999$

Figura 24 - Comparação dos resultados entre o caso base e as estratégias

Figura 25 - Decisão ótima no E\&P em cada estratégia de otimização

Figura 26 - Decisão ótima no refino em cada estratégia de otimização

Figura 27 - Histogramas: Caso base e Estratégia 1

Figura 28 - Histogramas: Caso base e Estratégia 2

Figura 29 - Histogramas: Caso base e Estratégia 3

Figura 30 - Distribuição de probabilidade acumulada dos valores esperados das estratégias

Figura 31 - Distribuição de probabilidade das diferenças entre estratégias e o caso base

Figura 32 - Distribuição acumulada das diferenças entre estratégias e o caso base 
Figura 34 - Reversão a média dos preços do petróleo pós-COVID 50

Figura 35 - Preço do petróleo revertendo a US\$30 por barril 51

Figura 36 - Demanda de gasolina pós-COVID 51

Figura 37- Demanda de diesel pós-COVID 52

Figura 38 - Participação no E\&P nos 4 cenários pós-COVID 52

Figura 39 - Participação no refino nos 4 cenários pós-COVID 53

Figura 40 - Distribuição acumulada dos resultados dos 4 casos 53

Figura 41 - Probabilidades subjetivas de cada caso 54

Figura 42 - Decisões de primeiro estágio para o E\&P 54

Figura 43 - Decisões de primeiro estágio para o refino 54

Figura 44 - Distribuições acumuladas dos resultados caso cenário otimista aconteça

Figura 45 - Distribuições acumuladas dos resultados caso cenário pessimista aconteça 


\section{Índice de Tabelas}

Tabela 1 - Índices $\quad 24$

Tabela 2 - Conjuntos $\quad 25$

Tabela 3 - Parâmetros $\quad 25$

Tabela 4 - Variáveis $\quad 26$

Tabela 5 - Dados do E\&P $\quad 29$

Tabela 6 - Dados do Refino 29

Tabela 7 - Rendimento do tipo de petróleo por produto derivado 29

Tabela 8 - Demais Dados $\quad 30$

Tabela 9 - Demanda por derivados $\quad 30$

Tabela 10 - resultados dos parâmetros do MRM 30

Tabela 11 - Taxa de declínio dos campos 32

Tabela 12 - Potencial e período de entrada dos novos poços 32

Tabela 13 - Resultados (participação no E\&P) 34

Tabela 14 - Resultados (participação nas refinarias) 34

Tabela 15 - Lucro do E\&P, refino e total 35

Tabela 16 - Resultados (participação nas refinarias) 36

Tabela 17 - Participação nos campos de produção 36

Tabela 18 - Resultados $\quad 36$

Tabela 19 - Lucro E\&P, Lucro Refino e CVaR 40

Tabela 20 - Definição das estratégias 45

Tabela 21 - Lucro esperado, CVaR, Quantil 5\% e Quantil 95\% das
diferenças

Tabela 22 - Valor esperado, CVaR e resultado para os cenários pós-
COVID

Tabela 23 - Valor esperado e CVaR caso cenário otimista aconteça 55

Tabela 24 - Valor esperado e CVaR caso cenário pessimista aconteça 56 


\section{Introdução}

A formação de portfólio de uma empresa do setor de óleo e gás apresenta complexidade devido ao ambiente de várias incertezas. Tipicamente, empresas altamente concentradas no segmento de Exploração e Produção - E\&P (upstream) tem seus resultados diretamente afetados pela variabilidade dos preços do petróleo e do gás natural no mercado mundial. Além disso, as incertezas relativas ao volume de petróleo nos reservatórios explorados, associadas às dificuldades técnicas de produção, tornam as decisões do setor ainda mais difíceis. Em contrapartida, investimentos em refinarias (setor de downstream), apesar de historicamente apresentarem um retorno menor do que o upstream, estão menos suscetíveis a variações dos preços e na maioria dos casos não assumem altos riscos técnicos.

Importantes decisões no setor de petróleo requerem a consideração de incertezas, longos horizontes de tempo e múltiplas alternativas nos modelos de decisão (Suslick \& Schiozer, 2004). Além das incertezas relacionadas a descoberta de volumes de petróleo economicamente recuperáveis (volume de petróleo que se consegue extrair do reservatório com valor econômico positivo), o setor de E\&P possui outras incertezas operacionais mesmo na fase de desenvolvimento e de produção tais como, infraestrutura, programação da produção, qualidade do óleo, custos operacionais, características do reservatório, entre outras (Suslick \& Schiozer, 2004). Segundo Sefair et al. (2017) os retornos de projetos no setor de E\&P estão sujeitos a altas incertezas de geologia, custos de equipamentos, preço do petróleo, nível de produtividade dos poços, qualidade do óleo, entre outros. Consequentemente, segundo os autores, os projetos de E\&P usualmente possuem distribuição de lucros bastante assimétrica, com alta probabilidade de lucros pequenos e baixa probabilidade de altos lucros.

Frente a alta volatilidade dos resultados da exploração e produção, o refino apresenta um contraponto no portfólio das empresas integradas, por reduzirem a incerteza de alocação do óleo cru, além de promoverem economias de escala e reduzirem o risco do negócio de maneira geral (Al-Obaidan \& Scully, 1993).

Uma companhia de petróleo é dita verticalmente integrada quando os diferentes estágios da cadeia de valor (exploração, produção, refino, etc) estão 
conectados (Stevens, 2003). Ao longo dos anos, as empresas de petróleo alteraram suas estratégias de verticalização frente ao ambiente instável do setor.

Até o segundo choque do petróleo (1978-81), as principais empresas de petróleo estavam verticalmente integradas, financeiramente e operacionalmente (Stevens, 2003). A instabilidade gerada pela segunda crise do petróleo fez as empresas mudarem suas estratégias de crescimento para encolhimento, diversificação para foco e de integração vertical para terceirização (Grant \& Cibin, 1996). Este movimento de "desvertizalização" mudou o papel do refino na indústria: de apenas prover segurança para alocação do óleo produzido para um setor lucrativo que retorna seu custo de capital (Grant \& Cibin, 1996).

Tipicamente, empresas buscam a integração vertical como uma estratégia para economizar estoques, reduzir a complexidade do refino e obter eficiência nos custos de transação do produto, obtendo vantagens logísticas no escoamento do petróleo (Al-Moneef, 1998). Ainda assim, a integração E\&Prefino possui críticas tais como, o baixo valor agregado do barril refinado quando comparado ao barril produzido, a baixa atratividade nos investimentos em downstream e a possível geração de instabilidade em mercados com empresas integradas e empresas independentes de refino ou de E\&P (Al-Moneef, 1998).

Nesse contexto, algumas empresas do setor de óleo e gás consideram a integração vertical como uma estratégia essencial para mitigar os riscos da atividade de óleo e gás. Em contrapartida, outras empresas focam na diversificação do portfólio, sem necessariamente estarem verticalmente integrada, e ainda há empresas que trabalham com foco em um determinado segmento.

A integração vertical é um tema discutido de tempos em tempos no setor de óleo gás, oscilando entre a estratégia de focar em um só negócio para buscar eficiência e a estratégia de se tornarem empresas integradas para obter ganhos com o hedge natural entre os setores. 


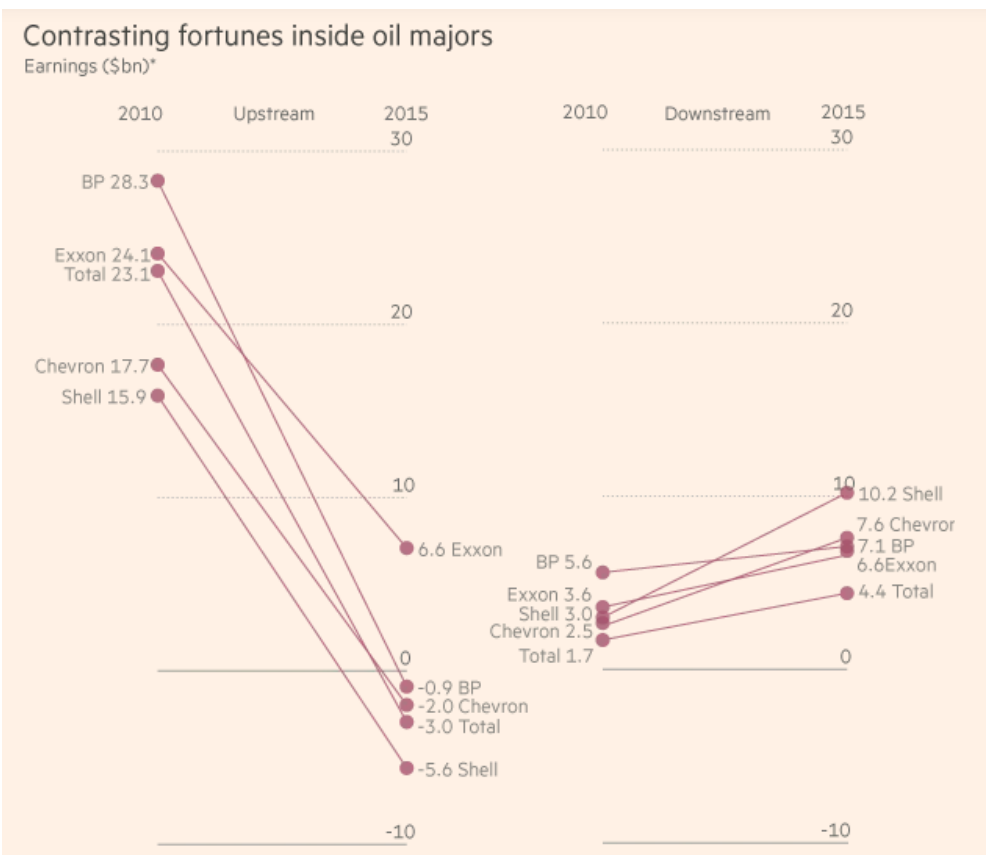

Figura 1 - Lucro operacional das principais companhias de petróleo por setor. Fonte: Financial times (https://www.ft.com/content/8ff8ec62-2dcc-11e6-a18d-a96ab29e3c95)

A figura 1 ilustra esse efeito quando a indústria viu os preços do petróleo despencarem entre 2010 e 2015, implicando em grandes reduções de lucro nos ativos de E\&P, que foram em parte compensados pelo aumento do lucro no refino.

No Brasil, mesmo após a quebra do monopólio da Petrobras em 1997, esta mantém suas atividades completamente integradas em todos os elos da cadeia, num sistema que vai desde a exploração de novas jazidas de petróleo até a distribuição para o consumidor final. Recentemente esta estratégia vem sendo questionada, devido aos expressivos resultados obtidos na exploração e produção de campos do pré-sal, frente a resultados marginais e até mesmo negativos no setor de refino, devido, entre outros fatores, ao controle de preço de derivados. No histórico do lucro operacional da empresa (Figura 2) pode se verificar tanto o ganho com a integração, nos anos de 2015 e 2016, quanto os prejuízos obtidos nos cenários de controle de preços, nos anos de 2013 e 2014. 


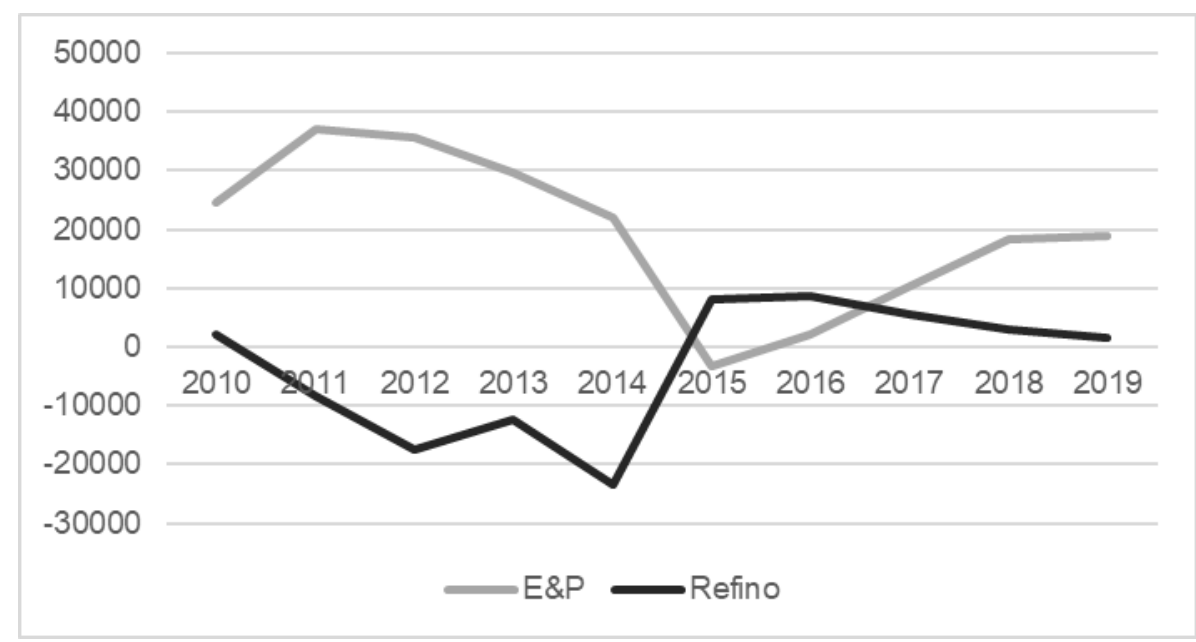

Figura 2 - Lucro operacional da Petrobras por segmento. Fonte dos dados: www.petrobras.com.br

A fim de melhor otimizar o valor de empresas do setor de petróleo em cenários de incerteza, uma metodologia para formação do portfólio considerando ambos os segmentos de E\&P e refino se faz necessária, para uma melhor análise desse efeito compensatório que pode ser observado entre eles. 


\section{1.}

\section{Objetivo e Contribuições}

Este trabalho tem por objetivo propor um modelo de formação de portfólio para empresas do setor de óleo e gás, que possuem atividades tanto no segmento de exploração e produção (upstream) quanto no segmento de refino (downstream), levando em conta a integração entre ambos.

Serão consideradas as principais incertezas da indústria: os preços do petróleo e a produção dos campos. Cenários de preços de petróleo serão gerados a partir de simulação utilizando o modelo de Reversão a Média (Dias, 2015). As incertezas na produtividade dos campos serão caracterizadas pela taxa de declínio da capacidade atual de produção e um potencial de entrada de um novo poço (Bomfim, 2017).

O modelo de formação de portfólio terá por objetivo identificar o conjunto de campos de produção e refinarias que maximizam a ponderação entre o valor esperado do portfólio da empresa e uma medida de risco, como em Fanzeres et al. (2015). No modelo se utilizará técnicas de programação estocástica com aversão a risco, sendo este último medido através do Conditional Value-at-Risk (CVaR).

A fim de ilustrar a aplicabilidade do modelo, serão apresentados dois experimentos numéricos: um exemplo ilustrativo e um estudo de caso. No estudo de caso serão avaliadas as vantagens da co-otimização do portfólio, os efeitos da aversão a risco e os impactos do novo contexto pós pandemia do corona vírus. Serão utilizados dados realísticos de uma empresa de óleo e gás para aplicação do modelo e análise dos resultados, bem como dados do mercado para variáveis econômicas que serão utilizados para a formulação, simulação e solução do problema em estudo. 


\section{2.}

\section{Revisão da Literatura}

\subsection{1.}

\section{Segmento de E\&P}

Devido as grandes incertezas e complexidades inerentes ao negócio de exploração e produção de petróleo, a formação de portfólio de E\&P vem sendo amplamente tratada na literatura, sob diversas óticas. A maioria dos trabalhos envolvem a aplicação e/ou adaptação da teoria moderna do portfólio, proposta pioneiramente por Markowitz (Markowitz , 1952). A teoria moderna do portfólio tem por objetivo buscar o portfólio de maior retorno para um nível fixo de variância, ou a menor variância dado um retorno esperado.

Orman \& Duggan (1999) demostram como uma empresa de E\&P pode utilizar os métodos de otimização de portfólio para definir o conjunto de projetos que resultam no menor risco, dado um nível de retorno. Os autores concluem que o uso da teoria moderna do portfólio torna a estratégia da companhia mais robusta e realista devido a consideração dos riscos.

Walls (2004) utiliza a teoria moderna do portfólio para otimização de portfólio de projetos de E\&P em conjunto com uma análise de preferência para identificar a tolerância a risco da empresa.

Mutavdzic \& Maybee (2015) agregam ao problema de otimização de portfólio de E\&P uma restrição de limite de investimentos e incluem projetos em fase de produção, além dos projetos exploratórios. Devido a sua menor variabilidade de retorno em relação aos projetos exploratórios, os autores associam os projetos em produção ao ativo livre de risco, e o utilizam para traçar uma linha de mercado de capitais. Bulai \& Horobet (2018) também consideram um portfólio com projetos em produção e projetos exploratórios para a construção de uma fronteira eficiente.

Motivados pela tendência das empresas de E\&P de busca contínua por eficiência de custos devido ao ambiente de baixos preços do petróleo, Tang et al. (2017) apresentam um modelo de programação quadrática que visa a realocação de investimentos no portfólio. O modelo proposto tem como objetivo minimizar o risco com restrições de orçamento de capacidade produtiva.

Yan \& Ji (2017) propõem um modelo de otimização sob incerteza para um portfólio de projetos de E\&P que maximiza o retorno esperado com restrições de risco de falência. Sefair et al. (2017) aplicam o modelo de média-semi-variância 
de seleção de portfólio da indústria de óleo e gás afim de obter o portfólio ótimo de projetos não divisíveis.

Lopes \& Almeida (2014) definem os três fatores chave para a seleção de portfólio de E\&P como sendo a natureza estocástica multi-objetivo da decisão, as sinergias entre os projetos e a influência que esses aspectos têm na estrutura de preferencias do decisor. Os autores propõem um modelo de decisão multiobjetivo para dar suporte a decisão de formação de portfólio de projetos em desenvolvimento (após sucesso da fase exploratória) com base na teoria da utilidade multi-atributo.

Assim como será tratado neste trabalho, Da Silva (2018) utilizou o conditional value at risk (CVaR) como medida de risco em um problema de formação de portfólio de E\&P que busca maximizar o valor esperado do portfólio.

Os diversos trabalhos que abordam a otimização do portfólio de E\&P, embora sejam robustos no tratamento das incertezas, dificilmente consideram sua sinergia com o portfólio de refino, como é o objetivo deste estudo.

\subsection{2. \\ Segmento do Refino}

Embora o problema de formação de portfólio de E\&P seja amplamente tratado na literatura, o portfólio de refino (downstream) é um problema pouco abordado.

Enquanto no segmento de E\&P modelos matemáticos são aplicados em problemas de seleção dos ativos de produção a serem desenvolvidos e problemas operacionais, no setor de downstream os modelos são mais aplicados em decisões de planejamento, programação e cronograma (Fiorencio et al., 2015).

Caetani et al. (2015) utilizam um modelo de decisão fuzzy chamado FETOPIS para ordenar as melhores alternativas para revitalização de uma refinaria no sul do Brasil. Os resultados dessa primeira etapa foram utilizados em um modelo de otimização de portfólio para selecionar o conjunto ótimo de projetos de revitalização.

Khor et al. (2017) tratam o problema de planejamento ótimo de uma refinaria através de programação estocástica, levando em consideração três incertezas: o preço do petróleo cru e o preço dos derivados, a demanda e o rendimento do petróleo cru nas unidades de destilação. 
Com o objetivo de maximizar o valor do parque de refino russo, Korotin et al. (2017) utilizam uma análise multi-critério para a seleção de projetos de melhoria em refinarias, dentro de um ambiente de incertezas na margem do produto final e nos regimes de tributação.

Modelos de otimização logística na cadeia de suprimentos do downstream são amplamente tratados na literatura (como em Fiorencio et al., 2015 e Ribas et al.,2010).

Carneiro (2008) propõe um modelo de otimização sob incerteza do portfólio de investimentos em projetos de aumento de capacidade em refinarias, com grande nível de detalhe do processo produtivo do downstream. O estudo aborda o risco por meio de duas medidas: CVaR e Minimax, levando em consideração incertezas no preço do petróleo e derivados, no fornecimento por tipo de petróleo e na demanda de derivados.

Carneiro et al. (2010) também propõe um modelo estocástico de dois estágios para a otimização dos investimentos e operações da cadeia de suprimentos do downstream sob incerteza, utilizando o CVaR como medida de risco.

Ribas et al. (2010) aborda a otimização do planejamento da cadeia de petróleo e dos investimentos no refino, considerando três diferentes abordagens para o tratamento das incertezas: um modelo estocástico de dois estágios, uma otimização robusta min-max e um modelo max-min.

Jonqua (2012) aprimora o modelo de otimização da cadeia do petróleo utilizado pela Petrobras (PLANINV) através da aplicação de técnicas de programação estocástica de dois estágios e técnicas de decomposição a fim de reduzir seu tempo computacional.

Carneiro (2008), Ribas et al. (2010), Carneiro et al. (2010) e Jonqua (2012) não consideram nos escopos dos seus trabalhos a otimização dos investimentos no setor de E\&P, nem trata de possíveis desinvestimentos (venda) dos ativos existentes.

Ainda que muitos trabalhos abordem a otimização do portfólio de exploração e produção considerando medidas de risco e alguns trabalhos abordem a otimização sob incerteza do portfólio de downstream, observou-se na literatura escassez de trabalhos abordando a decisão conjunta de investir ou desinvestir no portfólio de upstream e downstream, como é o foco deste trabalho. 


\section{Caracterização das Incertezas}

Nesta sessão serão abordadas as incertezas consideradas no problema: o preço do petróleo e a produção dos campos de petróleo.

\section{1.}

\section{Preços de Petróleo}

Historicamente, conforme exposto na Figura 3 abaixo, os preços do petróleo apresentaram altas variações por estarem correlacionados a diversos fatores, entre eles, o crescimento econômico mundial, descoberta de novas jazidas de petróleo e conflitos geopolíticos envolvendo os países produtores, tais como acordo entre os países membros da OPEP (Organização dos Países Exportadores de Petróleo), sansões dos Estados Unidos ao Irã e a instabilidade política da Venezuela.

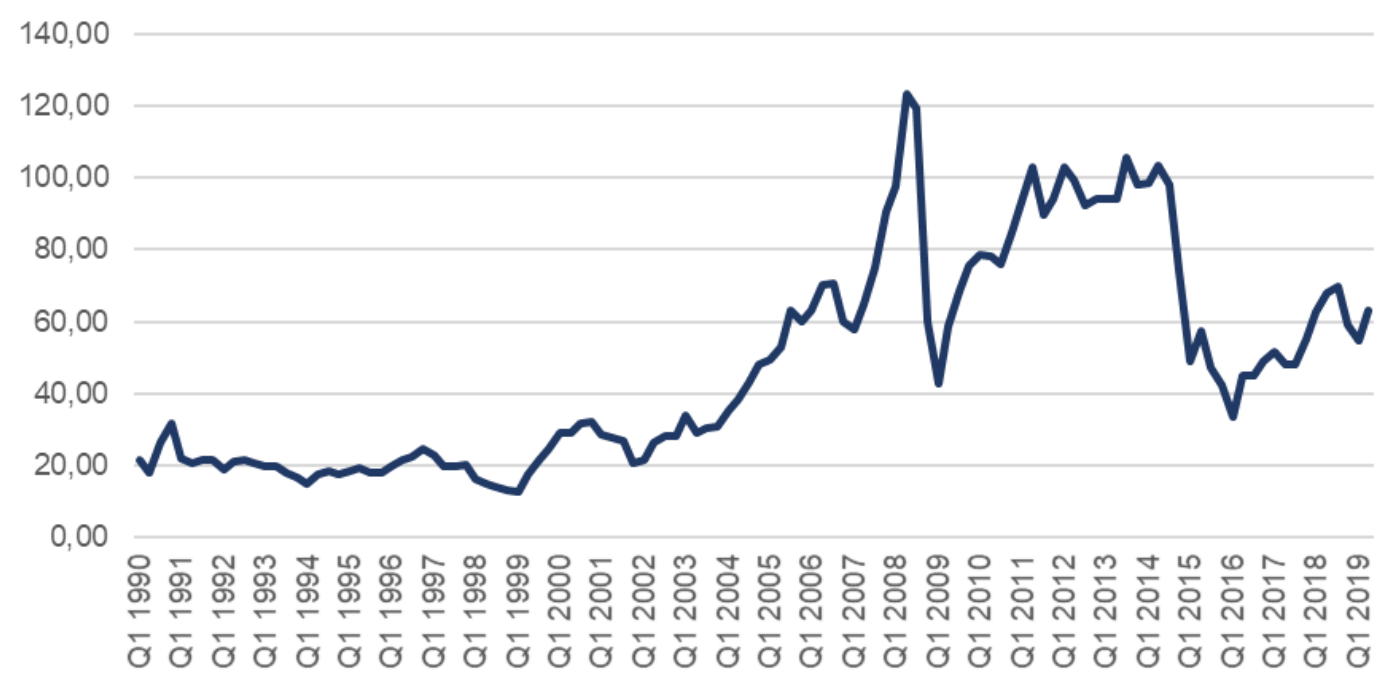

Figura 3 - Preços históricos do petróleo (referência WTI). Fonte dos dados: Evaluate Energy

A grande volatilidade dos preços do petróleo afeta diretamente as decisões de investimentos e o planejamento estratégico das empresas de óleo e gás, sendo considerada como o principal risco de mercado do negócio (Dias \& Rocha, 1999).

Neste contexto, consideração de um preço futuro determinístico pode levar a decisões equivocadas e grandes perdas de valor nas companhias. Considerar o 
preço de petróleo como incerteza é de extrema relevância e, por este motivo, sua modelagem estocástica vem sendo amplamente tratada na literatura ao longo dos anos, com diversas aplicações, como em Dias \& Rocha (1999), Gibson e Schwartz (1990) e Hahn et al (2014).

Cabe ressaltar que neste trabalho, considera-se que o volume produzido pela empresa não é grande o suficiente para ter influência no preço do petróleo, sendo este completamente definido por variáveis externas. Para a simulação estocástica dos preços de petróleo, neste trabalho, se utilizará o movimento de reversão a média, por ser comumente utilizado na simulação de preços de comodities (Dias,2015), como em Da Silva (2018) e em Dias \& Rocha (1999).

Os processos de reversão a média consideram que no longo prazo, os preços convergem para um valor médio. Esse processo estocástico proposto por Ornstein \& Uhlenbeck (1930) pode ser definido como:

$d x=\eta(\bar{x}-x) d t+\sigma d z$

onde $\eta$ é a velocidade de reversão, $\bar{x}$ é o valor médio de retorno, $\sigma$ é a volatilidade e $d z$ é o processo de Weiner de movimento browniano.

A equação (1) é a versão contínua de um processo auto regressivo de ordem 1 (AR1) quando $\Delta t$ tende a zero (Dixit \& Pindyck, 1994):

$x_{t}-x_{t-1}=\bar{x}\left(1-e^{-\eta}\right)+\left(e^{-\eta}-1\right) x_{t-1}+\varepsilon_{t}$

Onde $\varepsilon_{t}$ é normalmente distribuído com média zero e variância $\sigma_{\varepsilon}^{2}=\frac{\sigma^{2}}{2 \eta}(1-$ $\left.e^{-2 \eta}\right)$

Assumindo como hipótese que os preços $(\pi)$ seguem uma distribuição Lognormal $\left(x_{t}=\ln \left(\pi_{t}\right)\right)$, os cenários de preços serão estimados pela seguinte equação:

$\ln \left(\pi_{t}\right)=e^{-\eta \Delta t} \ln \left(\pi_{t-1}\right)+\bar{x}\left(1-e^{-\eta \Delta t}\right)+\sigma \sqrt{\frac{1-e^{-2 \eta \Delta t}}{2 \eta}} \beta$

(3)

Onde $\beta$ segue uma distribuição normal com média zero e desvio padrão igual a um. Os parâmetros $\eta, \bar{x}$ e $\sigma$ podem ser estimados por regressão linear pela equação (4) abaixo:

$\ln \left(\pi_{t}\right)-\ln \left(\pi_{t-1}\right)=b \ln \left(\pi_{t-1}\right)+a+\varepsilon$

\section{2.}

\section{Produção do E\&P}


A produção dos campos de petróleo apresenta incertezas em suas diversas fases de desenvolvimento. $\mathrm{Na}$ fase exploratória inicial do campo a grande incerteza está na existência ou não de petróleo tecnicamente e economicamente viável. Mesmo após a descoberta, declaração de comercialidade do campo e implantação do projeto de produção, as incertezas no volume produzido continuam sendo relevantes. Nesta fase, o risco de produção está associado às características geológicas do reservatório, que mesmo após a produção do primeiro óleo, não são totalmente conhecidas.

Neste trabalho considera-se apenas campos em produção, portanto sem 0 risco da descoberta da fase exploratória inicial do projeto.

À medida que são obtidas mais informações sobre o campo de petróleo, as incertezas quanto ao volume de petróleo no reservatório vão sendo mitigadas e as incertezas quanto ao fator de recuperação do óleo vão ganhando mais importância (Suslick \& Schiozer, 2004).

A estocasticidade na produção tipicamente é simulada em complexos modelos de reservatórios que levam em consideração incertezas nas características geológicas dos mesmos tais como porosidade, permeabilidade, modelo estrutural, conectividade entre as estruturas, entre outros, conforme tratado por dos Santos \& Schiozer (2003). Tecnologias de simulação de reservatórios evoluíram bastante nos últimos 20-30 anos, e hoje são consideradas maduras e amplamente aceitas e utilizadas pelas empresas do setor (Gorell \& Bassett, 2001).

A previsão de produção de petróleo envolve a combinação de dados geológicos, sísmicos, geofísico e de poços de diferentes fontes com complexas equações não lineares para a simulação de fluidos de reservatórios (Ballin et al.,1993).

Salomão \& Grell (2001) tratam as incertezas relativas à produção de petróleo em dois grupos: o volume de óleo "in place" e o fator de recuperação.

- As incertezas relativas ao volume de óleo "in place" estão relacionadas a fatores como os limites do reservatório, o contato do óleo com demais fluidos e os tipos de falhas no reservatório, cujos ranges são normalmente estimados a partir de interpretações de dados sísmicos e caracterização de porosidade e heterogeneidade das rochas.

- O fator de recuperação do reservatório é estimado a partir de fatores como a permeabilidade da rocha e dos fluidos, a viscosidade do óleo e a produtividade dos poços. 
Salomão \& Grell (2001) estimam a produção de um campo de petróleo utilizando a distribuição de probabilidade do volume de óleo, estimados a partir de dados geofísicos e geológicos, combinados com a distribuição de probabilidade do fator de recuperação, estimados em um modelo de simulação de fluidos.

Steagall \& Schiozer (2001) utilizam uma simulação numérica de fluidos para obter o impacto das incertezas na previsão de produção de petróleo. A partir da aplicação em um estudo de caso, os autores concluíram que a porosidade e a permeabilidade horizontal da rocha são os fatores de maior influência na incerteza de produção.

Subbey et al. (2003) combinam simulações de diferenças finitas e simulação de linhas de fluxo para caracterizar as incertezas na previsão de performance de reservatórios.

Bomfim (2017) modela a produção de um campo em produção a partir de quatro variáveis: potencial produtivo instalado, entrada de novos poços, parada programada para manutenção e eficiência.

A incerteza da produção, neste trabalho, utilizará como base o modelo empregado por Bomfim (2017), que modela campos já em produção, portanto sem risco exploratório e de desenvolvimento, que é o caso deste presente estudo. Por simplificação, apenas as variáveis de potencial produtivo instalado e entrada de novos poços. As paradas programadas para manutenção e a eficiência serão desconsideradas, por serem variáveis mais relevantes para análises de curto prazo, mas não para o longo prazo, conforme o caso a ser analisado neste estudo.

Segundo da Hora et al. (2019), uma vez atingindo o pico, a produção de campos de petróleo tendem a declinar com o tempo. O potencial produtivo instalado consiste na capacidade atual de produção do campo, que tende a ser reduzida ao longo dos anos a uma taxa de declínio incerta, conforme equação (5) abaixo.

$$
P_{t}=C_{i} * \tilde{T}_{d e c l}^{t}
$$

Onde o $P_{t}$ é o potencial produtivo instalado no período $t, C_{i}$ é a capacidade de produção inicial e $T_{\text {decl }}$ é a taxa de declínio acumulada no período $t$.

Bomfim (2017) trata a taxa de declínio através de uma função discreta com três valores: otimista, esperado e pessimista, cuja probabilidade de ocorrência de cada cenário é dada pela Lei de Swanson $\left(\mathrm{P}_{\text {otimista }}=0,3, \mathrm{P}_{\text {esperado }}=0,4 \mathrm{e}\right.$ $\left.P_{\text {pessimista }}=0,3\right)$. 


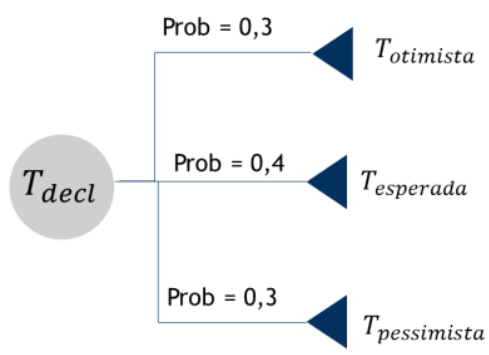

Figura 4 - Cenários de taxa de declínio

Devido à dificuldade dos especialistas em gerar prospectos de reservatórios para um percentil acima de $90 \%$ e abaixo de 10\%, Swanson propôs, em um memorando interno da Exxon, o uso do tamanho médio do prospecto através dos percentuais 30-40-30 (Hurst et al., 2000). Segundo Hurst et al. (2000), a lei de Swanson, desde então, vem sendo amplamente usada na indústria de exploração de petróleo.

A entrada de novos poços é modelada em Bomfim (2017) como um potencial inicial do novo poço vezes a taxa de declínio do novo poço, ambos incertos. Bomfim (2017) também considera a data de entrada do poço como incerta, entretanto, neste estudo, será considerado que a decisão da data de realização do poço já foi tomada e a data esperada já está disponível, sendo portanto determinística. Desta maneira, no presente estudo, a entrada de novos poços será tratada conforme equação 6 a seguir.

$$
q_{t}= \begin{cases}q_{t-1} * \tilde{T}_{\text {decl }}^{\text {novo }} & \forall t>\tau \\ \tilde{q}_{i} & \forall t=\tau \\ 0 & \forall t<\tau\end{cases}
$$

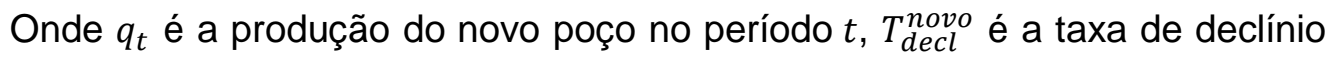
do novo poço, $\tilde{q}_{i}$ é o potencial inicial do novo poço e $\tau$ é o período no qual o novo poço inicia a produção.

Bomfim (2017) trata o potencial inicial do novo poço como uma distribuição triangular com parâmetros otimista, pessimista e mais provável (equação 7). A taxa de declínio do novo poço é caracterizada de maneira similar a taxa de declínio da capacidade instalada.

$\tilde{q}_{i}=\operatorname{DistTriang}\left(q_{\text {otimista }}, q_{\text {esperada }}, q_{\text {pessimista }}\right)$ 


\section{Modelo de Formação de Portfólio}

O problema a ser modelado consiste em uma empresa do setor de petróleo que possui campos de produção de petróleo e refinarias. A empresa tem a opção de refinar o petróleo em suas refinarias para abastecer a demanda do mercado interno, ou exportar o petróleo bruto para o mercado externo. A empresa ainda tem a opção de importar o petróleo cru do mercado externo para refiná-lo em suas refinarias para abastecer a demanda interna. $O$ objetivo da empresa é escolher o portfólio ótimo de campos de produção e refinarias que maximiza a ponderação do valor esperado do portfólio e uma medida de risco. A figura 5 abaixo ilustra o problema.

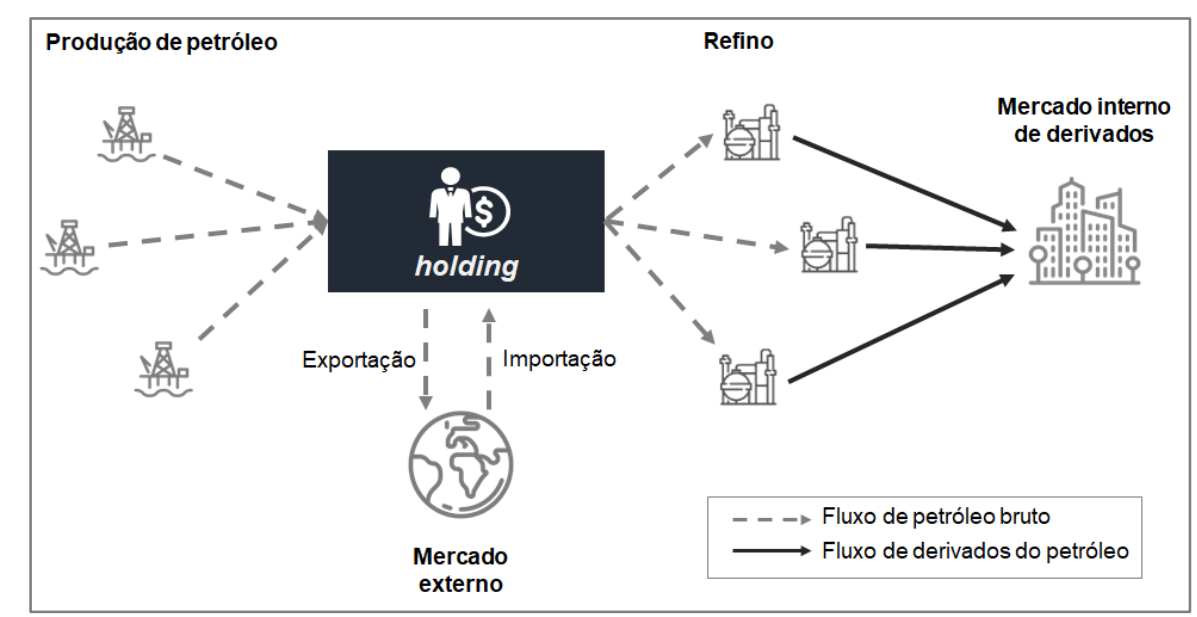

Figura 5: llustração do problema de uma empresa de petróleo

A importação e exportação de produtos derivados não é considerada neste modelo por simplificação. Os produtos derivados podem ser estocados, incorrendo em custos e limitados a capacidade de estoque das refinarias. $O$ estoque de petróleo cru, entretanto, não está sendo tratada neste trabalho.

Tipicamente, a demanda por derivados possui uma correlação direta com o crescimento econômico do país, sua distribuição demográfica de população rural e urbana, e o crescimento das atividades industriais (Parikh et al., 2007). Neste modelo, a demanda do mercado interno será tratada como determinística, sendo um insumo do problema. Mais de um cenário de demanda interna será analisado.

O modelo não possui restrição de demanda externa por petróleo cru, entretanto, considera que há um custo adicional para alocação do petróleo cru no mercado externo relacionado a logística, bem como na importação de óleo cru. 
A escolha do portfólio ótimo é feita considerando a decisão de investimento e desinvestimento em campos de produção de petróleo e em refinarias já em fase de operação. Isto é, a decisão de investimento refere-se a compra (farm-in) de ativos já construídos e em produção, onde os resultados são obtidos imediatamente a decisão de se investir. A exploração e desenvolvimento de novos campos e construção de novas plataformas e refinarias incorrem em um tempo maior para obtenção de resultados (média de 8 anos, para o caso do campo de produção), e não estão no escopo deste trabalho. Investimentos residuais necessários para continuidade operacional dos ativos são consideradas nas parcelas dos custos fixos.

Cabe ressaltar que o valor de investimento e desinvestimento dos campos de E\&P variam em função do patamar do preço do petróleo, aumentando de valor nos cenários de preços altos. Esta variação está sendo considerada no modelo.

O lucro do segmento de E\&P é formado pela receita do óleo produzido em função do preço do petróleo menos seus custos de produção. Já o segmento de refino tem seu lucro constituído pela receita de venda do produto derivado (como diesel e gasolina) menos seus custos de refino e custos de matéria prima, que é o próprio petróleo cru. O produto derivado tem seu preço de venda formado pelo preço do petróleo, acrescido de uma margem. No problema tratado, existe um preço máximo de petróleo que a refinaria consegue repassar integralmente no preço de venda do produto derivado. Este preço máximo visa representar o controle de preços dos derivados já ocorridos no Brasil, em momentos de alto preço internacional do petróleo.

Como os dados de entrada do problema estão dólar, o impacto de variações cambiais não será tratado neste modelo.

O problema apresentado anteriormente será tratado pelo modelo descrito a seguir.

\section{Índices}

\begin{tabular}{ll}
\hline $\mathrm{i}$ & Campos de produção: $\{1 \ldots \mathrm{N} 1$ final $\}$ \\
$\mathrm{j}$ & Refinarias: $\left\{1 \ldots \mathrm{N} 2 \_\right.$final $\}$ \\
$\mathrm{t}$ & Períodos: $\quad\{1 \ldots \mathrm{T}$ final $\}$ \\
$\mathrm{s}$ & Cenários: $\quad\left\{1 \ldots . \mathrm{S} \_\right.$final $\}$ \\
$\mathrm{k}$ & Grau API do petróleo $\{$ leve, médio, pesado $\}$ \\
$\mathrm{d}$ & Derivado $\left\{1 \ldots \mathrm{D} \_\right.$final $\}$
\end{tabular}

\section{Conjuntos}




\begin{tabular}{ll}
\hline $\mathrm{N}^{1}$ & Conjunto de campos de produção \\
$\mathrm{N}^{2}$ & Conjuntos de refinarias \\
$\mathrm{T}$ & Conjunto de períodos \\
$\mathrm{S}$ & Conjunto de cenários \\
$\mathrm{K}$ & Conjunto de tipo de óleo (leve, médio, pesado) \\
$\mathrm{D}$ & Conjunto de tipo de derivado (gasolina, diesel) \\
\hline Tabela 2-Conjuntos
\end{tabular}

Tabela 2 - Conjuntos

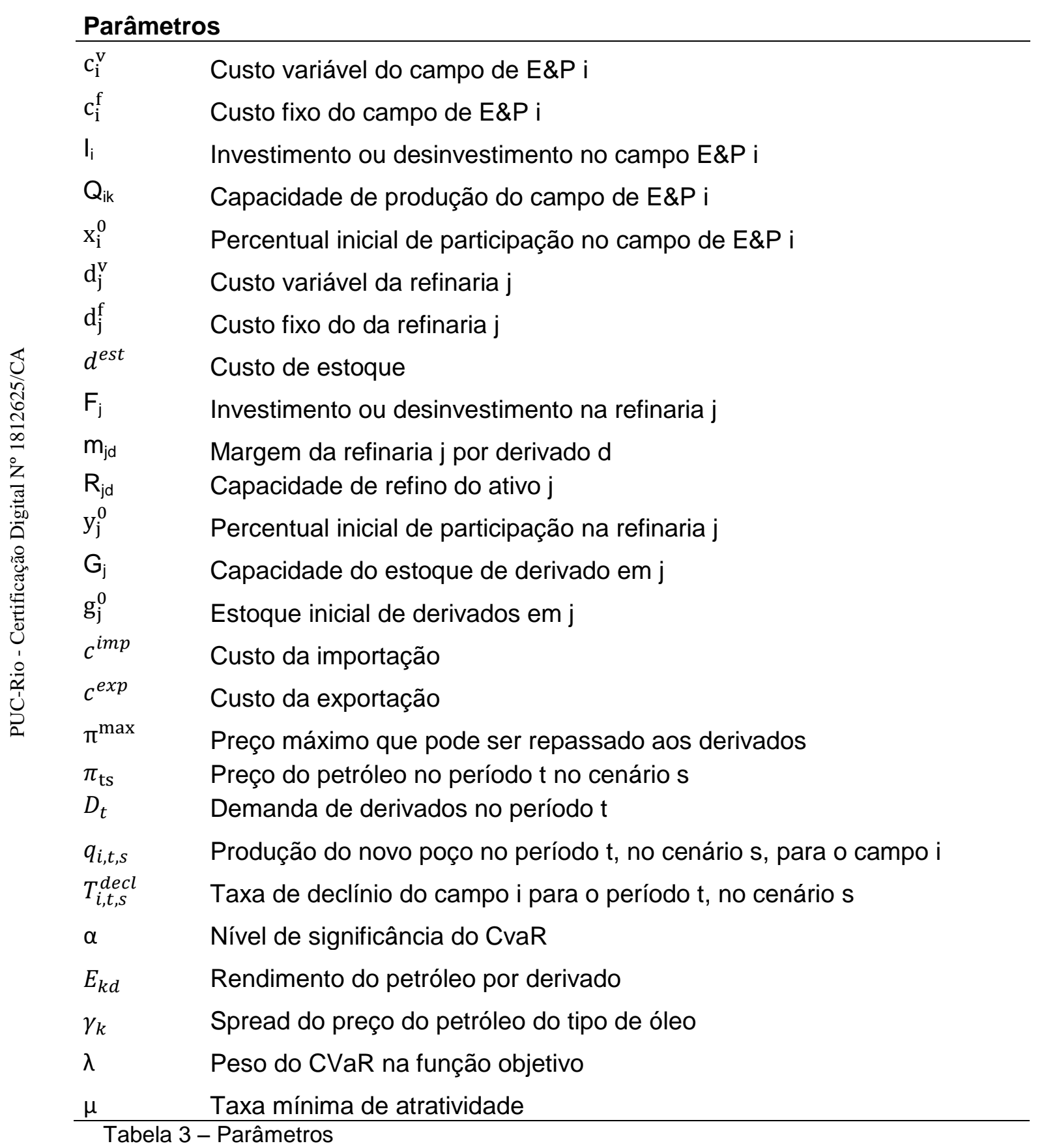




\begin{tabular}{ll}
\hline $\mathrm{x}_{\mathrm{i}}$ & Mudança na participação no campo de E\&P \\
$\mathrm{y}_{\mathrm{i}}$ & Mudança na participação na refinaria \\
$\mathrm{z}_{\mathrm{ijtsk}}$ & Produção do campo i que é refinada em j \\
$\mathrm{W}_{\text {itsk }}$ & Quantidade de óleo exportada do campo i \\
$\mathrm{h}_{\mathrm{j} \text { tsk }}$ & Quantidade de óleo importada para a refinaria j \\
$\mathrm{r}_{\mathrm{j} \text { tsd }}$ & Quantidade de derivado d refinado na refinaria j \\
$\mathrm{V}_{\mathrm{j} \text { tsd }}$ & Quantidade vendida de derivado d em j \\
$\mathrm{g}_{\mathrm{jtsd}}$ & Estoque de derivado d em j \\
$L_{S}^{E \& P}$ & Valor presente do segmento E\&P \\
$L_{s}^{\text {Ref }}$ & Valor presente do segmento de refino \\
$\mathrm{a}$ & Valor limite de ocorrência de um lucro inferior com \\
$\mathrm{b}$ & $\quad$ probabilidade (1- a) \\
\hline Tabela 4 - Variáveis
\end{tabular}

\section{Modelo:}

$\operatorname{Maximizar}\left(\frac{\sum_{s \in S} \mathrm{~L}_{\mathrm{s}}^{\mathrm{E} \& \mathrm{P}}+\mathrm{L}_{\mathrm{s}}^{\mathrm{Ref}}}{|\mathrm{S}|}\right) *(1-\lambda)+\left(\mathrm{a}-\frac{\left[\sum_{\mathrm{s} \in \mathrm{S}} \mathrm{b}_{\mathrm{s}}\right] / \mathrm{S}}{1-\alpha}\right) * \lambda$

Sujeito a

$$
\begin{aligned}
& L_{S}^{E \& P}=\sum_{\mathrm{i} \in N^{1}} \sum_{\mathrm{t} \in \mathrm{T}}\left(\sum _ { \mathrm { k } \in \mathrm { K } } \left(\left(\left(\sum_{j \in N^{2}} \mathrm{z}_{\mathrm{ijtsk}}\right) * \pi_{\mathrm{ts}} * \gamma_{k}+\mathrm{W}_{\mathrm{itsk}} *\left(1-\mathrm{c}^{\text {exp }}\right) * \pi_{\mathrm{ts}} * \gamma_{k}-\mathrm{c}_{\mathrm{i}}^{\mathrm{v}} *\left(\mathrm{z}_{\mathrm{ijtsk}}\right.\right.\right.\right. \\
& \left.\left.\left.+\mathrm{W}_{\mathrm{itsk}}\right)\right)-\left(\mathrm{c}_{\mathrm{i}}^{\mathrm{f}} *\left(\mathrm{x}_{\mathrm{i}}^{0}+\mathrm{x}_{\mathrm{i}}\right)\right)\right) /(1+\mu)^{t}-\mathrm{I}_{\mathrm{i}} * \mathrm{x}_{\mathrm{i}} \quad \forall s \in S \\
& L_{s}^{\text {Ref }}=\sum_{\mathrm{t} \in \mathrm{T}} \sum_{\mathrm{i} \in N^{1}} \sum_{\mathrm{j} \in N^{2}} \sum_{d \in D} \sum_{k \in K}\left(\mathrm{v}_{\mathrm{jtsd}} *\left(\operatorname{Min}\left\{\pi_{\mathrm{ts}}, \pi^{\mathrm{max}}\right\}+\mathrm{m}_{\mathrm{jd}}\right)-\left(\mathrm{d}_{\mathrm{j}}^{\mathrm{f}} *\left(\mathrm{y}_{\mathrm{j}}^{0}+\mathrm{y}_{\mathrm{j}}\right)+\mathrm{d}_{\mathrm{j}}^{\mathrm{v}} * \mathrm{r}_{\mathrm{jtsd}}\right.\right. \\
& \left.+d^{\text {est }} * g_{j t s d}\right)-\left(\mathrm{z}_{\mathrm{ijtsk}} * \pi_{\mathrm{ts}} * \gamma_{k}+\mathrm{h}_{\mathrm{jtsk}} * \pi_{\mathrm{ts}} *\left(1+c^{i m p}\right)\right. \\
& \left.\left.* \gamma_{k}\right)\right) /(1+\mu)^{t}-\mathrm{F}_{\mathrm{j}} * \mathrm{y}_{\mathrm{j}} \quad \forall s \in S \\
& \sum_{\mathrm{j} \in N^{2}} \mathrm{z}_{\mathrm{ijtsk}}+\mathrm{W}_{\mathrm{itsk}} \leq\left(Q_{i, k} * T_{i, t, s}^{d e c l}+q_{i, t, s}\right) *\left(\mathrm{x}_{\mathrm{i}}^{0}+\mathrm{x}_{\mathrm{i}}\right) \quad \forall \mathrm{i} \in N^{1}, \mathrm{t} \in \mathrm{T}, \mathrm{s} \in \mathrm{S}, \mathrm{k} \in \mathrm{K} \\
& \mathrm{r}_{\mathrm{jtsd}} \leq \mathrm{R}_{\mathrm{jd}} *\left(\mathrm{y}_{\mathrm{j}}^{0}+\mathrm{y}_{\mathrm{i}}\right) \quad \forall \mathrm{j} \in N^{2}, \mathrm{t} \in \mathrm{T}, \mathrm{s} \in \mathrm{S}, \mathrm{d} \in \mathrm{D} \\
& \mathrm{r}_{\mathrm{jtsd}}=\sum_{k \in K} \sum_{\mathrm{i} \in N^{1}} \mathrm{z}_{\mathrm{ijtsk}} * E_{k d j}+\mathrm{h}_{\mathrm{jtsk}} * E_{k d j} \quad \forall \mathrm{j} \in N^{2}, \mathrm{t} \in \mathrm{T}, \mathrm{s} \in \mathrm{S}, \mathrm{d} \in \mathrm{D}
\end{aligned}
$$

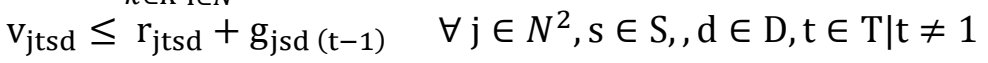

$$
\begin{aligned}
& \mathrm{v}_{\mathrm{jtsd}} \leq \mathrm{r}_{\mathrm{jtsd}}+\mathrm{g}_{\mathrm{jd}}^{0} \quad \forall \mathrm{j} \in N^{2}, \mathrm{~s} \in \mathrm{S}, \mathrm{d} \in \mathrm{D}, \mathrm{t} \in \mathrm{T} \mid \mathrm{t}=1 \\
& \mathrm{~g}_{\mathrm{jtsd}}=\mathrm{r}_{\mathrm{jtsd}}+\mathrm{g}_{\mathrm{jsd}(\mathrm{t}-1)}-\mathrm{v}_{\mathrm{jtsd}} \quad \forall \mathrm{j} \in N^{2}, \mathrm{~s} \in \mathrm{S}, \mathrm{d} \in \mathrm{D}, \mathrm{t} \in \mathrm{T} \mid \mathrm{t} \neq 1 \\
& \mathrm{~g}_{\mathrm{jtsd}}=\mathrm{r}_{\mathrm{jtsd}}+\mathrm{g}_{\mathrm{jd}}^{0}-\mathrm{v}_{\mathrm{jtsd}} \quad \forall \mathrm{j} \in N^{2}, \mathrm{~s} \in \mathrm{S}, \mathrm{t} \in \mathrm{T} \mid \mathrm{t}=1 \\
& \sum_{d \in D} \mathrm{~g}_{j t s d} \leq \mathrm{G}_{\mathrm{j}} \quad \forall \mathrm{t} \in \mathrm{T}, \mathrm{s} \in \mathrm{S}
\end{aligned}
$$




$$
\begin{aligned}
& \sum_{\mathrm{j} \in N^{2}} \mathrm{v}_{\mathrm{jtsd}} \leq \mathrm{D}_{d t} \quad \forall \mathrm{t} \in \mathrm{T}, \mathrm{s} \in \mathrm{S}, \mathrm{d} \in \mathrm{D} \\
& 0 \leq \mathrm{x}_{\mathrm{i}}^{0}+\mathrm{x}_{\mathrm{i}} \leq 1 \quad \forall \mathrm{i} \in N^{1} \\
& 0 \leq \mathrm{y}_{\mathrm{j}}^{0}+\mathrm{y}_{\mathrm{j}} \leq 1 \quad \forall \mathrm{j} \in N^{2} \\
& b_{s} \geq 0 \quad \forall \mathrm{s} \in \mathrm{S} \\
& \mathrm{b}_{\mathrm{s}} \geq \mathrm{a}-\left(\mathrm{L}_{\mathrm{s}}^{\mathrm{E \& P}}+\mathrm{L}_{\mathrm{s}}^{\text {Ref }}\right) \quad \forall s \in S
\end{aligned}
$$

O modelo tem por objetivo maximizar o lucro do portfólio ponderado por uma medida de risco, através de um fator $\lambda$ (equação 8 ). A primeira parcela é a soma dos valores presentes esperados do E\&P e do Refino em todos os cenários e a segunda parcela é o CVaR. O cálculo do valor presente do E\&P e do valor presente do refino estão nas restrições (9) e (10) respectivamente.

Na equação (9), o valor do E\&P é definido como a soma da produção que será destinada ao refino $\left(z_{i j t s k}\right)$ vezes o preço $\left(\pi_{t s}\right)$ do petróleo, mais a quantidade produzida que será exportada $\left(W_{\text {itsk }}\right)$ vezes o preço do petróleo com um desconto devido aos custos de exportação (1-c exp $)$. A terceira e a quarta parcela da equação referem-se aos custos fixos dos campos de produção e aos custos variáveis em função do total produzido respectivamente. Todo lucro operacional é trazido a valor presente a uma taxa de desconto $(\mu)$. Por fim, a última parcela da equação representa o investimento em novos campos ou valor de desinvestimento dos campos de E\&P.

O valor do refino definido pela equação (10) é calculado pela soma do produto da quantidade de refino vendida $\left(v_{\text {jtsd }}\right)$ pelo preço de venda do derivado, representado pelo mínimo entre preço do petróleo e o preço máximo de aceitação do mercado, acrescido de uma margem $\left(m_{\mathrm{jd}}\right)$. A segunda e terceira parcela da equação representam respectivamente o custo fixo do refino e o custo variável com a quantidade de óleo refinada. As quarta parcela da equação representa os custos com a matéria prima do refino, que é o petróleo cru comprado do segmento de E\&P $\left(z_{i j t s k}\right)$ pelo valor do preço do petróleo mais a quantidade importada de petróleo $\left(h_{\mathrm{jtsk}}\right)$ por um preço superior ao preço de mercado $\left(1+c^{i m p}\right)$. A última parcela representa os investimentos em novos projetos ou valor de desinvestimento nas refinarias existentes. Os lucros do refino também são trazidos a valor presente por uma taxa $(\mu)$.

A equação (11) representa a restrição de capacidade de produção de petróleo dos campos, onde a quantidade de óleo destinada ao refino mais a quantidade de óleo exportada não deve ser maior que a produção do campo. A 
produção do campo é definida pela capacidade total da plataforma $\left(Q_{i t s k}\right)$, vezes uma taxa de declínio $T_{i t s}^{\text {decl }}$ mais a capacidade adicionada pelos novos poços $\left(q_{i t s}\right)$.

A restrição (12) limita a quantidade refinada à capacidade das refinarias. Esta restrição considera como hipótese, que a quantidade de óleo alocado em uma dada refinaria que está sob decisão da empresa em questão é proporcional ao seu percentual de participação na mesma.

A restrição (13) também limita a quantidade de produto refinado a quantidade de óleo produzida vezes seu respectivo rendimento em derivados $\left(E_{\mathrm{kd}}\right)$ mais o óleo importado vezes seu rendimento em derivados.

As equações (14) e (15) restringem a quantidade vendida de derivados a quantidade de produto refinado mais a quantidade de derivados em estoque. As restrições (16) e (17) definem a quantidade de derivados em estoque como sendo o balanço entre o estoque do período anterior, mais a quantidade refinada menos a quantidade vendida de derivados. O volume estocado está sujeito a uma capacidade de estoque (equação 18).

A restrição (19) garante que a quantidade vendida de derivados não será maior que a demanda.

A equação (20) limita a participação da empresa no campo de produção de $0 \%$ a $100 \%$. A equação (21) faz o mesmo para refinarias.

Por fim, as equações (22) e (23) representam as restrições do CVaR. 
4.

\section{Experimentos Numéricos}

Neste capítulo serão mostradas duas aplicações do modelo proposto, um exemplo ilustrativo e um estudo de caso. O modelo foi implementado em Julia, utilizando o solver Gurobi. O modelo completo leva cerca de uma hora para ser executado.

\section{1}

\section{Dados do estudo numérico}

Tanto para o exemplo ilustrativo quanto para o estudo de caso, serão utilizados dados realistas* de 9 campos de produção de petróleo e 9 refinarias, expostos nas tabelas $5,6,7$ e 8 a seguir.

\begin{tabular}{|c|c|c|c|c|c|c|c|c|c|c|c|}
\hline & & und & E\&P1 & E\&P2 & E\&P3 & E\&P4 & E\&P5 & E\&P6 & E\&P7 & E\&P8 & E\&P9 \\
\hline$c_{i}^{v}$ & $\begin{array}{l}\text { Custo variável do campo de } \\
\text { E\&P i }\end{array}$ & US $\$ /$ barril & 17,8 & 34,5 & 22,0 & 32,2 & 31,2 & 46,8 & 23,5 & 16,5 & 32,0 \\
\hline$c_{i}^{4}$ & Custo fixo do campo de E\&P i & US\$ MMMês & 36,9 & 116,8 & 18,8 & 15,7 & 25,1 & 14,5 & 39,2 & 283,9 & 11,1 \\
\hline $\mathrm{li}_{\mathrm{i}}$ & $\begin{array}{l}\text { Investimento ou } \\
\text { desinvestimento no campo }\end{array}$ & US\$MM & 1.073 & 15.687 & 1.520 & 1.542 & 2.009 & 78 & 2.975 & 23.104 & 2.556 \\
\hline$Q_{i}$ & $\begin{array}{l}\text { Capacidade de produção do } \\
\text { campo de E\&P i }\end{array}$ & MM barris/mês & 2,6 & 31,3 & 2,7 & 3,1 & 5,4 & 0,5 & 5,7 & 29,1 & 4,0 \\
\hline$x_{i}^{0}$ & $\begin{array}{l}\text { Percentual inicial de } \\
\text { participação no campo de E\&P }\end{array}$ & $\%$ & $100 \%$ & $60 \%$ & $100 \%$ & $100 \%$ & $100 \%$ & $100 \%$ & $100 \%$ & $100 \%$ & $100 \%$ \\
\hline $\operatorname{Tipo}_{i, k}$ & Tipo de Oleo & & Medio & Leve & Pesado & Leve & Pesado & Pesado & Pesado & Leve & Leve \\
\hline$V_{k}$ & Spread do óleo & $\%$ & 0,95 & 1 & 0,9 & 1 & 0,9 & 0,9 & 0,9 & 1 & 1 \\
\hline
\end{tabular}

Tabela 5 - Dados do E\&P

\begin{tabular}{|c|c|c|c|c|c|c|c|c|c|c|c|}
\hline & & & REF 1 & REF 2 & REF 3 & REF 4 & REF 5 & REF 7 & REF 8 & REF 9 & REF 11 \\
\hline $\mathrm{d}_{\mathrm{i}}^{\mathrm{v}}$ & Custo variável da refinaria j & US $\$ /$ barril & 3,9 & 3,9 & 3,9 & 3,9 & 3,9 & 3,9 & 3,9 & 3,9 & 3,9 \\
\hline $\mathrm{d}_{\mathrm{j}}^{\mathrm{f}}$ & Custo fixo do da refinaria j & US\$ MMmês & 50 & 37 & 43 & 85 & 48 & 58 & 22 & 34 & 36 \\
\hline$F_{j}$ & $\begin{array}{l}\text { Investimento ou desinvestimento } \\
\text { na refinaria j }\end{array}$ & US\$MM & 835 & 624 & 732 & 1434 & 812 & 981 & 369 & 579 & 602 \\
\hline$m_{j d}$ & Margem da Gasolina & US $\$ /$ barril & 17 & 17 & 17 & 17 & 17 & 17 & 17 & 17 & 17 \\
\hline$m_{j d}$ & Margem do Diesel & US $\$ /$ barril & 14 & 14 & 14 & 14 & 14 & 14 & 14 & 14 & 14 \\
\hline $\mathrm{R}_{\mathrm{jd}}$ & Capacidade de refino de diesel & MM barril/mês & 5,8 & 4,4 & 5,1 & 10,0 & 5,7 & 6,9 & 2,6 & 4,0 & 4,2 \\
\hline $\mathrm{R}_{\mathrm{jd}}$ & Capacidade de refino de gasolina & MM barril/mês & 3,4 & 2,6 & 3,0 & 5,9 & 3,3 & 4,0 & 1,5 & 2,4 & 2,5 \\
\hline$y_{j}^{0}$ & $\begin{array}{l}\text { Percentual inicial de participação } \\
\text { na refinaria j }\end{array}$ & $\%$ & $100 \%$ & $100 \%$ & $100 \%$ & $100 \%$ & $100 \%$ & $100 \%$ & $100 \%$ & $100 \%$ & $100 \%$ \\
\hline$G_{j}$ & $\begin{array}{l}\text { Capacidade do estoque de } \\
\text { derivado em j }\end{array}$ & MM barril/mês & 0,92 & 0,69 & 0,81 & 1,59 & 0,90 & 1,09 & 0,41 & 0,64 & 0,67 \\
\hline $\mathrm{g}_{\mathrm{i}}^{0}$ & Estoque inicial de derivados em j & MM barris & 0,00 & 0,00 & 0,00 & 0,00 & 0,00 & 0,00 & 0,00 & 0,00 & 0,00 \\
\hline$d^{\text {est }}$ & Custo de estoque & MM boe/mês & 2,35 & 2,35 & 2,35 & 2,35 & 2,35 & 2,35 & 2,35 & 2,35 & 2,35 \\
\hline
\end{tabular}

Tabela 6 - Dados do Refino

\begin{tabular}{lcc} 
Rendimento do petróleo por derivado (\%) & Gasolina & Diesel \\
\hline Oleo leve & 0,3 & 0,7 \\
Oleo médio & 0,4 & 0,6 \\
Oleo pesado & 0,5 & 0,5 \\
\hline
\end{tabular}

Tabela 7 - Rendimento do tipo de petróleo por produto derivado

*Os dados apresentados nas tabelas 5 e 6 foram modificados devido a confidencialidade 
O preço de petróleo máximo que pode ser integralmente no preço dos derivados considerado foi de $70 \mathrm{US} \$ / \mathrm{bbl}$. O modelo será aplicado para 60 períodos.

Para o estudo de caso, serão utilizados os dados adicionais da tabela 9 abaixo, dados da demanda interna, cenários de preço de petróleo e cenários de produção dos campos, simulados a seguir.

\begin{tabular}{lcc}
\hline Custo da importação & $c^{\text {imp }}$ & $30 \%$ \\
Custo da exportação & $c^{\exp }$ & $30 \%$ \\
Cenários & $S$ & 1000 \\
Peso do Cvar na função objetivo & $\lambda$ & 0,5 \\
Nível de significância do Cvar & $\alpha$ & $95 \%$ \\
\hline
\end{tabular}

Tabela 8- Demais Dados

A demanda interna por produtos derivados será considerada constante para o estudo de caso pré-covid, conforme tabela 10 abaixo.

\begin{tabular}{lll|l}
\hline Demanda de Diesel & MM bbl/mês & 31 \\
\hline Demanda por gasolina & MM bbl/mês & 18 \\
\hline
\end{tabular}

Tabela 9 - Demanda por derivados

Para a geração de cenários de preço de petróleo, aplicou-se o modelo de reversão a média com os dados de preços históricos de abril de 1983 a dezembro de 2019 na referência WTI (West Texas Intermediate) e chegou-se aos seguintes valores de parâmetros:

Tabela 10 - Resultados dos parâmetros do MRM

\begin{tabular}{|c|c|}
\hline Parâmetro & Resultado \\
\hline $\mathrm{a}$ & 0,059 \\
\hline $\mathrm{b}$ & 0,985 \\
\hline$\eta$ & 0,186 \\
\hline$\sigma$ & 0,327 \\
\hline $\bar{x}$ & 3,847 \\
\hline
\end{tabular}

A figura 6 a distribuição dos cenários de preços por período gerados pelo modelo, bem como seu valor esperado. A distribuição dos preços no primeiro e no último período estão na figura 7 , onde pode ser observada a tendência de reversão a média de 56 US\$/barril ao longo do tempo. A distribuição dos preços nos demais períodos estão no anexo 1. 


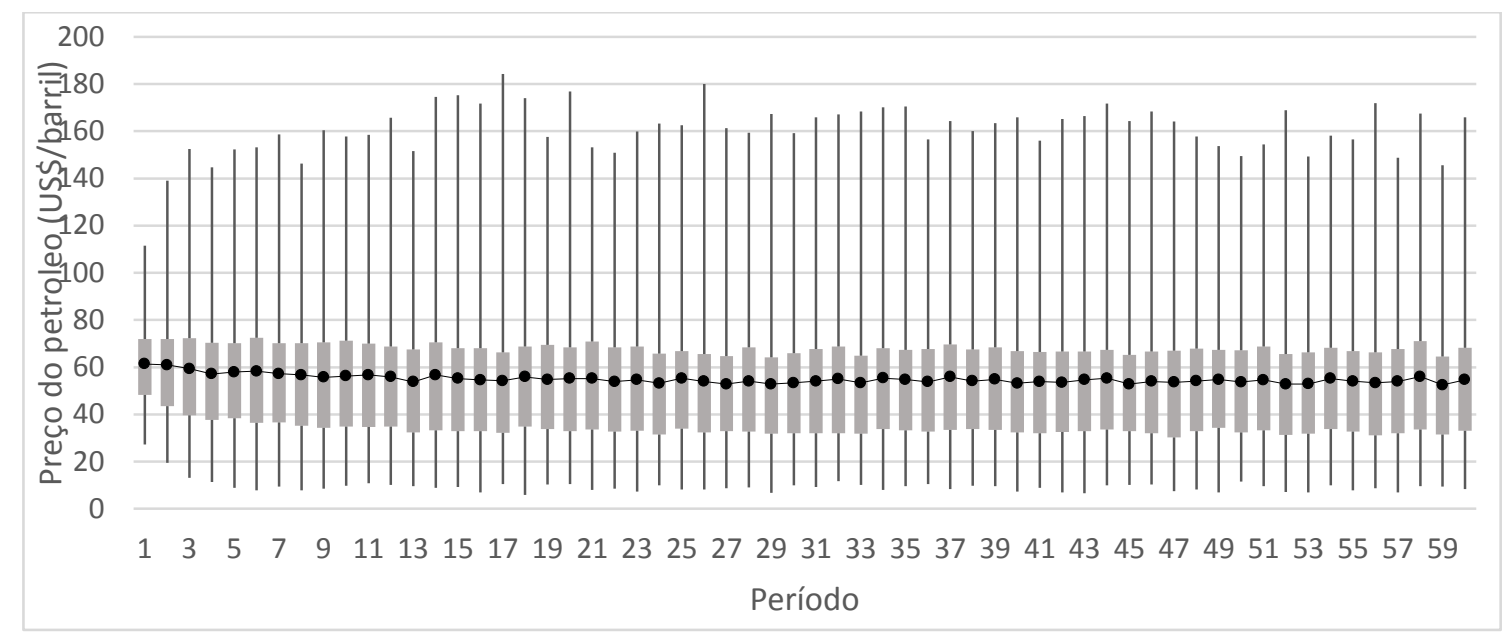

Figura 6 - Cenários de preços de petróleo gerados a partir do MRM.

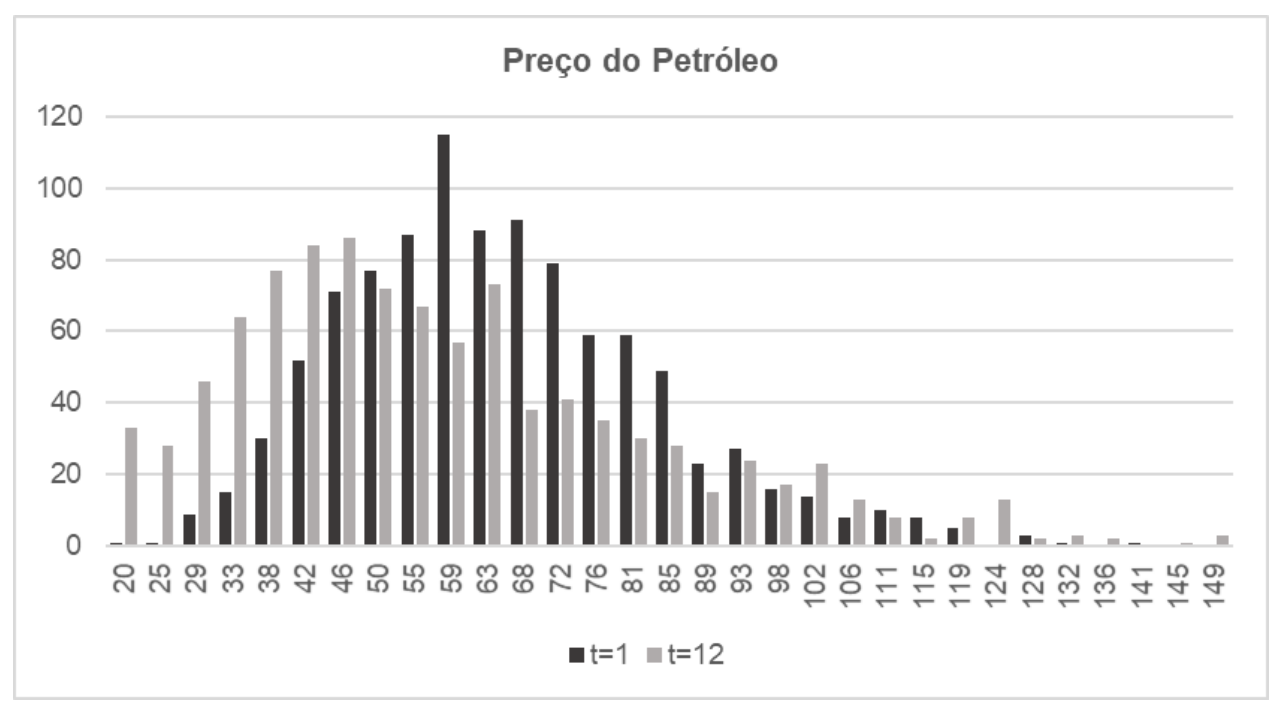

Figura 7 - Distribuição dos preços em $\mathrm{t}=1$ e $\mathrm{t}=12$

O gráfico na figuras 8 abaixo mostra o mesmo modelo com os preços revertendo a uma média de US\$30 por barril, que será utilizada em algumas sensibilidades do estudo de caso. Para este caso, observa-se um tempo de reversão a média de aproximadamente 12 períodos. 


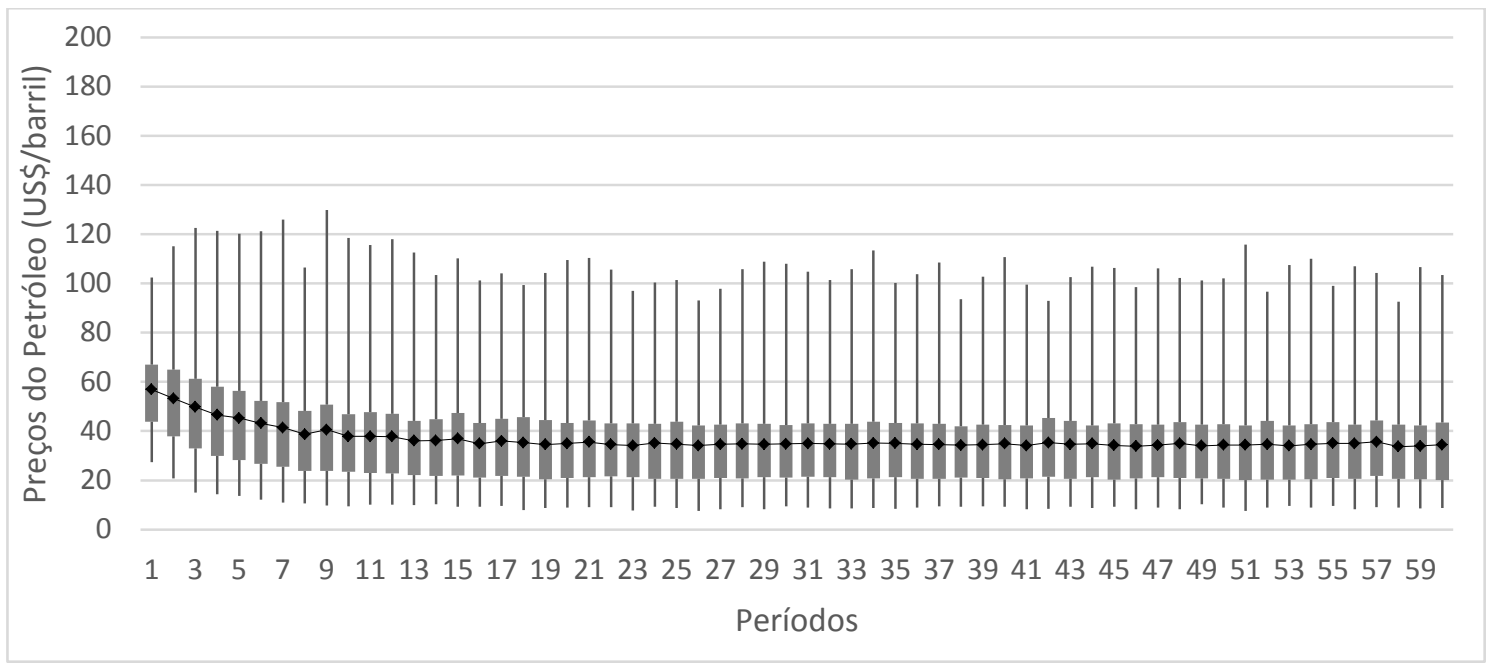

Figura 8 - Cenários de preços de petróleo convergindo para US\$30/bbl

Para a geração de cenários de produção dos campos de E\&P, utilizou-se os seguintes parâmetros das tabelas 12 e 13 abaixo.

\begin{tabular}{|c|c|c|c|c|c|c|c|c|c|c|}
\hline \multicolumn{2}{|c|}{ Taxa de Declínio } & E\&P 1 & E\&P 2 & E\&P 3 & E\&P 4 & E\&P 5 & E\&P 6 & E\&P 7 & E\&P 8 & E\&P 9 \\
\hline Pessimista & \%/mês & $1,03 \%$ & $1,41 \%$ & $1,75 \%$ & $1,67 \%$ & $1,38 \%$ & $2,09 \%$ & $1,05 \%$ & $1,70 \%$ & $2,19 \%$ \\
\hline Médio & \%/mês & $0,54 \%$ & $0,91 \%$ & $1,26 \%$ & $1,18 \%$ & $0,89 \%$ & $1,59 \%$ & $0,55 \%$ & $1,21 \%$ & $1,70 \%$ \\
\hline Otimista & $\% /$ mês & $0,04 \%$ & $0,42 \%$ & $0,77 \%$ & $0,68 \%$ & $0,39 \%$ & $1,10 \%$ & $0,05 \%$ & $0,72 \%$ & $1,21 \%$ \\
\hline
\end{tabular}

Tabela 11 - Taxa de declínio dos campos

\begin{tabular}{|l|c|c|c|c|c|c|c|c|c|c|}
\hline Potencial novo poço & & E\&P 1 & E\&P 2 & E\&P 3 & E\&P 4 & E\&P 5 & E\&P 6 & E\&P 7 & E\&P 8 & E\&P 9 \\
\hline Pessimista & MMboe/mês & 1,548 & 0,170 & 1,777 & 0,029 & 0,260 & 0,179 & 0,295 & 3,390 & 0,000 \\
\hline Médio & MMboe/mês & 1,613 & 0,177 & 1,852 & 0,030 & 0,271 & 0,186 & 0,307 & 3,531 & 0,000 \\
\hline Otimista & MMboe/mês & 1,677 & 0,184 & 1,926 & 0,031 & 0,281 & 0,194 & 0,320 & 3,673 & 0,000 \\
\hline Período de entrada do novo poço & período (t) & 28 & 34 & 28 & 13 & 18 & 14 & 20 & 24 & 1 \\
\hline
\end{tabular}

Tabela 12 - Potencial e período de entrada dos novos poços

Utilizando o modelo proposto por Bonfim (2017) descritos no capítulo 2.2 deste trabalho, obteve-se os seguintes cenários de produção para os campos de produção.

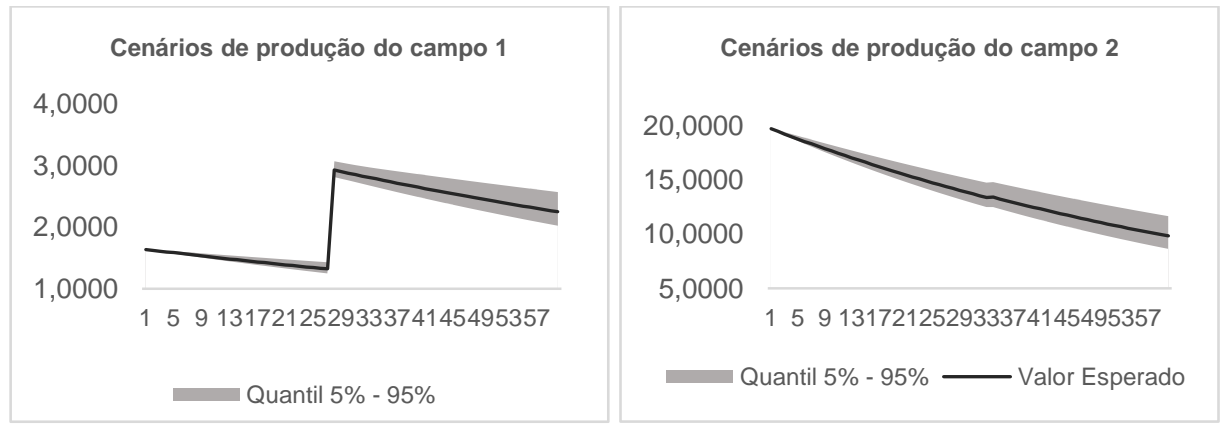




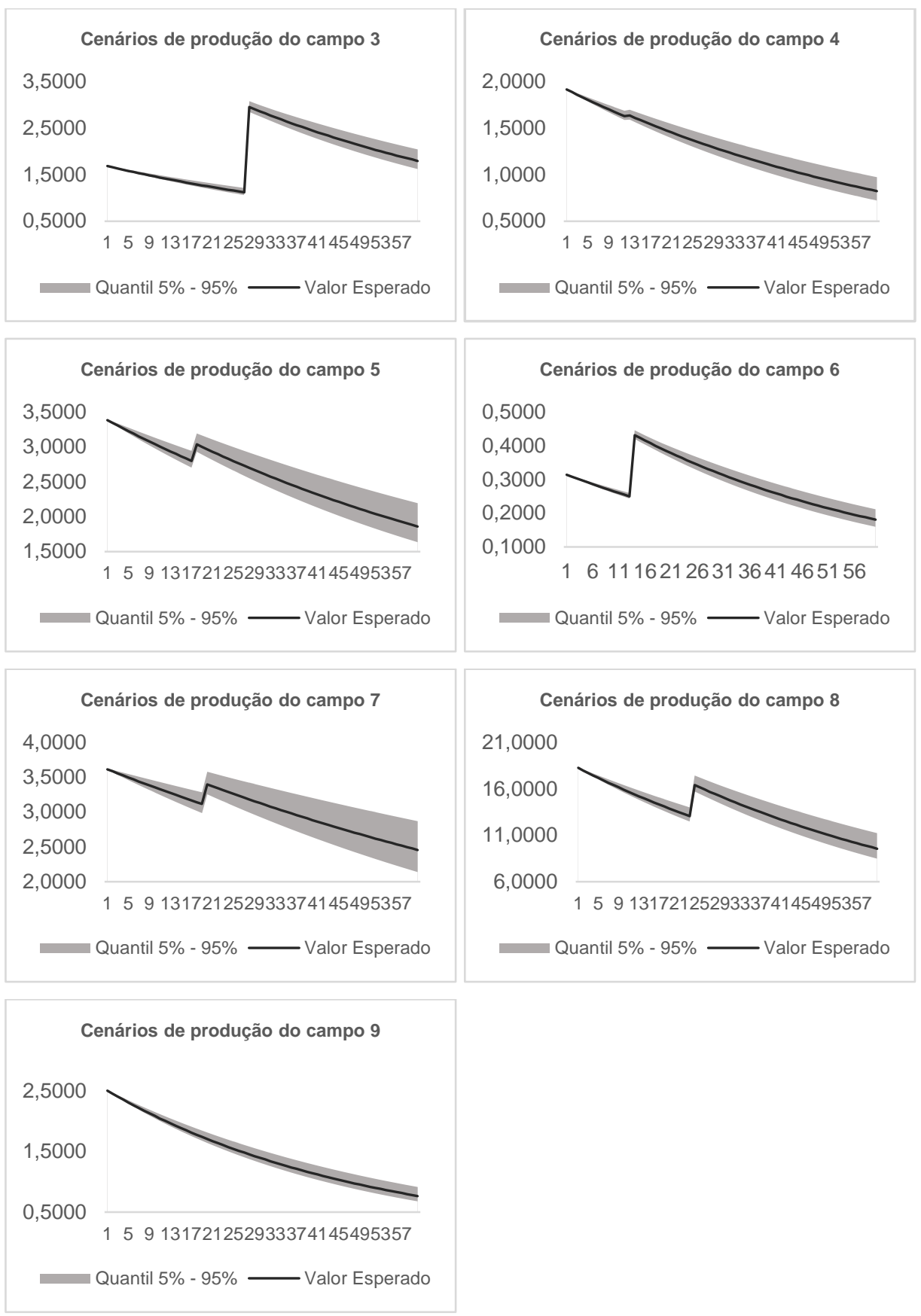

Figura 9 - Cenários de produção dos campos

\section{2.}

\section{Exemplo llustrativo}

Em uma primeira análise, foi avaliado o resultado do modelo para alguns cenários determinísticos. Este exemplo ilustrativo tem por objetivo verificar a eficácia do modelo, observando os comportamentos típicos do setor. 


\subsubsection{Sensibilidades ao preço do petróleo}

Em uma primeira análise, considerou-se a demanda por derivados do petróleo como sendo igual a capacidade total de todas as refinarias e a produção dos campos como sendo igual as suas respectivas capacidades (sem declínio e sem novos poços). Mantendo o preço máximo de aceitação do mercado em US $\$ 70$ por barril, e o custo de importação e exportação em 10\%, obteve-se os resultados expostos nas tabelas 14 e 15 abaixo para nove cenários de preço de petróleo entre US\$20 por barril a US\$100 por barril, para os 60 períodos.

\begin{tabular}{|c|c|c|c|c|c|c|c|c|c|}
\hline $\begin{array}{l}\text { Preço do } \\
\text { petróleo }\end{array}$ & US $\$ 100 / b b l$ & US $\$ 90 / b b l$ & US $\$ 80 / b b l$ & US\$ $70 /$ bbl & US $\$ 60 / \mathrm{bbl}$ & US\$ 50/bbl & US $\$ 40 / \mathrm{bbl}$ & US $\$ 30 / \mathrm{bbl}$ & US $\$ 20 / \mathbf{b b l}$ \\
\hline E\&P_1 & $100 \%$ & $100 \%$ & $100 \%$ & $100 \%$ & $100 \%$ & $100 \%$ & $100 \%$ & $0 \%$ & $0 \%$ \\
\hline$E \& P 2$ & $100 \%$ & $100 \%$ & $100 \%$ & $100 \%$ & $100 \%$ & $100 \%$ & $100 \%$ & $0 \%$ & $0 \%$ \\
\hline E\&P_3 & $100 \%$ & $100 \%$ & $100 \%$ & $100 \%$ & $100 \%$ & $100 \%$ & $100 \%$ & $0 \%$ & $0 \%$ \\
\hline$E \& P \_4$ & $100 \%$ & $100 \%$ & $100 \%$ & $100 \%$ & $100 \%$ & $100 \%$ & $100 \%$ & $0 \%$ & $0 \%$ \\
\hline E\&P_5 & $100 \%$ & $100 \%$ & $100 \%$ & $100 \%$ & $100 \%$ & $100 \%$ & $100 \%$ & $0 \%$ & $0 \%$ \\
\hline$E \& P \_6$ & $100 \%$ & $100 \%$ & $100 \%$ & $100 \%$ & $0 \%$ & $0 \%$ & $0 \%$ & $0 \%$ & $0 \%$ \\
\hline E\&P_7 & $100 \%$ & $100 \%$ & $100 \%$ & $100 \%$ & $100 \%$ & $100 \%$ & $100 \%$ & $0 \%$ & $0 \%$ \\
\hline$E \& P \_8$ & $100 \%$ & $100 \%$ & $100 \%$ & $100 \%$ & $100 \%$ & $100 \%$ & $100 \%$ & $0 \%$ & $0 \%$ \\
\hline E\&P_9 & $100 \%$ & $100 \%$ & $100 \%$ & $100 \%$ & $100 \%$ & $100 \%$ & $100 \%$ & $0 \%$ & $0 \%$ \\
\hline
\end{tabular}

Tabela 13 - Resultados (participação no E\&P)

\begin{tabular}{|c|c|c|c|c|c|c|c|c|c|}
\hline $\begin{array}{l}\text { Preço do } \\
\text { petróleo }\end{array}$ & US $\$ 100 / b b l$ & US\$ 90/bbl & US $\$ 80 /$ bbl & US\$ 70/bbl & US\$ $60 / \mathrm{bbl}$ & US $\$ 50 /$ bbl & US\$ 40/bbl & US\$ $30 / b b l$ & US $\$ 20 / \mathrm{bbl}$ \\
\hline Ref_1 & $0 \%$ & $29 \%$ & $100 \%$ & $100 \%$ & $100 \%$ & $100 \%$ & $100 \%$ & $100 \%$ & $100 \%$ \\
\hline Ref_2 & $0 \%$ & $43 \%$ & $100 \%$ & $100 \%$ & $100 \%$ & $100 \%$ & $100 \%$ & $100 \%$ & $100 \%$ \\
\hline Ref_3 & $0 \%$ & $33 \%$ & $100 \%$ & $100 \%$ & $100 \%$ & $100 \%$ & $100 \%$ & $100 \%$ & $100 \%$ \\
\hline Ref_4 & $0 \%$ & $13 \%$ & $100 \%$ & $100 \%$ & $100 \%$ & $100 \%$ & $100 \%$ & $100 \%$ & $100 \%$ \\
\hline Ref_5 & $0 \%$ & $22 \%$ & $100 \%$ & $100 \%$ & $100 \%$ & $100 \%$ & $100 \%$ & $100 \%$ & $100 \%$ \\
\hline Ref_6 & $0 \%$ & $16 \%$ & $100 \%$ & $100 \%$ & $100 \%$ & $100 \%$ & $100 \%$ & $100 \%$ & $100 \%$ \\
\hline Ref_7 & $0 \%$ & $49 \%$ & $100 \%$ & $100 \%$ & $100 \%$ & $100 \%$ & $100 \%$ & $100 \%$ & $100 \%$ \\
\hline Ref_8 & $0 \%$ & $31 \%$ & $100 \%$ & $100 \%$ & $100 \%$ & $100 \%$ & $100 \%$ & $100 \%$ & $100 \%$ \\
\hline Ref_9 & $0 \%$ & $19 \%$ & $100 \%$ & $100 \%$ & $100 \%$ & $100 \%$ & $100 \%$ & $100 \%$ & $100 \%$ \\
\hline
\end{tabular}

Tabela 14 - Resultados (participação nas refinarias)

Os resultados da tabela 14 acima, mostram que em cenários de preços de petróleo mais altos, é vantajoso para a empresa manter os campos existentes e investir em novos campos de produção. O mesmo não ocorre para cenários de preços mais baixos, onde o resultado ótimo é obtido se desfazendo dos ativos que possuem maiores custos variáveis, custos fixos ou investimentos. 
O resultado oposto pode ser observado na tabela 15 para o refino. Em cenários de preços muito altos não é ótimo para a empresa permanecer no segmento de refino devido a eliminação de repasse do preço do petróleo bruto nos derivados. Nos cenários de preços mais baixos a decisão ótima é manter as refinarias.

Os lucros obtidos em cada cenário estão na tabela 16 abaixo.

\begin{tabular}{crrrc}
$\begin{array}{c}\text { Preço do } \\
\text { petroleo }\end{array}$ & Lucro E\&P & Lucro refino & Lucro total & $\begin{array}{c}\text { \% do E\&P no } \\
\text { lucro total }\end{array}$ \\
\hline US\$ 100/bbl & 201,972 & 4,441 & 206,413 & $98 \%$ \\
\hline US\$ 90/bbl & 177,935 & 760 & 178,695 & $100 \%$ \\
\hline US\$ 80/bbl & 168,340 & 5,836 & 162,504 & $104 \%$ \\
\hline US\$ 70/bbl & 137,110 & 21,850 & 158,960 & $86 \%$ \\
\hline US\$ 60/bbl & 106,109 & 21,092 & 127,201 & $83 \%$ \\
\hline US\$ 50/bbl & 75,039 & 20,515 & 95,554 & $79 \%$ \\
\hline US\$ 40/bbl & 43,968 & 19,939 & 63,907 & $69 \%$ \\
\hline US\$ 30/bbl & 32,251 & 14,407 & 46,658 & $69 \%$ \\
\hline US\$ 20/bbl & 32,251 & 15,110 & 47,361 & $68 \%$ \\
\hline
\end{tabular}

Tabela 15 - Lucro do E\&P, refino e total

Os lucros obtidos em cada caso na tabela 16 acima, mostram que quanto menor o preço do petróleo, maior será a participação do segmento de refino do lucro total, e o oposto acontece para preços de petróleo mais altos. Enquanto os lucros no segmento de E\&P apresentam grande volatilidade associada ao preço do petróleo, o lucro no segmento de refino possuem uma menor volatilidade, principalmente para preços menores que US\$70 por barril.

Também cabe observar na tabela 16 que em alguns cenários, como a preços de US\$ 80 por barril, o modelo obtém resultados negativos no segmento de refino em contrapartida a um maior resultado no E\&P. Isto significa que, para estes casos, o custo de exportar o petróleo cru supera as perdas por não repassar integralmente os preços do petróleo no produto derivado.

\subsubsection{Sensibilidades a demanda interna}

Uma segunda análise foi feita com os mesmos parâmetros da sensibilidade anterior, mantendo o preço do petróleo constante US\$70 por barril e variando a demanda por derivados do petróleo. 
Os resultados obtidos na tabela 17 abaixo mostram que a decisão ótima da empresa de possuir refinarias está diretamente atrelada a existência de mercado consumidor interno. À medida que a demanda interna diminui, a decisão ótima da empresa passa a ser se desfazer de suas refinarias menos lucrativas.

\begin{tabular}{|c|c|c|c|c|c|c|c|c|c|c|c|}
\hline & $\begin{array}{l}\text { Oferta >>> } \\
\text { Demanda }\end{array}$ & $\begin{array}{c}\text { Oferta }= \\
\text { Demanda }\end{array}$ & $\begin{array}{c}-10 \% \\
\text { Demanda }\end{array}$ & $\begin{array}{c}-20 \% \\
\text { Demanda }\end{array}$ & $\begin{array}{c}-30 \% \\
\text { Demanda }\end{array}$ & $\begin{array}{c}-40 \% \\
\text { Demanda }\end{array}$ & $\begin{array}{c}-50 \% \\
\text { Demanda }\end{array}$ & $\begin{array}{c}-60 \% \\
\text { Demanda }\end{array}$ & $\begin{array}{c}-70 \% \\
\text { Demanda }\end{array}$ & $\begin{array}{c}-80 \% \\
\text { Demanda }\end{array}$ & $\begin{array}{c}-90 \% \\
\text { Demanda }\end{array}$ \\
\hline Ref_1 & $100 \%$ & $100 \%$ & $100 \%$ & $75 \%$ & $56 \%$ & $45 \%$ & $61 \%$ & $51 \%$ & $30 \%$ & $16 \%$ & $12 \%$ \\
\hline Ref_2 & $100 \%$ & $100 \%$ & $100 \%$ & $100 \%$ & $100 \%$ & $100 \%$ & $64 \%$ & $53 \%$ & $36 \%$ & $23 \%$ & $5 \%$ \\
\hline Ref_3 & $100 \%$ & $100 \%$ & $100 \%$ & $59 \%$ & $100 \%$ & $37 \%$ & $55 \%$ & $50 \%$ & $42 \%$ & $27 \%$ & $17 \%$ \\
\hline Ref_4 & $100 \%$ & $100 \%$ & $79 \%$ & $68 \%$ & $23 \%$ & $25 \%$ & $28 \%$ & $23 \%$ & $17 \%$ & $8 \%$ & $6 \%$ \\
\hline Ref_5 & $100 \%$ & $100 \%$ & $100 \%$ & $94 \%$ & $91 \%$ & $98 \%$ & $61 \%$ & $41 \%$ & $27 \%$ & $15 \%$ & $3 \%$ \\
\hline Ref_6 & $100 \%$ & $100 \%$ & $100 \%$ & $64 \%$ & $47 \%$ & $41 \%$ & $35 \%$ & $32 \%$ & $25 \%$ & $19 \%$ & $3 \%$ \\
\hline Ref_7 & $100 \%$ & $100 \%$ & $0 \%$ & $100 \%$ & $100 \%$ & $100 \%$ & $100 \%$ & $55 \%$ & $49 \%$ & $48 \%$ & $49 \%$ \\
\hline Ref_8 & $100 \%$ & $100 \%$ & $100 \%$ & $100 \%$ & $100 \%$ & $100 \%$ & $89 \%$ & $56 \%$ & $38 \%$ & $30 \%$ & $22 \%$ \\
\hline Ref_9 & $100 \%$ & $100 \%$ & $100 \%$ & $100 \%$ & $100 \%$ & $70 \%$ & $50 \%$ & $28 \%$ & $36 \%$ & $23 \%$ & $0 \%$ \\
\hline
\end{tabular}

Tabela 16- Resultados (participação nas refinarias)

Para estas simulações, as decisões de investimento/desinvestimento nos campos de E\&P não se alteraram.

\begin{tabular}{|c|c|c|c|c|c|c|c|c|c|c|c|}
\hline & $\begin{array}{l}\text { Oferta >>> } \\
\text { Demanda }\end{array}$ & $\begin{array}{c}\text { Oferta }= \\
\text { Demanda }\end{array}$ & $\begin{array}{c}-10 \% \\
\text { Demanda }\end{array}$ & $\begin{array}{c}-20 \% \\
\text { Demanda }\end{array}$ & $\begin{array}{c}-30 \% \\
\text { Demanda }\end{array}$ & $\begin{array}{c}-40 \% \\
\text { Demanda }\end{array}$ & $\begin{array}{c}-50 \% \\
\text { Demanda }\end{array}$ & $\begin{array}{c}-60 \% \\
\text { Demanda }\end{array}$ & $\begin{array}{c}-70 \% \\
\text { Demanda }\end{array}$ & $\begin{array}{c}-80 \% \\
\text { Demanala }\end{array}$ & $\begin{array}{c}-90 \% \\
\text { Demanda }\end{array}$ \\
\hline$E \& P_{-} 1$ & $100 \%$ & $100 \%$ & $100 \%$ & $100 \%$ & $100 \%$ & $100 \%$ & $100 \%$ & $100 \%$ & $100 \%$ & $100 \%$ & $100 \%$ \\
\hline E\&P_2 & $100 \%$ & $100 \%$ & $100 \%$ & $100 \%$ & $100 \%$ & $100 \%$ & $100 \%$ & $100 \%$ & $100 \%$ & $100 \%$ & $100 \%$ \\
\hline E\&P_3 & $100 \%$ & $100 \%$ & $100 \%$ & $100 \%$ & $100 \%$ & $100 \%$ & $100 \%$ & $100 \%$ & $100 \%$ & $100 \%$ & $100 \%$ \\
\hline$E \& P_{4} 4$ & $100 \%$ & $100 \%$ & $100 \%$ & $100 \%$ & $100 \%$ & $100 \%$ & $100 \%$ & $100 \%$ & $100 \%$ & $100 \%$ & $100 \%$ \\
\hline E\&P_5 & $100 \%$ & $100 \%$ & $100 \%$ & $100 \%$ & $100 \%$ & $100 \%$ & $100 \%$ & $100 \%$ & $100 \%$ & $100 \%$ & $100 \%$ \\
\hline$E \& P$ G & $100 \%$ & $100 \%$ & $100 \%$ & $100 \%$ & $100 \%$ & $100 \%$ & $100 \%$ & $100 \%$ & $100 \%$ & $100 \%$ & $100 \%$ \\
\hline E\&P_7 & $100 \%$ & $100 \%$ & $100 \%$ & $100 \%$ & $100 \%$ & $100 \%$ & $100 \%$ & $100 \%$ & $100 \%$ & $100 \%$ & $100 \%$ \\
\hline E\&P_8 & $100 \%$ & $100 \%$ & $100 \%$ & $100 \%$ & $100 \%$ & $100 \%$ & $100 \%$ & $100 \%$ & $100 \%$ & $100 \%$ & $100 \%$ \\
\hline E\&P 9 & $100 \%$ & $100 \%$ & $100 \%$ & $100 \%$ & $100 \%$ & $100 \%$ & $100 \%$ & $100 \%$ & $100 \%$ & $100 \%$ & $100 \%$ \\
\hline
\end{tabular}

Tabela 17 - Participação nos campos de produção

A tabela 19 abaixo apresenta os resultados obtidos em cada um dos cenários, por onde observa-se que o resultado da empresa também está diretamente relacionado a sua demanda, como era de se esperar.

\begin{tabular}{c|c|c|c|} 
US \$ Milhões & Lucro E\&P & Lucro Refino & Lucro total \\
\hline Oferta > > Demanda & 137.110 & 21.850 & 158.960 \\
\hline Oferta = Demanda & 137.110 & 21.850 & 158.960 \\
\hline -10\% Demanda & 135.305 & 20.706 & 156.010 \\
\hline -20\% Demanda & 133.445 & 19.527 & 152.971 \\
\hline -30\% Demanda & 136.156 & 17.029 & 153.185 \\
\hline -40\% Demanda & 129.725 & 17.169 & 146.894 \\
\hline -50\% Demanda & 128.327 & 14.685 & 143.012 \\
\hline -60\% Demanda & 125.807 & 13.081 & 138.888 \\
\hline -70\% Demanda & 123.818 & 10.961 & 134.779 \\
\hline -80\% Demanda & 121.802 & 8.666 & 130.468 \\
\hline -90\% Demanda & 119.814 & 6.553 & 126.367
\end{tabular}

Tabela 18 - Resultados 


\subsubsection{Sensibilidades combinadas}

A seguir serão apresentados resultados de análises combinadas de preço e demanda para este mesmo modelo determinístico.

No caso de um alto preço do petróleo (US\$ 90 por barril) combinado com uma demanda alta (igual a capacidade total do parque de refino), a decisão ótima encontrada consiste em manter todas as participações possíveis nos ativos de E\&P, pois sua receita está diretamente relacionada a este preço, e desinvestir em boa parte do refino, devido ao alto controle nos preços que gera uma perda de US\$20 por barril (figura 10). O resultado encontrado foi de US\$ 179.266 milhões.

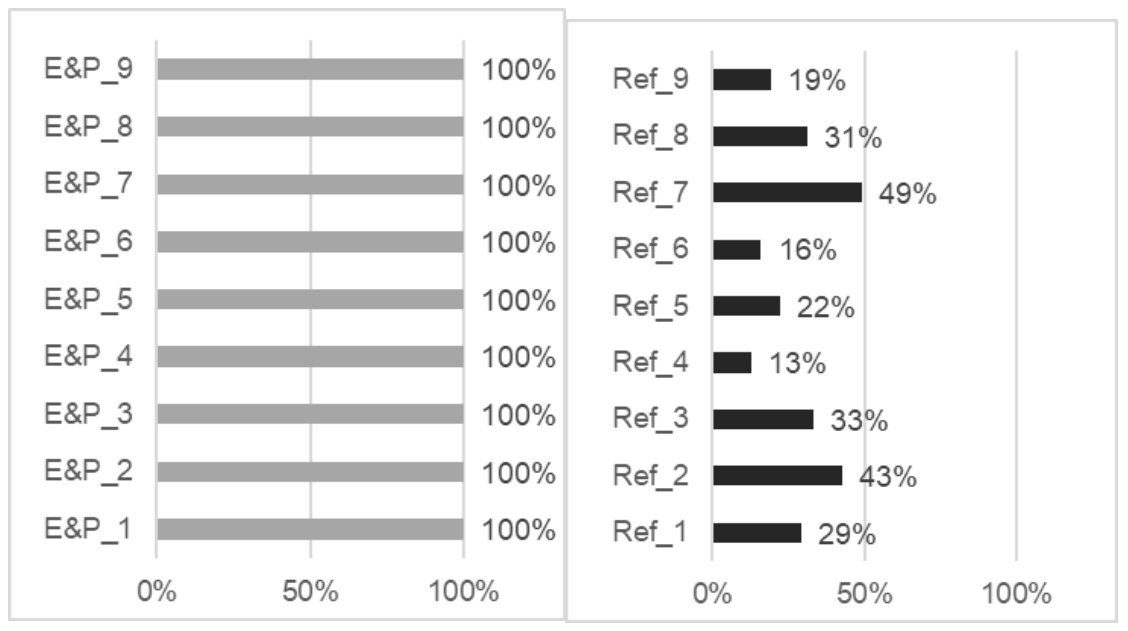

Figura 10 - Decisão ótima para alto preço de petróleo

Reduzindo-se a demanda em $20 \%$ para o mesmo preço de US $\$ 90$ por barril obteve-se o mesmo resultado exibido na figura 10 acima. Isso acontece porque neste cenário de preços de US\$90 por barril a participação ótima nas refinarias já é muito inferior a demanda devido ao controle no repasse dos preços, sendo indiferente a redução da demanda.

Ainda para o cenário acima de preços de petróleo a US\$90 por barril e demanda $20 \%$ menor que a capacidade instalada, fez-se uma análise aumentando o custo de exportação e importação de $10 \%$ para $20 \%$. O resultado obtido foi de US\$161.299 milhões com as participações da figura 11. 


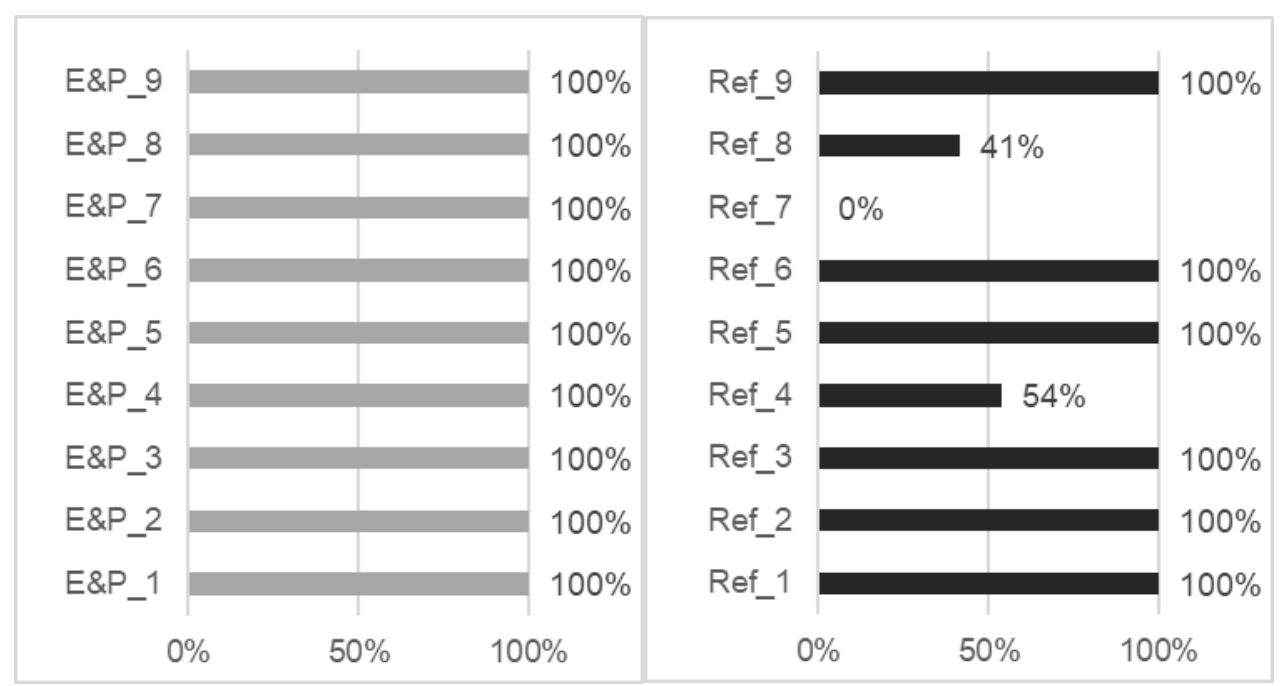

Figura 11 - Decisão ótima para preço de US\$ 90/bbl, demanda 20\% menor e custo de exportação de $20 \%$

Observa-se que decisão ótima neste caso (figura 11) apresentou um aumento nas participações em refino quando comparada com o caso onde o custo de importação e exportação é 10\% (figura 10). Com isso, conclui-se que os custos de importação e exportação vão representar a relevância da integração para Companhia. Isto é, quanto maiores os custos de importação e exportação, mais dependentes um do outro são o portfólio de E\&P e o portfólio de refino.

No caso de um preço de petróleo muito baixo (US\$30 por barril) com uma alta demanda interna, o resultado ótimo é de US\$ 46.657 milhões e consiste na saída de todo segmento de upstream e participação máxima no refino (Figura 12).

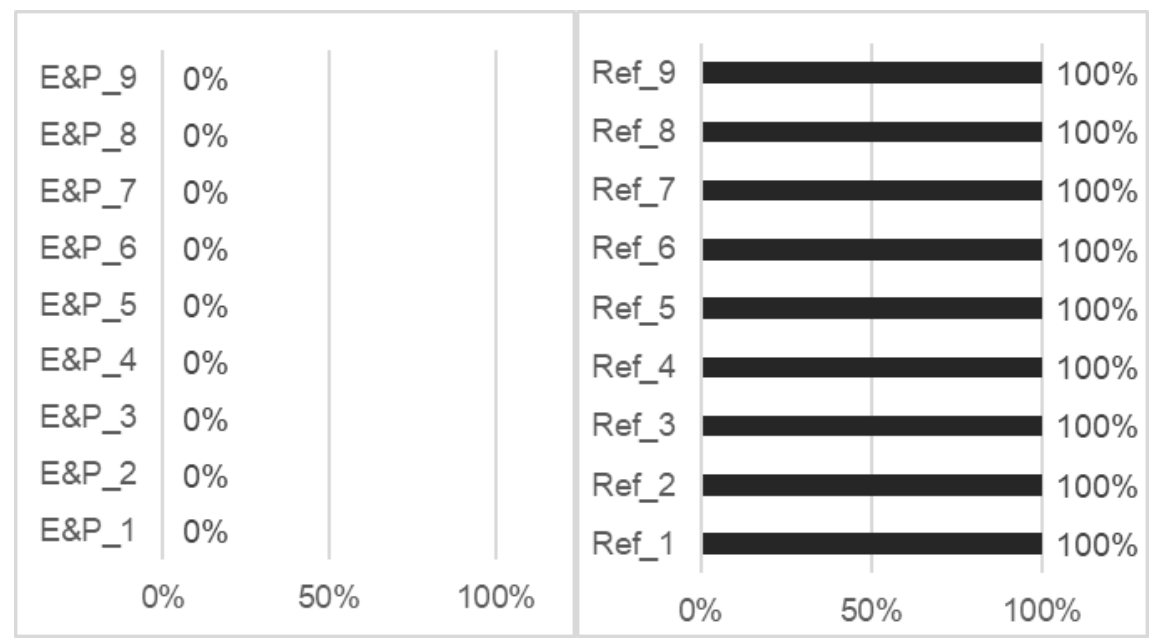

Figura 12 - Decisão ótima para preço de US\$30/bbl

O posicionamento no refino se justifica pelo fato de este ser um segmento cuja rentabilidade está associada a margem e, portanto, não é tão afetado pelos 
baixos preços de petróleo. Entretanto, no caso de uma redução de $20 \%$ na demanda, esta participação $100 \%$ em todas as refinarias não é mantida, conforme gráficos da figura 13 , e o resultado também reduz para US $\$ 44.682$ milhões. Em outras palavras, a participação no segmento de refino é vantajosa para preços não muito altos somente se houver demanda interna para consumo dos produtos derivados.

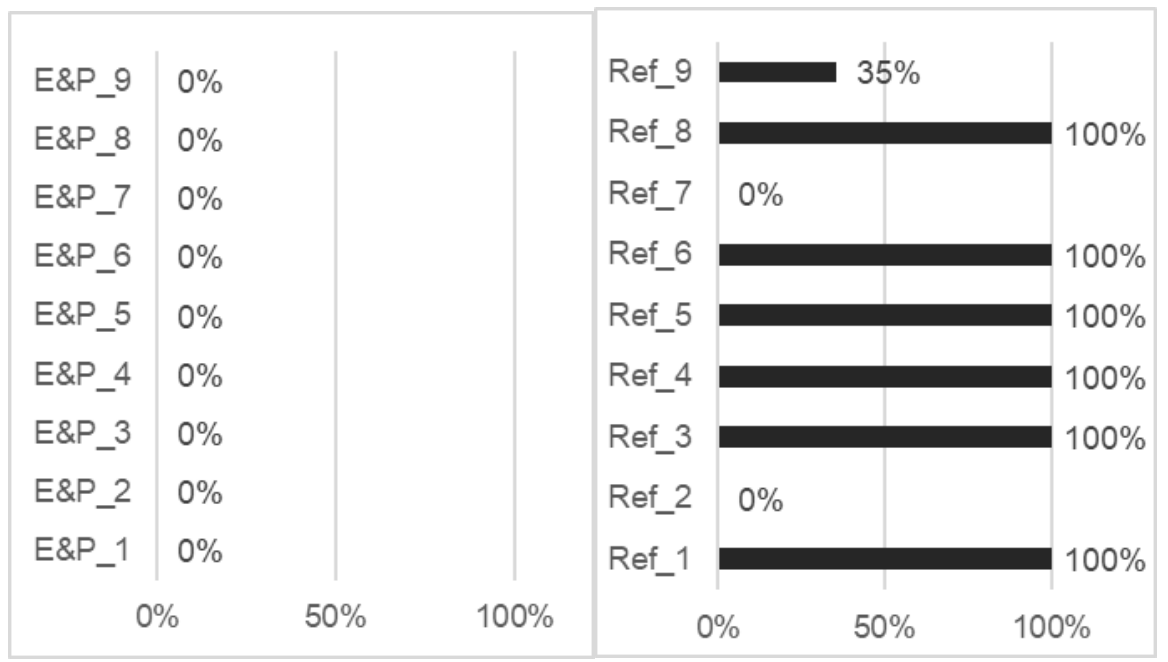

Figura 13 - Decisão ótima para preço de US\$30/bbl e demanda 20\% menor

Um aumento nos custos de importação e exportação de $10 \%$ para $20 \%$ para este mesmo caso (preço de petróleo US\$30 por barril e demanda $20 \%$ menor que a capacidade instalada) também resulta no mesmo efeito do caso com preço de petróleo a US\$ 90 por barril. Neste caso, a decisão ótima consiste na permanência em um dos campos de produção, devido ao aumento da dependência entre os segmentos. O resultado para este caso é de US\$ 40.096 milhões.

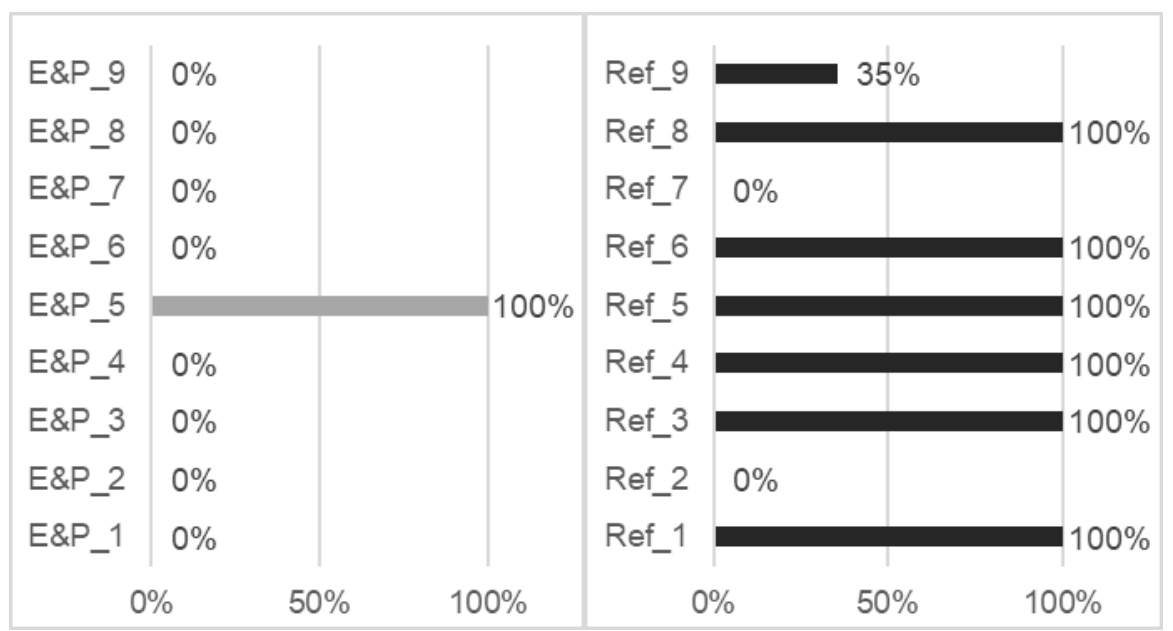

Figura 14 - Decisão ótima para preço de US\$30/bbl, e demanda 20\% menor e custo de exportação de $20 \%$ 


\section{3.}

\section{Estudo de caso pré-COVID}

\subsubsection{Resultados do Caso Base}

Neste caso base será considerado o modelo estocástico com aversão a risco, incluindo os cenários de preço do petróleo antes da pandemia e produção dos campos de E\&P. A otimização proposta no modelo, considerando o cenário de preços convergindo para uma média histórica e uma demanda interna constante, obteve um resultado na função objetivo de US\$54.374 milhões, com a seguinte decisão de participação nas refinarias e campos de produção.

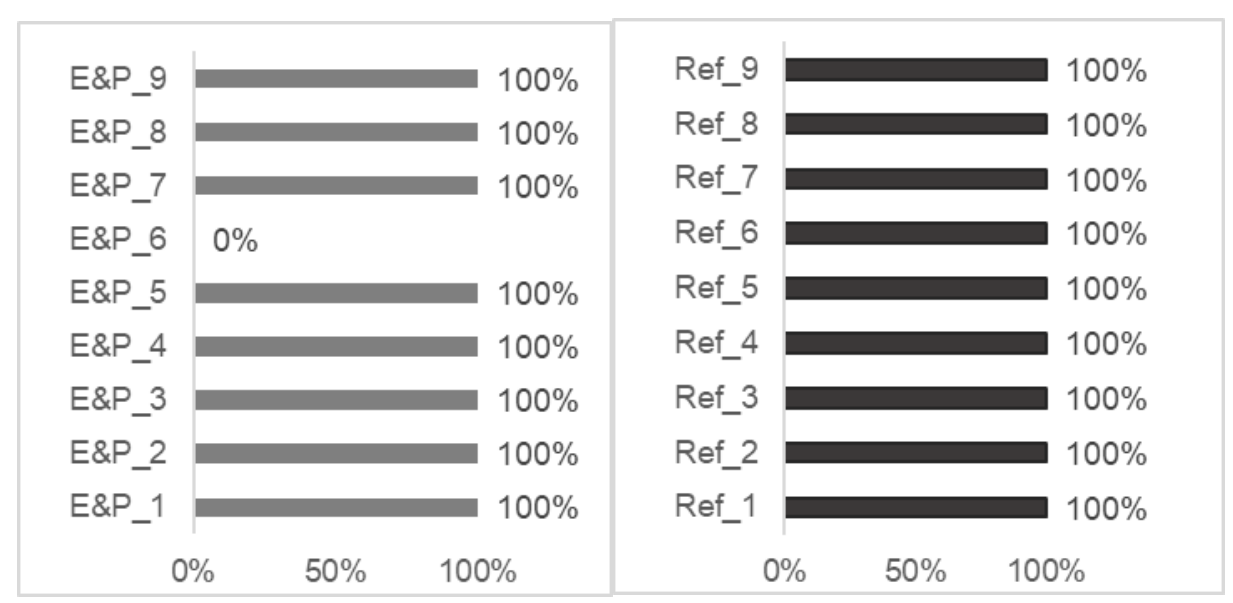

Figura 15 - Decisão ótima para o caso base

Devido a média dos cenários de preço estar em aproximadamente US\$50 por barril, grande parte dos campos de produção são lucrativos, bem como todas as refinarias já que o preço de repasse máximo está acima da média do preço do petróleo. Os resultados obtidos para o valor esperado do segmento E\&P, valor esperado do segmento Refino e o valor do CVaR estão na tabela 20 abaixo.

US\$ Milhões

\begin{tabular}{ll}
\hline Valo Esperado E\&P & 48.447 \\
Valor Esperado Refino & 11.483 \\
CVaR do valor total & 48.819 \\
\hline
\end{tabular}

Tabela 19- Lucro E\&P, Lucro Refino e CVaR

A distribuição dos valores presentes do E\&P e do Refino, bem como suas respectivas distribuições acumuladas podem ser visualizadas nos gráficos das figuras 16 e 17 abaixo. 


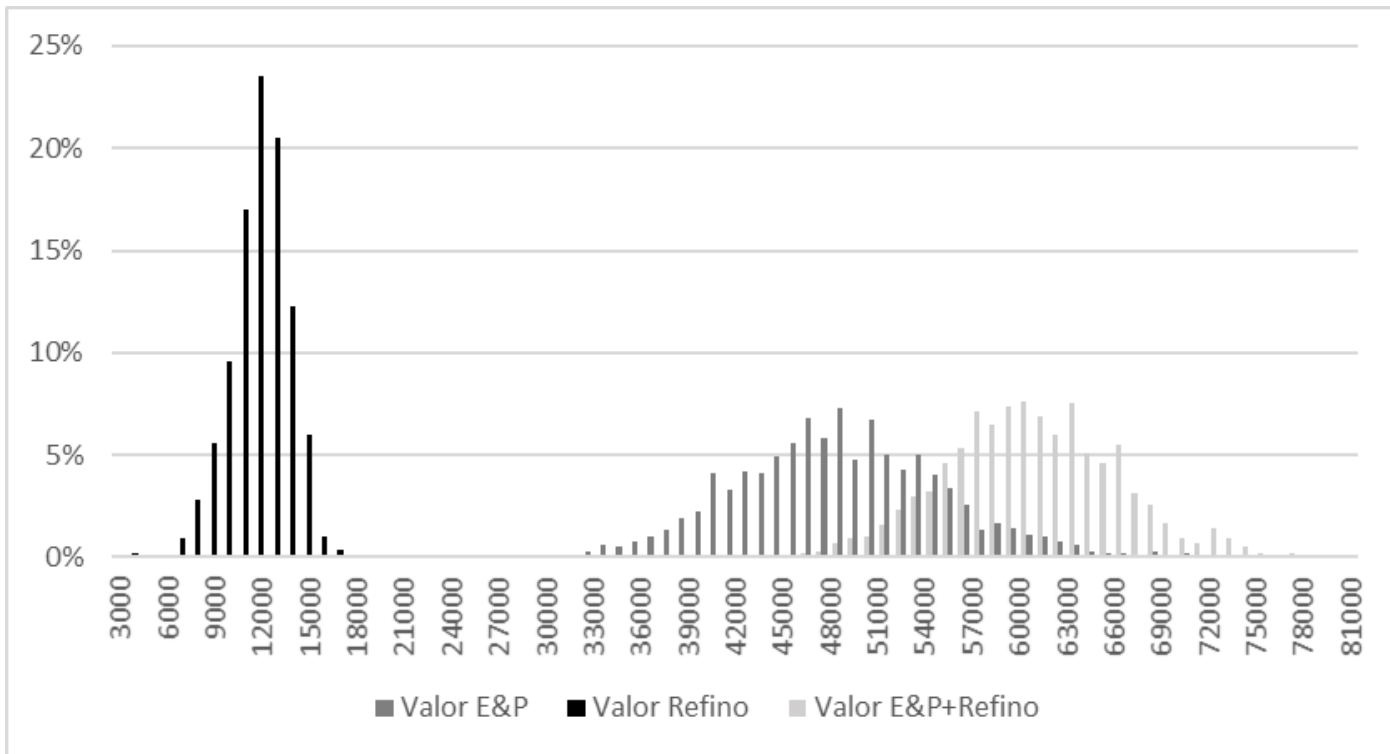

Figura 16 - Histograma dos valores do E\&P e do refino

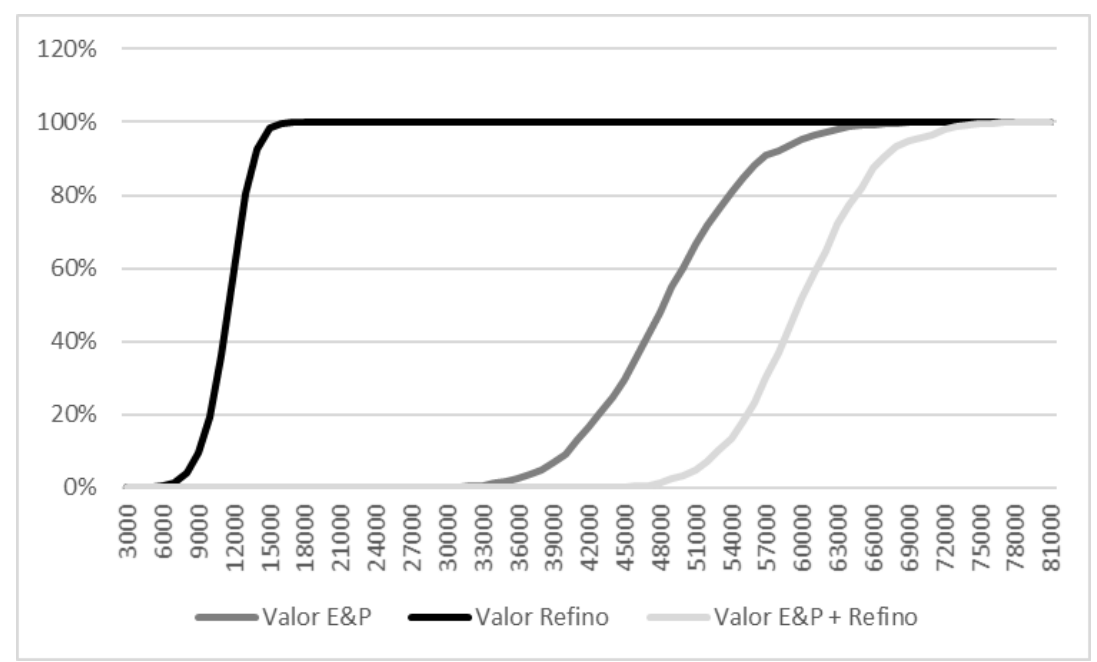

Figura 17 - Distribuição acumulada dos valores do E\&P e do refino

Nos gráficos acima expostos observa-se que a dispersão dos resultados do E\&P é consideravelmente maior que a do refino. Isto se deve ao fato de o segmento de E\&P ser de maior risco por estar diretamente associado a variável externa do preço do petróleo, que possui alta volatilidade, além de possuir certa incerteza na produção.

Como o preço do petróleo está convergindo para uma média de US\$ 56 por barril e o preço máximo de repasse no preço dos derivados é de US $\$ 70$ por barril, o controle de preços representado no modelo não está afetando a decisão de primeiro estágio de escolha do portfolio de E\&P e refino. Ao se retirar do modelo a limitação do preço máximo, obteve-se a mesma decisão ótima da figura 15, apesar do valor da função objetivo ser superior (US\$ 63.309 milhões), conforme esperado. 


\subsubsection{Sensibilidade 2: perfil de risco}

O objetivo desta sensibilidade é avaliar os resultados do modelo a partir da variação do perfil de risco do decisor, representado pelo parâmetro $\lambda$, que pondera os resultados do CVaR e do valor esperado na função objetivo. Quando maior o parâmetro $\lambda$, maior o peso do CVaR na função objetivo e, portanto, mais avesso a rico é o decisor. Para esta análise considerou-se o caso da demanda constante e dos preços do petróleo revertendo a US\$30 por barril. Ao variar o parâmetro $\lambda$ de 0 a 0,999, o modelo resultou nas seguintes participações no E\&P e no refino.

\begin{tabular}{|c|c|c|c|c|c|c|}
\hline & $\lambda=0$ & $\lambda=0,2$ & $\lambda=0,4$ & $\lambda=0,6$ & $\lambda=0,8$ & $\lambda=0,999$ \\
\hline E\&P_1 & $100 \%$ & $100 \%$ & $100 \%$ & $100 \%$ & $100 \%$ & $100 \%$ \\
\hline$E \& P \_2$ & $100 \%$ & $100 \%$ & $100 \%$ & $100 \%$ & $100 \%$ & $15 \%$ \\
\hline E\&P_3 & $100 \%$ & $100 \%$ & $100 \%$ & $100 \%$ & $100 \%$ & $100 \%$ \\
\hline$E \& P \_4$ & $100 \%$ & $100 \%$ & $100 \%$ & $0 \%$ & $0 \%$ & $0 \%$ \\
\hline E\&P_5 & $100 \%$ & $100 \%$ & $100 \%$ & $100 \%$ & $100 \%$ & $100 \%$ \\
\hline E\&P_6 & $0 \%$ & $0 \%$ & $0 \%$ & $0 \%$ & $0 \%$ & $0 \%$ \\
\hline E\&P_7 & $100 \%$ & $100 \%$ & $100 \%$ & $0 \%$ & $0 \%$ & $0 \%$ \\
\hline$E \& P \_8$ & $79 \%$ & $54 \%$ & $0 \%$ & $0 \%$ & $0 \%$ & $0 \%$ \\
\hline E\&P_9 & $0 \%$ & $0 \%$ & $0 \%$ & $0 \%$ & $0 \%$ & $0 \%$ \\
\hline
\end{tabular}

Figura 18 - Decisões ótimas no E\&P frente ao parâmetro $\lambda$

\begin{tabular}{lllllll} 
& $\boldsymbol{\lambda}=\mathbf{0}$ & $\boldsymbol{\lambda}=\mathbf{0 , 2}$ & $\boldsymbol{\lambda}=\mathbf{0 , 4}$ & $\boldsymbol{\lambda}=\mathbf{0 , 6}$ & $\boldsymbol{\lambda}=\mathbf{0 , 8}$ & $\boldsymbol{\lambda}=\mathbf{0 , 9 9 9}$ \\
\hline Ref_1 & $100 \%$ & $80 \%$ & $93 \%$ & $97 \%$ & $99 \%$ & $100 \%$ \\
Ref_2 & $100 \%$ & $100 \%$ & $99 \%$ & $93 \%$ & $100 \%$ & $93 \%$ \\
Ref_3 & $100 \%$ & $100 \%$ & $86 \%$ & $98 \%$ & $100 \%$ & $98 \%$ \\
Ref_4 & $100 \%$ & $99 \%$ & $59 \%$ & $69 \%$ & $100 \%$ & $100 \%$ \\
Ref_5 & $100 \%$ & $92 \%$ & $91 \%$ & $98 \%$ & $99 \%$ & $100 \%$ \\
Ref_6 & $100 \%$ & $98 \%$ & $91 \%$ & $96 \%$ & $99 \%$ & $100 \%$ \\
Ref_7 & $100 \%$ & $100 \%$ & $95 \%$ & $99 \%$ & $100 \%$ & $99 \%$ \\
Ref_8 & $100 \%$ & $100 \%$ & $100 \%$ & $99 \%$ & $99 \%$ & $98 \%$ \\
Ref_9 & $100 \%$ & $100 \%$ & $100 \%$ & $93 \%$ & $100 \%$ & $94 \%$
\end{tabular}

Figura 19 - Decisões ótimas no refino frente ao parâmetro $\lambda$

Conforme já era esperado, verifica-se que quanto mais avesso a risco é o decisor, menor sua participação no segmento de E\&P, que é de fato o segmento mais arriscado. A participação no portfólio de refino não apresentou variações expressivas, por ser um segmento com menos riscos e por apresentar lucros estáveis num cenário de preços mais baixos.

No gráfico da figura 20 abaixo, observa-se que o resultado esperado da função objetivo do modelo reduz em detrimento de uma maior aversão a risco. 0 
mesmo ocorre para os valores esperados do E\&P e do refino. Já o CvaR aumenta conforme o parâmetro $\lambda$ aumenta.

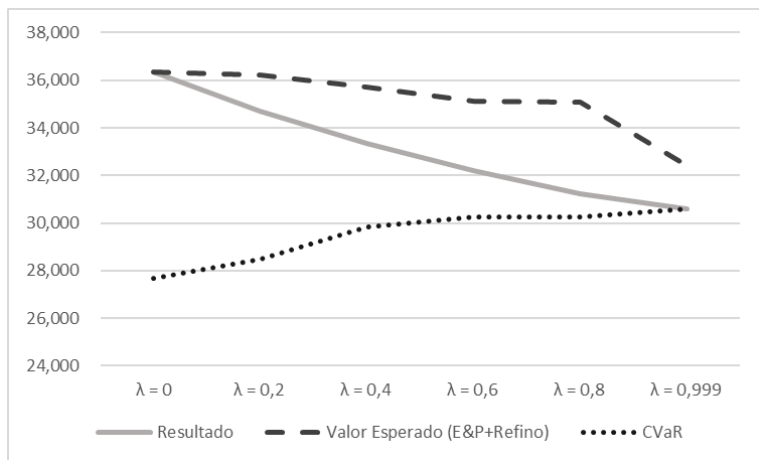

Figura 20- Função Objetivo, soma valores esperados e CVaR para variações do $\lambda$

O gráfico na figura 21 abaixo apresenta os valores esperados para 0 segmento de E\&P e refino.

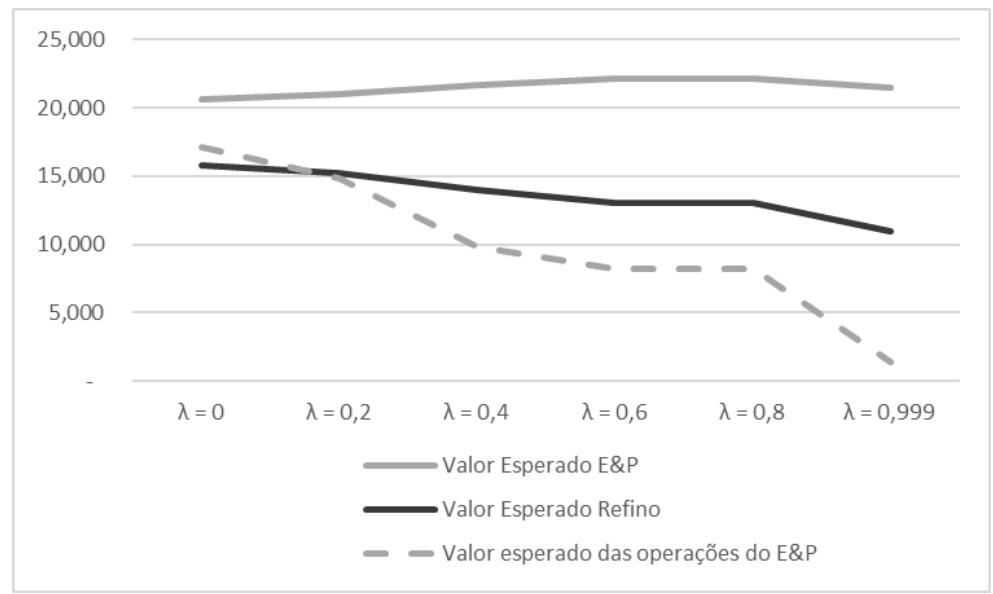

Figura 21 - Lucro esperado do E\&P e do refino e lucro operacional do E\&P

Mesmo com pouca variação no portfólio de refino, o seu valor esperado reduz devido a maior necessidade de importação de petróleo bruto devido a redução do portfólio do E\&P. O valor esperado do E\&P chega a apresentar um ligeiro aumento nos casos de maior $\lambda$, entretanto esse efeito se deve ao valor recebido pela venda dos campos de produção. Uma vez expurgado esse efeito, verifica-se que o valor esperado apenas das operações do E\&P diminui com o aumento da aversão a risco.

As figuras 22 e 23 abaixo comparam as distribuições dos resultados para diferentes valores de $\lambda$. 


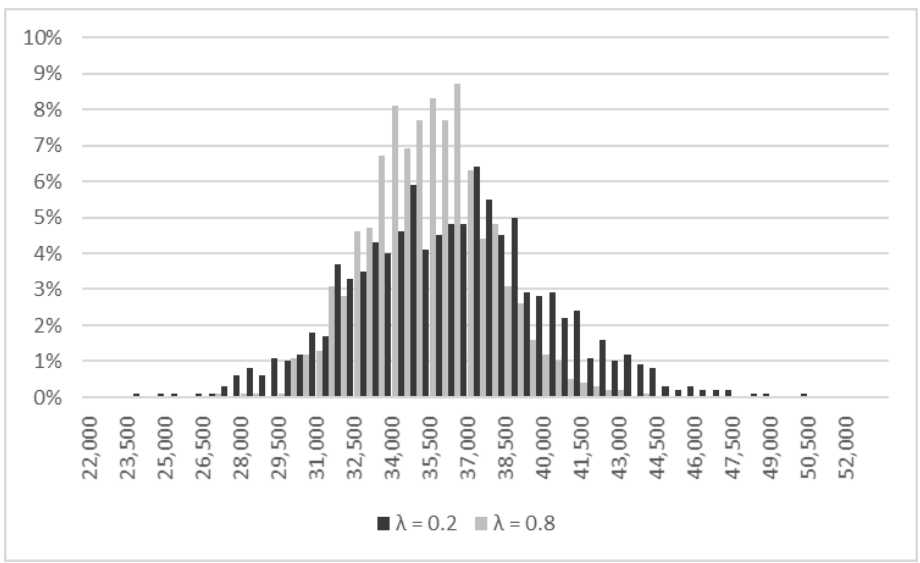

Figura 22 - Histograma dos resultados para $\lambda=0,2$ e $\lambda=0,8$

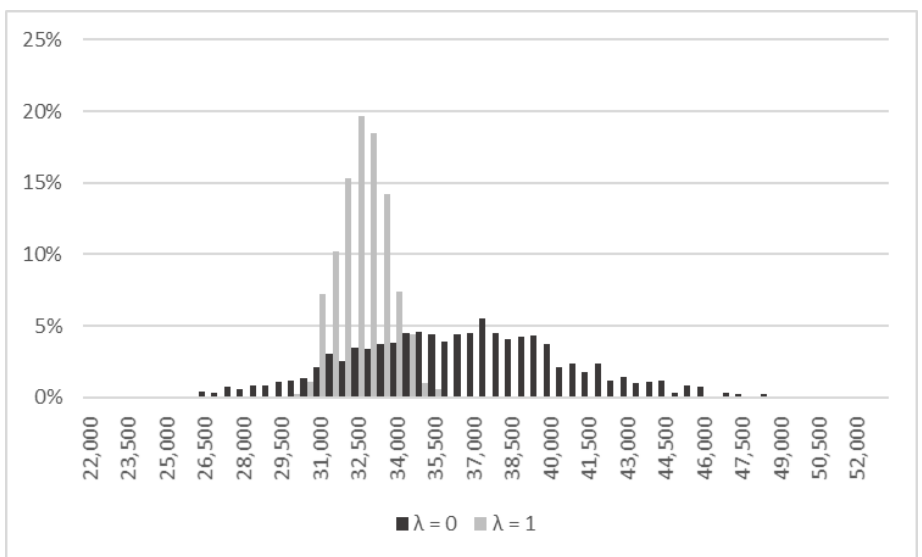

Figura 23 - histograma dos resultados para $\lambda=0$ e $\lambda=0,999$

Nos gráficos apresentados acima fica evidente a menor dispersão dos casos mais avessos a risco, em detrimento de um valor esperado menor.

\subsubsection{Análise comparativa das estratégias de portfolio}

O modelo proposto otimiza o portfólio completo, incluindo o setor de E\&P e de refino simultaneamente, levando em conta a integração entre eles. Esta pode não ser a prática adotada pela indústria, onde muitas vezes os setores de upstream e downstream não trabalham de maneira integrada. Com o objetivo de verificar o ganho de se considerar o portfólio completo e a integração entre os segmentos de refino E\&P, serão testadas três estratégias adicionais de otimização que podem ser utilizadas:

- Estratégia 1 - Otimização local: portfolios do E\&P e do refino são otimizados paralelamente, sem considerar a existência do outro.

- Estratégia 2 - Otimização apenas no E\&P: Otimização do portfólio do E\&P sem considerar o refino, e no refino não acontece nenhum tipo de otimização; 
- Estratégia 3 - otimização do refino posteriormente a definição no E\&P: otimização do portfólio do E\&P sem considerar o refino e otimização do refino posteriormente, considerando a decisão da ótima obtida no E\&P;

A tabela 21 abaixo resume a forma de cálculo de cada uma das estratégias no modelo.

\begin{tabular}{|l|c|c|c|}
\hline \multicolumn{1}{|c|}{$\begin{array}{c}\text { Estratégia 1 } \\
\text { Otimização local }\end{array}$} & $\begin{array}{c}\text { Estratégia 2 } \\
\text { Otimização apenas no E\&P }\end{array}$ & $\begin{array}{c}\text { Estratégia 3 } \\
\text { Otimização do refino posteriormente a } \\
\text { definição no E\&P }\end{array}$ \\
\hline $\begin{array}{l}\text { Tratamento } \\
\text { do E\&P }\end{array}$ & Modelo sem refino $(\mathrm{y}+\mathrm{y} 0=0)$ & Modelo sem refino $(\mathrm{y}+\mathrm{y} 0=0)$ & Modelo sem refino $(\mathrm{y}+\mathrm{y} 0=0)$ \\
\hline $\begin{array}{l}\text { Tratamento } \\
\text { do refino }\end{array}$ & Modelo sem E\&P $(\mathrm{x}+\mathrm{x} 0=0)$ & Portfolio inicial, sem otimização & $\begin{array}{c}\text { Modelo com participações no E\&P já } \\
\text { definidas }\left(\mathrm{x}=\left[\begin{array}{l}\text { resultado do modelo } \\
\text { sem refino }])\end{array}\right.\right.\end{array}$
\end{tabular}

Tabela 20 - Definição das estratégias

Foram utilizados os mesmos parâmetros do caso base. A comparação entre os resultados do caso base com as três estratégias estão no gráfico da figura 24 abaixo, onde se observa que a co-otimização (caso base) apresenta resultados superiores aos demais casos.

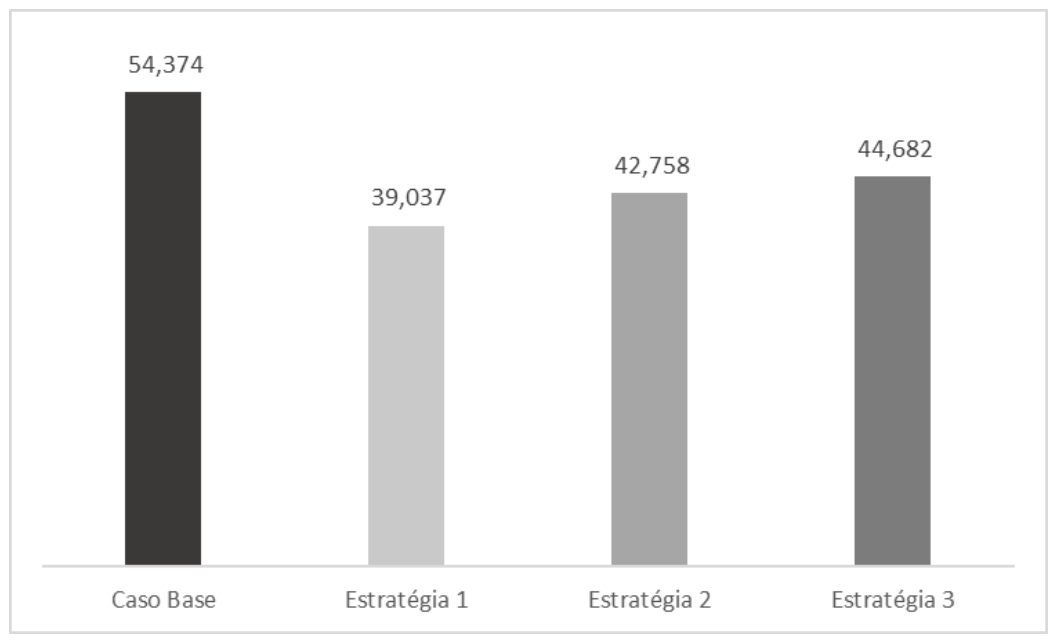

Figura 24 - Comparação dos resultados entre o caso base e as estratégias

As diferentes estratégias de otimização do portfólio apresentam diferentes decisões de primeiro estágio tanto no E\&P quanto no refino, conforme pode ser observado na figura 25 e 26 abaixo. 


\begin{tabular}{lrrrr} 
& Caso Base & Estratégia 1 & Estratégia 2 & Estratégia 3 \\
\hline E\&P_1 & $100 \%$ & $100 \%$ & $100 \%$ & $100 \%$ \\
\hline E\&P_2 & $100 \%$ & $100 \%$ & $100 \%$ & $100 \%$ \\
\hline E\&P_3 & $100 \%$ & $100 \%$ & $100 \%$ & $100 \%$ \\
\hline E\&P_4 & $100 \%$ & $100 \%$ & $100 \%$ & $100 \%$ \\
\hline E\&P_5 & $100 \%$ & $100 \%$ & $100 \%$ & $100 \%$ \\
E\&P_6 & $0 \%$ & $0 \%$ & $0 \%$ & $0 \%$ \\
E\&P_7 & $100 \%$ & $0 \%$ & $0 \%$ & $0 \%$ \\
E\&P_8 & $100 \%$ & $0 \%$ & $0 \%$ & $0 \%$ \\
E\&P_9 & $100 \%$ & $0 \%$ & $0 \%$ & $0 \%$
\end{tabular}

Figura 25 - Decisão ótima no E\&P em cada estratégia de otimização

\begin{tabular}{|c|c|c|c|c|}
\hline & Caso Base & Estratégia 1 & Estratégia 2 & Estratégia 3 \\
\hline$\overline{\text { Ref_1 }}$ & $100 \%$ & $27 \%$ & $100 \%$ & $53 \%$ \\
\hline Ref 2 & $100 \%$ & $27 \%$ & $100 \%$ & $69 \%$ \\
\hline Ref_3 & $100 \%$ & $27 \%$ & $100 \%$ & $59 \%$ \\
\hline Ref 4 & $100 \%$ & $27 \%$ & $100 \%$ & $33 \%$ \\
\hline Ref 5 & $100 \%$ & $27 \%$ & $100 \%$ & $56 \%$ \\
\hline Ref_6 & $100 \%$ & $27 \%$ & $100 \%$ & $45 \%$ \\
\hline Ref 7 & $100 \%$ & $27 \%$ & $100 \%$ & $99 \%$ \\
\hline Ref_8 & $100 \%$ & $27 \%$ & $100 \%$ & $77 \%$ \\
\hline Ref 9 & $100 \%$ & $27 \%$ & $100 \%$ & $72 \%$ \\
\hline
\end{tabular}

Figura 26 - Decisão ótima no refino em cada estratégia de otimização

A partir dos gráficos de distribuição e a distribuição acumulada da soma dos lucros dos segmentos dos três casos acima descritos (figuras 27 a 30 ) pode-se observar que, apesar de todas as estratégias possuírem dispersões semelhantes, o caso base domina de primeira ordem as demais estratégias, com destaque para a estratégia 1 de otimização local que possui maior distanciamento do caso base.

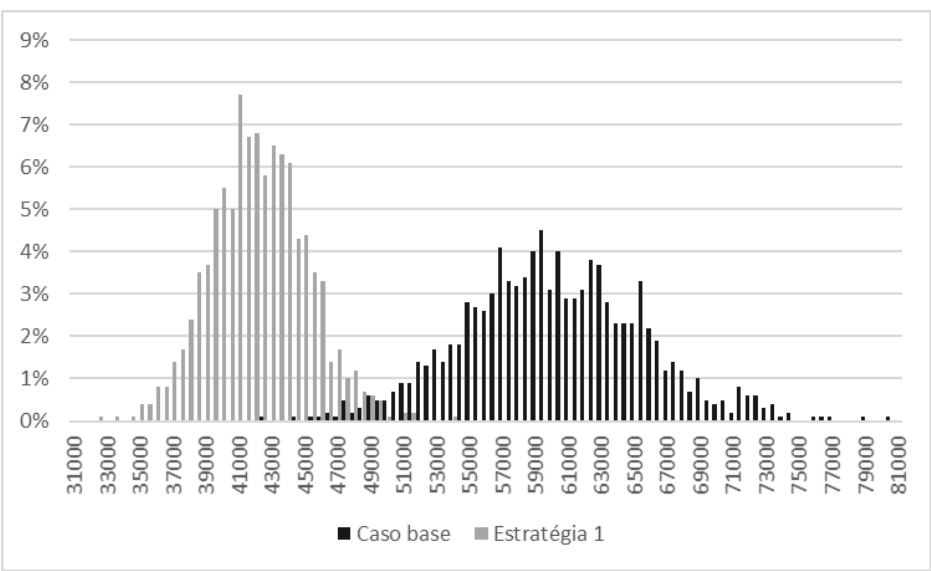

Figura 27 - Histogramas: Caso base e Estratégia 1 


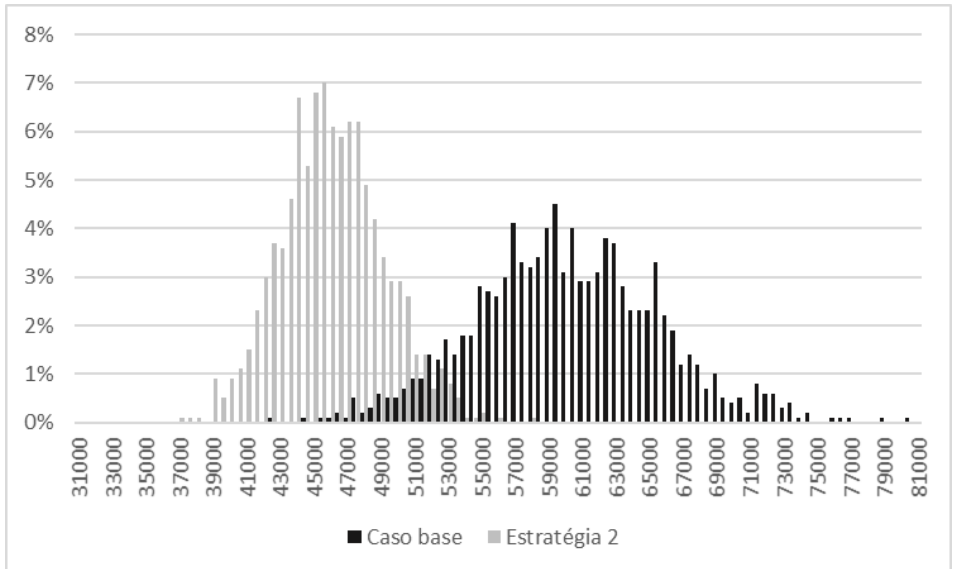

Figura 28 - Histogramas: Caso base e Estratégia 2

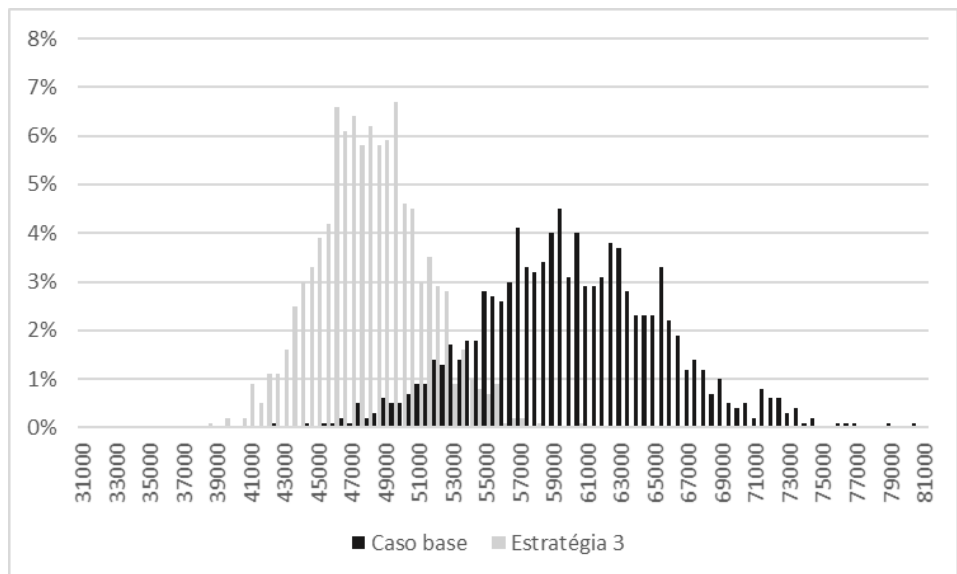

Figura 29 - Histogramas: Caso base e Estratégia 3

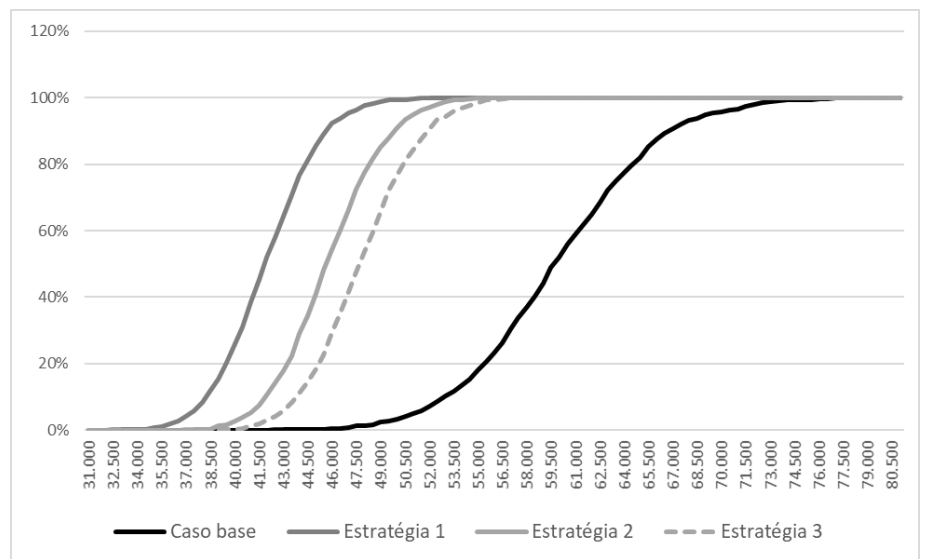

Figura 30 - Distribuição de probabilidade acumulada dos valores esperados das estratégias

As diferenças entre as estratégias e o caso base pode ser mais bem visualizadas nos gráficos de distribuição e distribuição acumulada para as diferenças (Figura 31 e 32). As diferenças entre os valores esperados, o CVaR e o valor nos percentis 5\% e 95\% estão na tabela 22 abaixo. 


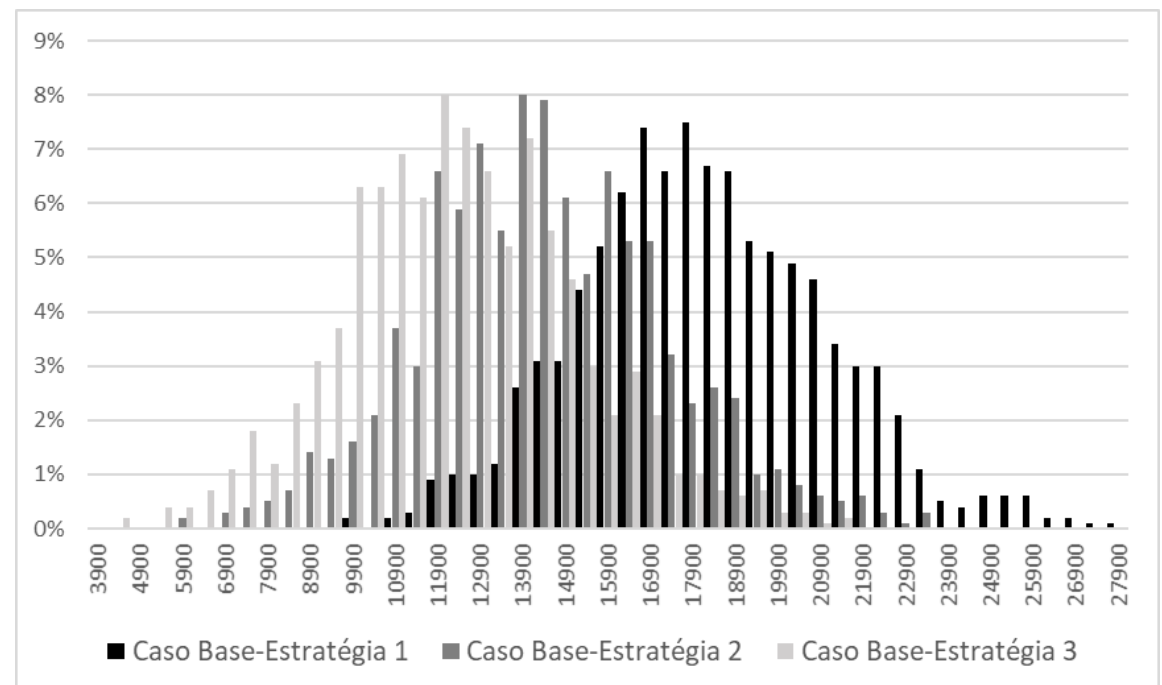

Figura 31 - Distribuição de probabilidade das diferenças entre estratégias e o caso base

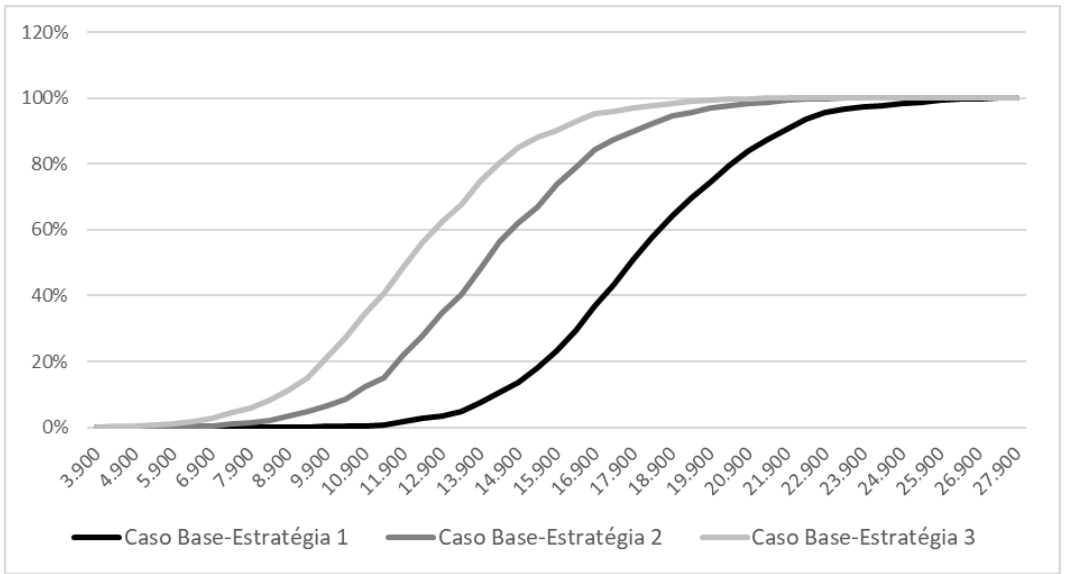

Figura 32 - Distribuição acumulada das diferenças entre estratégias e o caso base

\begin{tabular}{|l|c|c|c|} 
& Base - Est1 & Base - Est2 & Base - Est3 \\
\hline Lucro esperado & 17.986 & 14.146 & 12.133 \\
\hline CVaR & 12.241 & 8.316 & 6.550 \\
\hline Quantil 5\% & 13.426 & 9.446 & 7.564 \\
\hline Quantil 95\% & 22.836 & 19.116 & 16.886 \\
\hline
\end{tabular}

Tabela 21 - Lucro esperado, CVaR, Quantil 5\% e Quantil 95\% das diferenças

\section{4.}

\section{Estudo de caso pós-COVID}

No início do ano de 2020 uma epidemia que começou em dezembro de 2019 em Wuhan, China, se espalhou pelo mundo trazendo com ela, além de impactos sanitários e sociais, impactos expressivos na economia global. A COVID-19 rapidamente foi considerada uma pandemia pela Organização Mundial da Saúde 
em março deste ano, e com ela observou-se reflexos nunca vistos na sociedade. A alta taxa de contágio e rápida disseminação da doença fez com que cidades fechassem fronteiras, comercio, atividades ao ar livre e a população foi recomendada a ficar isolada em suas casas.

No âmbito da indústria do petróleo, o impacto nos preços começou a ser sentido já em fevereiro, com as ações de lockdown (fechamento total) na China. À medida que a epidemia foi se espalhando e mais países passaram a adotar ações de quarentena, a demanda por combustíveis foi diminuindo cada vez mais.

A fim de evitar uma queda ainda maior dos preços do petróleo, os membros da OPEP se reuniram no início do mês de março para discutir cortes na produção e não chegaram a um acordo, tornando a situação ainda mais dramática para o setor. Em abril deste ano, os preços do petróleo chegaram ao seu menor patamar desde 1990, com contratos futuros do WTI chegando a preços negativos em alguns dias. Posteriormente, a Arábia Saudita e Rússia conseguiram chegar a um acordo de corte de 9,7 MM de barris por dia de produção, que na ocasião foi insuficiente para balancear a redução da demanda.

Dado o ineditismo do contexto no qual a economia mundial e, consequentemente, o setor de petróleo se encontra, se torna ainda mais difícil fazer projeções futuras, devido ao ambiente de grandes incertezas.

Nesse sentido, Carlsson-Szlezak et al. (2020) considera razoável pensar em três cenários para recuperação economia: $V$-shaped, $U$-shaped e $L$-shaped. $O$ cenário $V$-shape é o mais otimista entre eles, e considera que o crescimento pós-choque será suficiente para recuperar as perdas. O cenário U-shape considera que o crescimento pós-choque será mais lento inicialmente, com alguma perda permanente. Já o cenário L-shape é o mais pessimista entre eles, e considera perdas estruturais significativas.

Apesar de Carlsson-Szlezak et al. (2020) considerar o cenário L-shaped pouco provável para a economia como um todo, para o setor do petróleo esse pode ser um cenário plausível devido a mudanças permanentes da sociedade após a experiencia do isolamento social. Efeitos como, menor poluição nas cidades e maior produtividade em home offices, podem levar a população a se locomover menos, e portanto, demandar menos combustíveis.

Neste capítulo, serão avaliados os resultados de quatro cenários dos efeitos pós-pandemia. Os cenários consideram que a recuperação de demanda pode ser V-shape ou L-shape e que os países da OPEP podem voltar a entrar em acordo ou não. A combinação desses dois fatores, recuperação da demanda e 
dinâmica da OPEP, formam os quatro cenários simulados, conforme figura 33 abaixo.

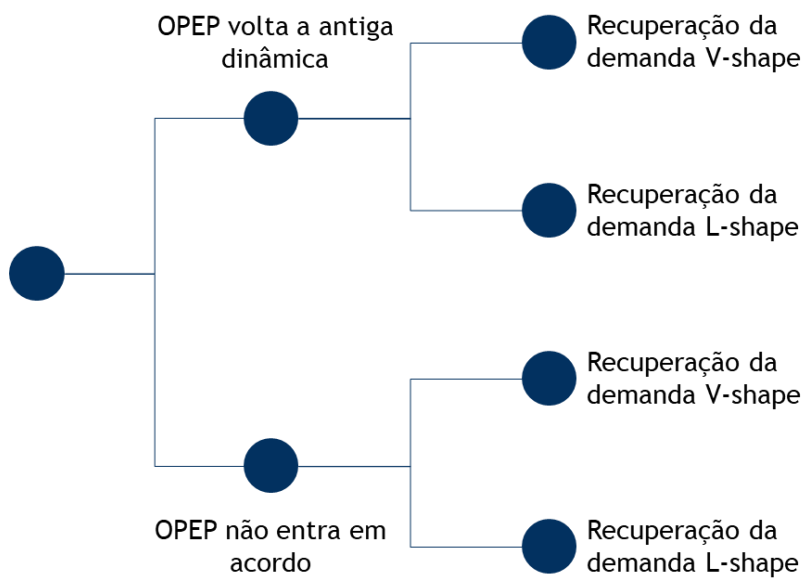

Figura 33 - Descrição dos cenários pós-COVID.

$\mathrm{Na}$ questão de corte de produção devido a acordos entre os países da OPEP, o cenário onde a OPEP volta a antiga dinâmica, considera que os preços do petróleo vão reverter a média, conforme o modelo descrito no capítulo 2.1. Para esta simulação foram acrescentados os preços de janeiro a abril de 2020 aos dados históricos. O valor esperado nesses cenários de preço bem como sua dispersão estão na figura 34 abaixo.

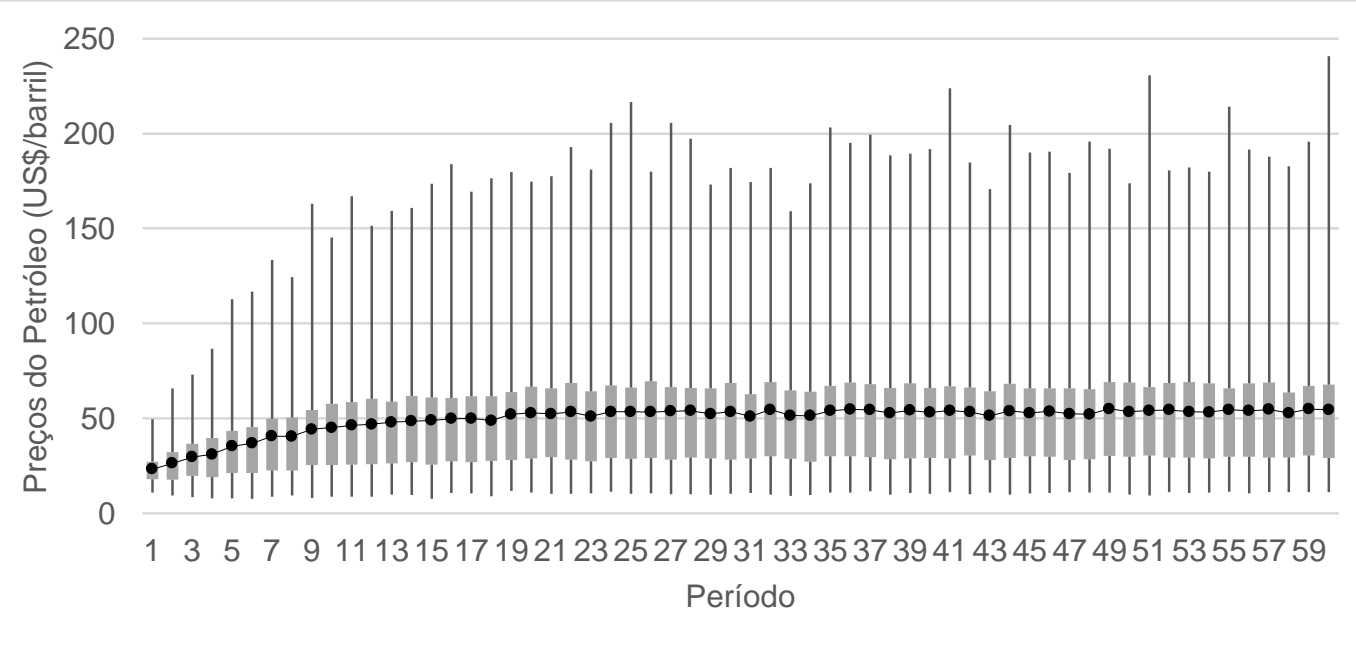

Figura 34 - Reversão a média dos preços do petróleo pós-COVID

Para o cenário onde os países da OPEP não conseguem mais chegar em acordos de cortes na produção, estabelecendo assim uma nova dinâmica com excesso de oferta de petróleo no mercado mundial, considera-se que os preços do petróleo não irão mais reverter ao antigo patamar histórico. Para este caso, 
foram simulados cenários de preços que revertem a US\$30 por barril, conforme figura 35 abaixo.

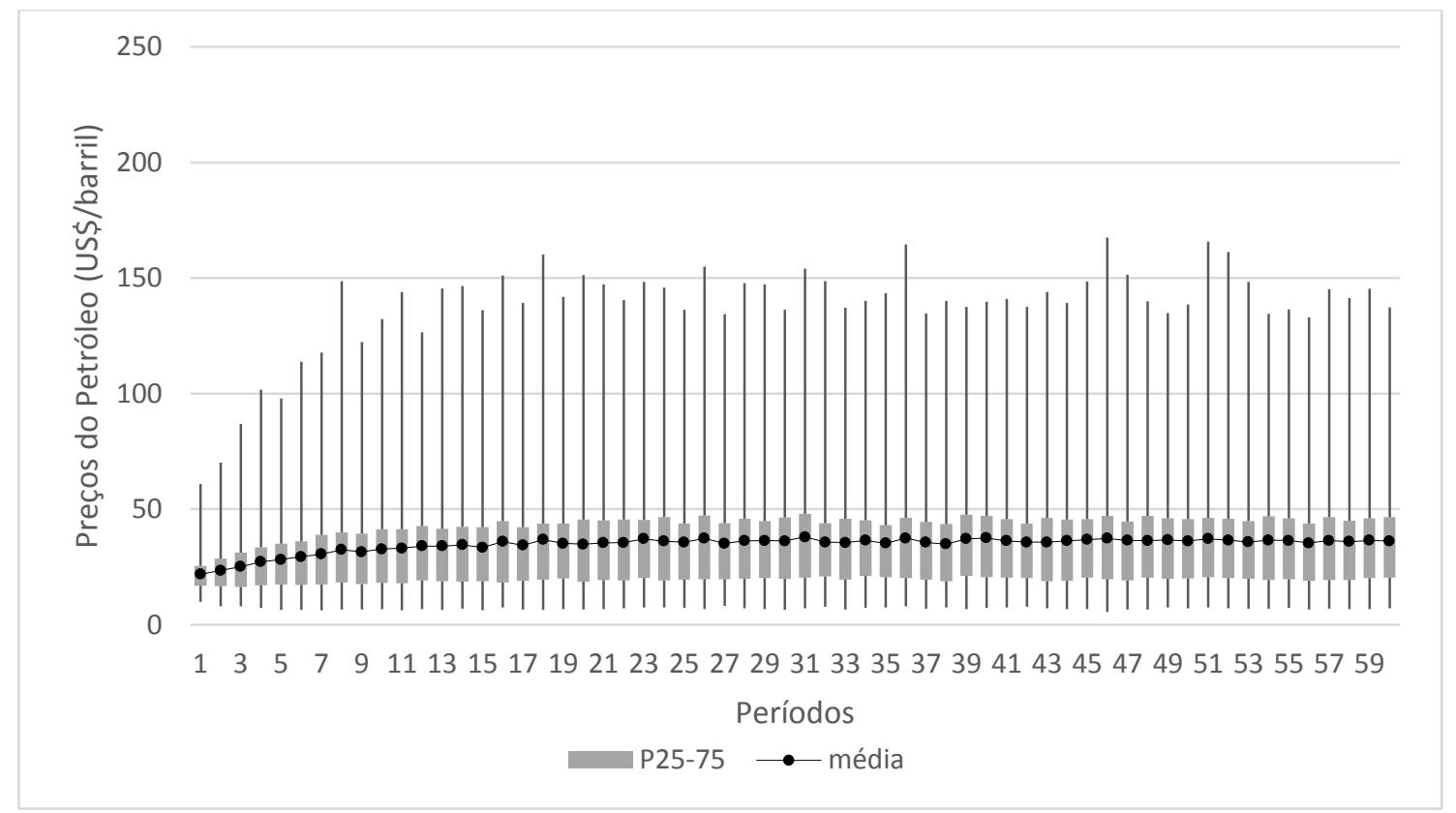

Figura 35 - Preço do petróleo revertendo a US\$ 30 por barril

Para a demanda por derivados, considerou-se um choque inicial de redução de $50 \%$ no consumo de gasolina e $30 \%$ no consumo de diesel, dados coerentes com os dados divulgados pelo atual presidente da Petrobras, em entrevista ao Valor Investe (abril/2020). Os cenários de recuperação V-shape e L-shape, podem ser vistos nos gráficos 36 e 37 abaixo. No cenário V-shape, considera-se que a demanda por combustíveis é recuperada em 20 períodos. Já no cenário Lshape, considera-se que há uma perda de $10 \%$ na taxa de crescimento por período (mensal) da demanda.

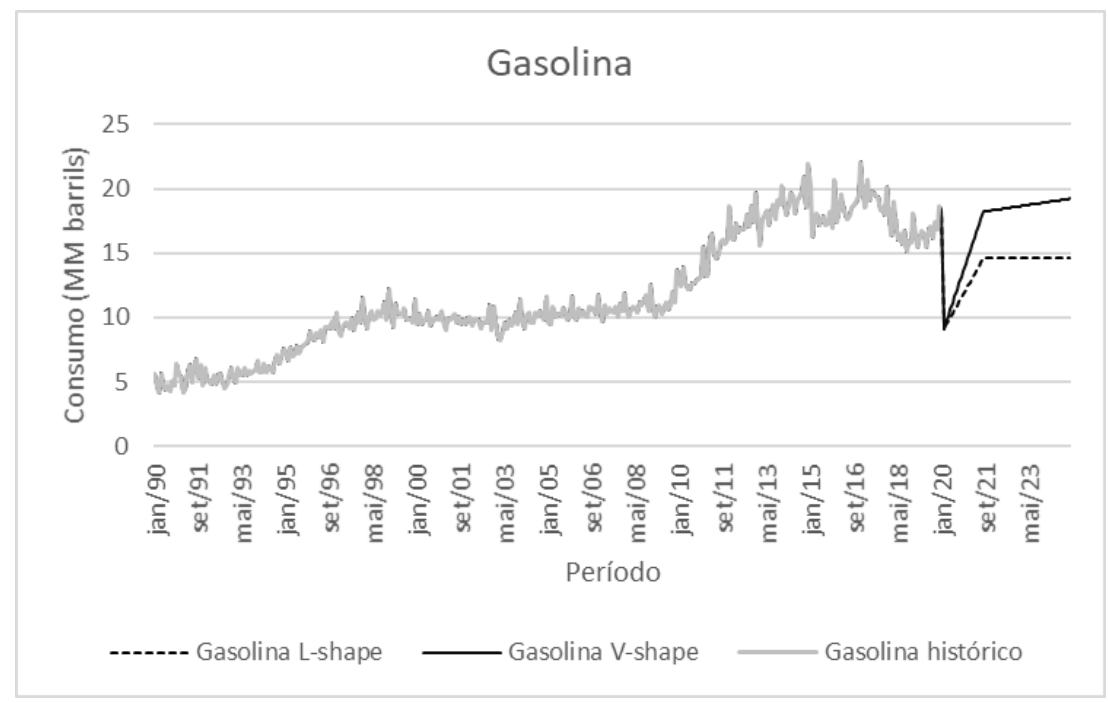


Figura 36 - Demanda de gasolina pós-COVID. Fonte dos dados históricos: ANP.

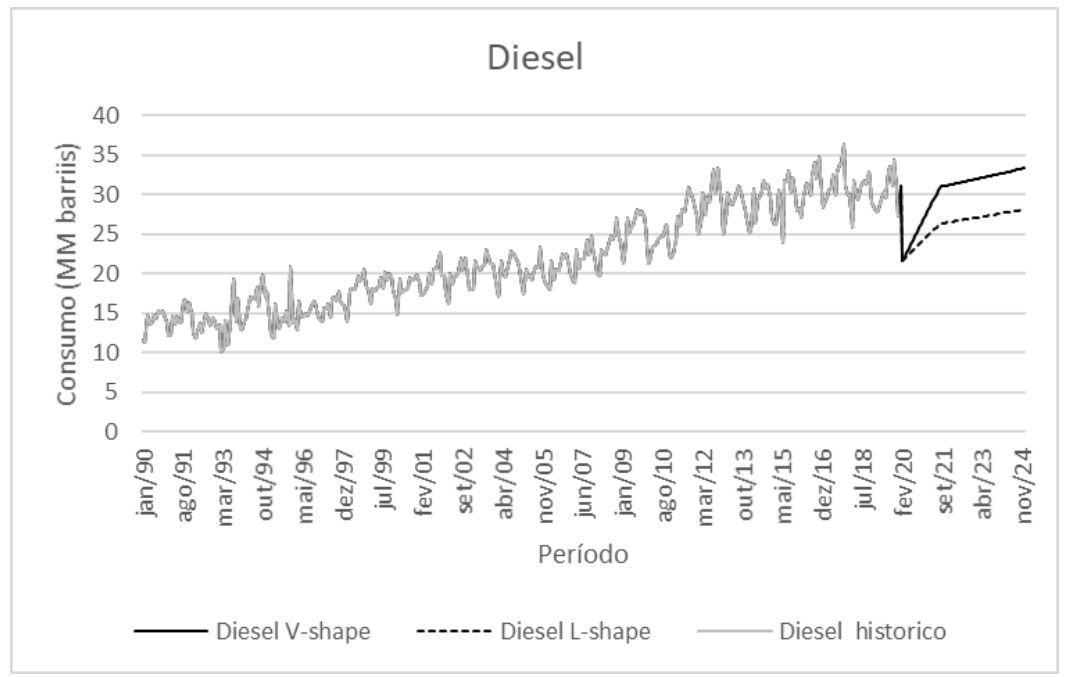

Figura 37 - Demanda de diesel pós-COVID. Fonte dos dados históricos: ANP.

Os resultados para os quatro casos pós pandemia estão na tabela 23 abaixo.

\begin{tabular}{|l|c|c|c|c|}
\cline { 2 - 5 } \multicolumn{1}{l|}{ US $\$$ Milhões } & $\begin{array}{c}\text { OPEP com acordo } \\
\text { + V-shape }\end{array}$ & $\begin{array}{c}\text { OPEP com acordo } \\
\text { + L-shape }\end{array}$ & $\begin{array}{c}\text { OPEP sem acordo } \\
\text { + V-shape }\end{array}$ & $\begin{array}{c}\text { OPEP sem acordo } \\
\text { + L-shape }\end{array}$ \\
\hline Valor Esperado & 46.668 & 44.986 & 27.743 & 27.090 \\
\hline CVaR & 36.166 & 35.672 & 20.974 & 21.135 \\
\hline Resultado & 41.417 & 40.329 & 24.359 & 24.112 \\
\hline
\end{tabular}

Tabela 22 - Valor esperado, CVaR e resultado para os cenários pós-COVID

Observa-se que, a depender do caso, as perdas no setor podem ser bastante expressivas, principalmente para o setor de exploração e produção de petróleo. As figuras 38 e 39 abaixo mostram a participação ótima em cada ativo para os quatro casos.

\begin{tabular}{|c|c|c|c|}
\hline \multicolumn{2}{|c|}{ OPEP em acordo } & \multicolumn{2}{|c|}{ OPEP não entra em acordo } \\
\hline V-shape & L-shape & V-shape & L-shape \\
\hline E\&P_1 $100 \%$ & $100 \%$ & $100 \%$ & $100 \%$ \\
\hline E\&P_2 100\% & $100 \%$ & $85 \%$ & $76 \%$ \\
\hline E\&P_3 100\% & $100 \%$ & $100 \%$ & $100 \%$ \\
\hline E\&P_4 100\% & $100 \%$ & $0 \%$ & $0 \%$ \\
\hline E\&P_5 $100 \%$ & $100 \%$ & $100 \%$ & $100 \%$ \\
\hline$E \& P \_60 \%$ & $0 \%$ & $0 \%$ & $0 \%$ \\
\hline E\&P_7 100\% & $100 \%$ & $100 \%$ & $82 \%$ \\
\hline E\&P_8 100\% & $100 \%$ & $0 \%$ & $0 \%$ \\
\hline E\&P_9 100\% & $0 \%$ & $0 \%$ & $0 \%$ \\
\hline
\end{tabular}

Figura 38 - Participação no E\&P nos 4 cenários pós-COVID 


\begin{tabular}{lllll} 
& \multicolumn{2}{c}{$\begin{array}{c}\text { OPEP em acordo } \\
\text { V-shape }\end{array}$} & \multicolumn{2}{c}{ OPEP não entra em acordo } \\
L-shape & V-shape & L-shape \\
\hline Ref_1 & $95 \%$ & $92 \%$ & $47 \%$ & $45 \%$ \\
Ref_2 & $100 \%$ & $99 \%$ & $67 \%$ & $58 \%$ \\
Ref_3 & $95 \%$ & $85 \%$ & $56 \%$ & $50 \%$ \\
Ref_4 & $62 \%$ & $53 \%$ & $32 \%$ & $32 \%$ \\
Ref_5 & $92 \%$ & $91 \%$ & $49 \%$ & $46 \%$ \\
Ref_6 & $98 \%$ & $78 \%$ & $41 \%$ & $40 \%$ \\
Ref_7 & $99 \%$ & $100 \%$ & $97 \%$ & $90 \%$ \\
Ref_8 & $100 \%$ & $100 \%$ & $73 \%$ & $61 \%$ \\
Ref_9 & $100 \%$ & $100 \%$ & $70 \%$ & $59 \%$
\end{tabular}

Figura 39 - Participação no refino nos 4 cenários pós-COVID

Pelas figuras acima, conclui-se que, para qualquer caso, a crise ocasionada pela pandemia do COVID-19 afetará o setor de óleo e gás, não só reduzindo lucros, mas também alterando a decisão ótima de participação no seu portfólio. No caso mais pessimista, quando a OPEP não entra em acordo e a recuperação da demanda é em $L$, observa-se que a solução ótima é de se desfazer de boa parte de seus ativos, mas ainda assim, pode-se dizer que que o contexto é insuficiente para pôr fim ao setor de óleo e gás como um todo.

Os resultados obtidos para cada cenário também evidenciam que a dinâmica da OPEP tem impactos mais expressivos que a redução da demanda devido ao COVID-19, pois mesmo para o caso mais pessimista, parte desta demanda tende a se recuperar no médio prazo. Estas conclusões podem ser mais bem observadas nos gráficos de distribuição acumulada dos quatro casos na figura 40 abaixo.

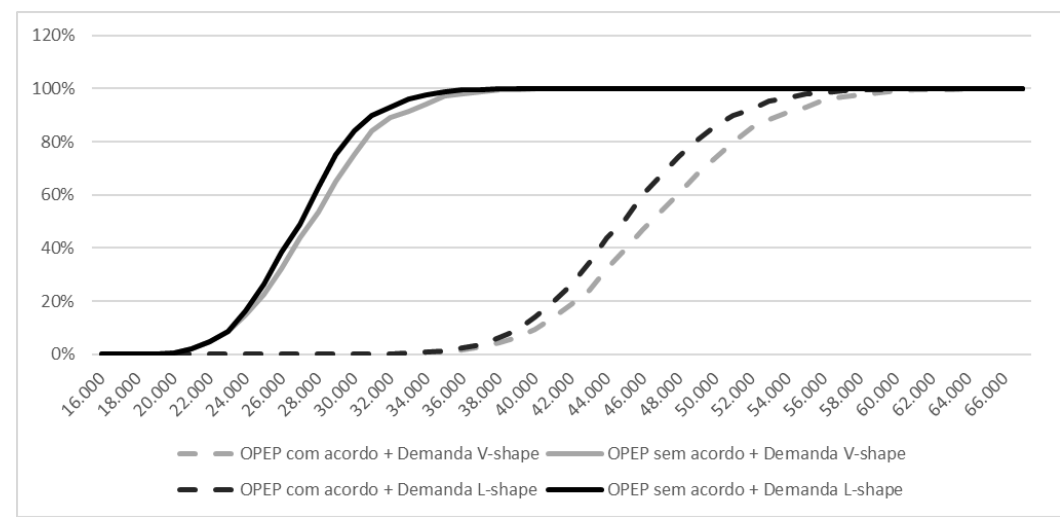

Figura 40 - Distribuição acumulada dos resultados dos 4 casos

Com o objetivo de obter apenas um resultado ótimo de decisão de portfólio, foram atribuídas probabilidades subjetivas para cada caso. Dada as últimas tentativas dos membros da OPEP em se chegar a um acordo de cortes na produção e a elevação do preço do petróleo em maio (para o patamar de US\$ 
40 por barril), considerou-se que o caso onde a OPEP volta a funcionar na antiga dinâmica tem $75 \%$ de chance de acontecer. Para os cenários de recuperação de demanda, cujo comportamento ainda é bastante incerto, considerou-se que uma recuperação em $L$ tem mais chances de acontecer (60\%) no Brasil, por este ser um país de economia menos desenvolvida. A figura 41 abaixo ilustra as probabilidades atribuídas a cada cenário.

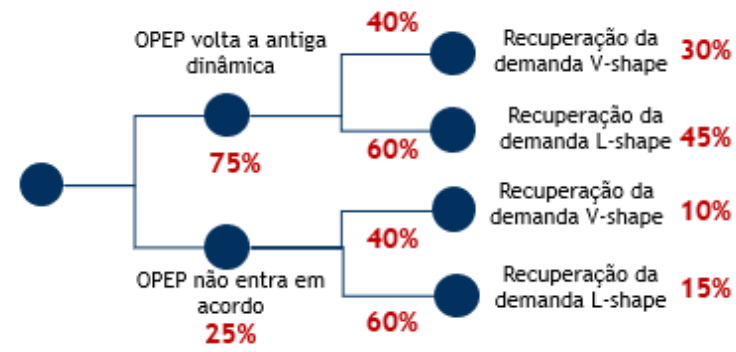

Figura 41 - Probabilidades subjetivas de cada caso

O modelo com probabilidades subjetivas obteve um resultado de US $\$ 36.647$ milhões. As figuras 42 e 43 abaixo comparam as decisões ótimas de primeiro estágio desta decisão única com os quatro cenários abordados.

\begin{tabular}{|c|c|c|c|c|}
\hline \multicolumn{2}{|c|}{ OPEP em acordo } & \multicolumn{2}{|c|}{ OPEP não entra em acordo } & \multirow[t]{2}{*}{ Prob. Subjetivas } \\
\hline V-shape & L-shape & V-shape & L-shape & \\
\hline E\&P_1 $100 \%$ & $100 \%$ & $100 \%$ & $100 \%$ & $100 \%$ \\
\hline E\&P_2 $100 \%$ & $100 \%$ & $85 \%$ & $76 \%$ & $100 \%$ \\
\hline E\&P_3 $100 \%$ & $100 \%$ & $100 \%$ & $100 \%$ & $100 \%$ \\
\hline E\&P_4 $100 \%$ & $100 \%$ & $0 \%$ & $0 \%$ & $100 \%$ \\
\hline E\&P_5 $100 \%$ & $100 \%$ & $100 \%$ & $100 \%$ & $100 \%$ \\
\hline E\&P_6 $0 \%$ & $0 \%$ & $0 \%$ & $0 \%$ & $0 \%$ \\
\hline E\&P_7 $100 \%$ & $100 \%$ & $100 \%$ & $82 \%$ & $100 \%$ \\
\hline E\&P_8 $100 \%$ & $100 \%$ & $0 \%$ & $0 \%$ & $42 \%$ \\
\hline E\&P_9 $100 \%$ & $0 \%$ & $0 \%$ & $0 \%$ & $0 \%$ \\
\hline
\end{tabular}

Figura 42- Decisões de primeiro estágio para o E\&P

\begin{tabular}{llllll} 
& \multicolumn{2}{c}{$\begin{array}{c}\text { OPEP em acordo } \\
\text { V-shape }\end{array}$} & L-shape & \multicolumn{2}{c}{ OPEP não entra em acordo } \\
& V-shape & L-shape & Prob. Subjetivas \\
\hline Ref_1 & $95 \%$ & $92 \%$ & $47 \%$ & $45 \%$ & $66 \%$ \\
Ref_2 & $100 \%$ & $99 \%$ & $67 \%$ & $58 \%$ & $51 \%$ \\
Ref_3 & $95 \%$ & $85 \%$ & $56 \%$ & $50 \%$ & $77 \%$ \\
Ref_4 & $62 \%$ & $53 \%$ & $32 \%$ & $52 \%$ & $57 \%$ \\
Ref_5 & $92 \%$ & $91 \%$ & $49 \%$ & $46 \%$ & $68 \%$ \\
Ref_6 & $98 \%$ & $78 \%$ & $41 \%$ & $40 \%$ & $55 \%$ \\
Ref_7 & $99 \%$ & $100 \%$ & $97 \%$ & $50 \%$ & $100 \%$ \\
Ref_8 & $100 \%$ & $100 \%$ & $73 \%$ & $51 \%$ & $59 \%$ \\
Ref_9 & $100 \%$ & $100 \%$ & $70 \%$ & $59 \%$ & $95 \%$
\end{tabular}

Figura 43- Decisões de primeiro estágio para o refino

O valor médio esperado sob informação perfeita (solução wait and see) gera um resultado de US\$36.654 milhões, que quando comparado ao resultado do modelo estocástico com probabilidades para cada cenário (US\$36.647 milhões), apresenta um valor esperado da informação perfeita (EVPI) de US\$ 8 milhões. $O$ 
resultado da função objetivo para o valor esperado dos cenários (EVV) é de US\$ 36.377 milhões. Portanto, o valor da solução estocástica (VSS) é de US\$270 milhões.

A fim de analisar melhor este último modelo, o gráfico da figura 44 abaixo mostra a distribuição acumulada dos resultados de três decisões caso o cenário mais otimista aconteça: decisão para o cenário mais otimista (decisão com informação perfeita), decisão do cenário mais pessimista e decisão com as probabilidades subjetivas. A tabela 24 mostra o valor esperado, o CVaR e o resultado da função objetivo para os três casos.

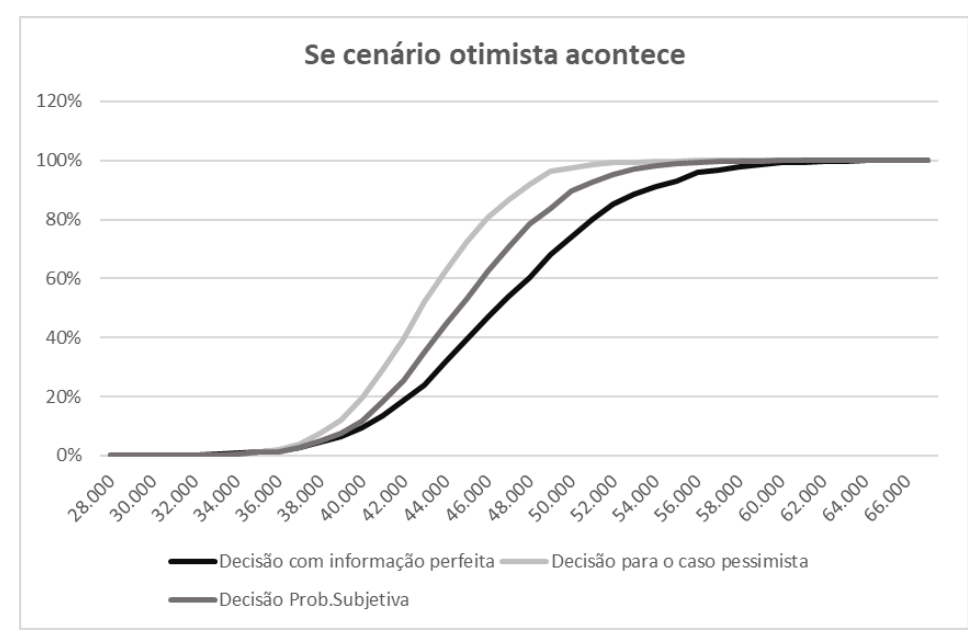

Figura 44 - Distribuições acumuladas dos resultados caso cenário otimista aconteça

\begin{tabular}{|l|c|c|c|}
\cline { 2 - 4 } US\$ Milhões & $\begin{array}{c}\text { Decisão com informação } \\
\text { perfeita }\end{array}$ & $\begin{array}{c}\text { Decisão para o caso } \\
\text { pessimista }\end{array}$ & Decisão Prob.Subjetiva \\
\hline Valor Esperado & 46.668 & 42.990 & 44.787 \\
\hline CVaR & 36.166 & 35.990 & 36.391 \\
\hline Função Objetivo & 41.417 & 39.490 & 40.589 \\
\hline
\end{tabular}

Tabela 23 - Valor esperado, CVaR e resultado caso cenário otimista aconteça

Pela figura 44 e tabela 26, observa-se que a solução com probabilidades subjetivas, para o caso de o cenário mais otimista se realizar, apresenta valores menores que a decisão com informação perfeita, mas que são, ainda assim superiores que aqueles obtidos com as decisões para o cenário mais pessimista. A decisão com probabilidades subjetiva ainda apresentou um maior CVaR, sendo, portanto, uma decisão mais segura frente as incertezas.

Com esses resultados

A mesma análise foi realizada para o caso de o cenário pessimista se concretizar. O gráfico de distribuição acumulada abaixo mostra os resultados das decisões para o cenário pessimista (com informação perfeita), para o caso 
otimista e para o caso com probabilidades subjetivas. Os valo res esperados, o CVaR e o resultado da função objetivo estão na tabela 25.

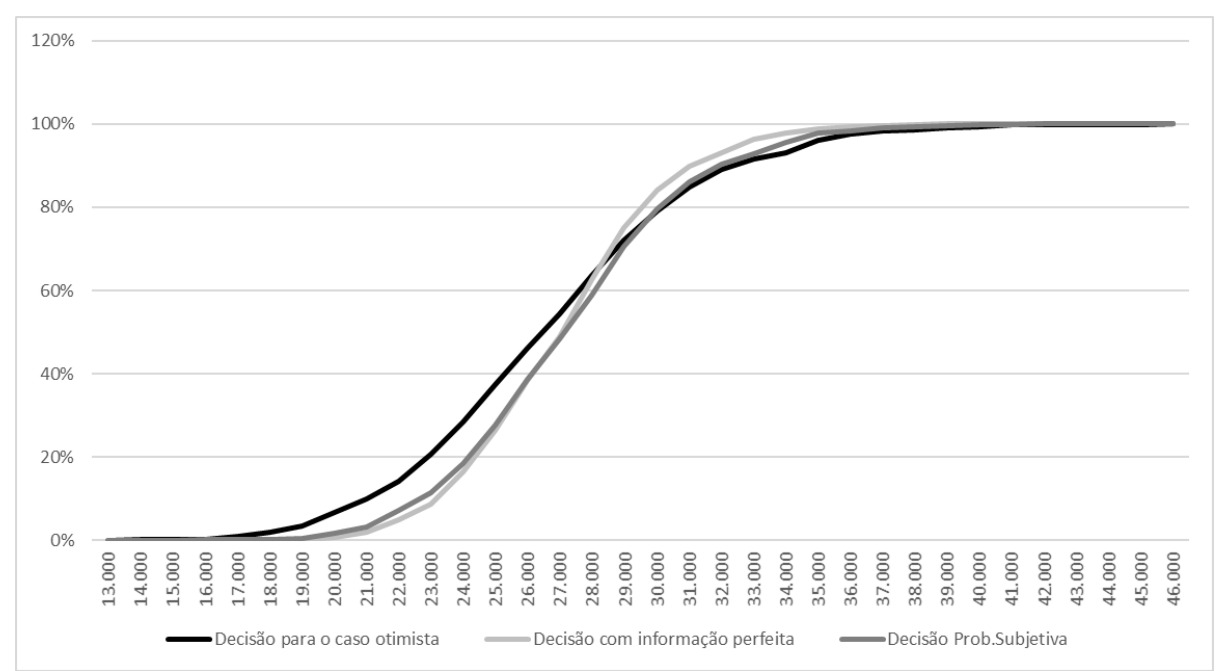

Figura 45 - Distribuições acumuladas dos resultados caso cenário pessimista aconteça

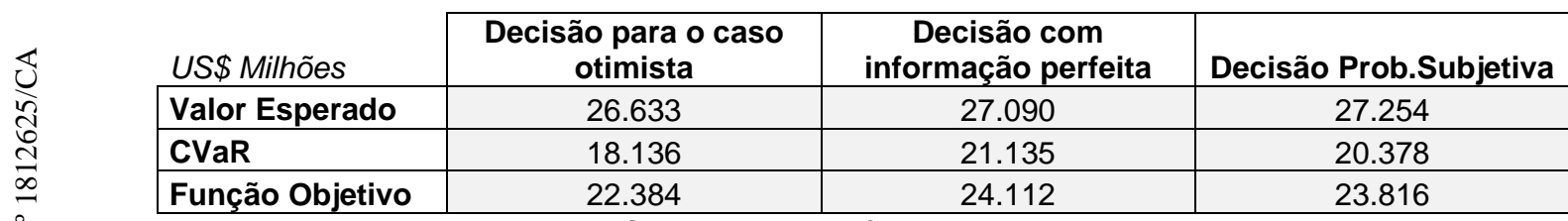

Tabela 24 - Valor esperado e CVaR caso cenário pessimista aconteça

Também para este caso de o cenário mais pessimista ocorrer, a decisão única com probabilidades subjetivas não apresenta grandes perdas frente a decisão com informação perfeita. Apesar da primeira apresentar menor CVaR, o valor esperado é ligeiramente maior que a decisão com informação perfeita. Se a decisão for tomada para o caso otimista e se o cenário pessimista se realizar, tanto o valor esperado quanto o $\mathrm{CVaR}$ se mostram piores.

Com isso conclui-se que, num ambiente de grandes incertezas quanto a cenários estruturais, é razoável a consideração de probabilidades, ainda que subjetiva, para a obtenção de uma decisão única. 


\section{5.}

\section{Conclusões}

Neste trabalho foi desenvolvido um modelo de otimização estocástica para o problema de escolha do portfólio ótimo de uma empresa de petróleo integrada, que possui tanto campos de produção quanto refinarias. O modelo proposto permite ao decisor a escolha dos melhores ativos para manter em seu portfólio, considerando as principais sinergias entre eles sem adicionar grandes complexidades ou alto nível de detalhamento, o que facilita sua aplicação na prática.

A partir de estudos numéricos, pode-se perceber nos resultados do modelo, vários comportamentos típicos do setor e dos segmentos de E\&P e refino. Ficou evidente o maior risco do segmento de E\&P, associado a maiores lucros esperados e um segmento de refino que funciona como uma renda fixa do setor para os casos onde não há controle nos repasses de preços. Também se observou que o modelo indica um portfólio de refino maior para decisores mais avesso a risco.

Verificou-se que controle de preços é prejudicial a rentabilidade do refino, entretanto, mesmo neste cenário, há casos em que pode ser ótimo manter refinarias operando com prejuízo, em contrapartida de um maior ganho na empresa como um todo.

Considerar os dois segmentos, de E\&P e de refino, em uma mesma otimização se mostrou relevante devido as vantagens obtidas com a integração nos custos de alocação do petróleo. Comparando o modelo proposto com outras estratégias que não consideram a integração entre os setores de E\&P e refino, constatou-se que a co-otimização traz ganhos para companhia em considerar a integração entre os campos de produção e as refinarias. Tomadas de decisão de maneira isolada em cada setor pode levar a resultados sub ótimos e perda relevante de valor.

Por fim, em uma análise onde se considerou o contexto da pandemia do COVID-19, mostrou que os impactos no setor são inevitáveis, implicando em diferentes decisões ótimas de portfólio, a depender do cenário. Nos parâmetros simulados, fica evidente que, mesmo no cenário mais pessimista, este novo contexto por si só, não justificaria uma saída completa do setor de óleo e gás. Também se verificou que a utilização de probabilidades subjetivas para os cenários estruturais para obter uma decisão única apresenta bons resultados, no 
sentido de não incorrer em grandes perdas no caso da ocorrência do cenário mais pessimista ou mais otimista. 


\section{6}

\section{Sugestão para Trabalhos Futuros}

Como trabalhos futuros sugere-se:

- O tratamento do estoque final (end effects), com o objetivo de tratar a incapacidade do modelo de enxergar a continuidade do negócio, distorcendo a operação no período final;

- A expansão do modelo proposto para o caso de um problema multi-estágio, visando aproximar o modelo da estratégia tradicionalmente implementada na empresa, envolvendo dois tipos de decisões:

- A decisão de participação em um ativo já existente e operado por outra empresa (farm-in). Neste caso, a implementação é imediata e as decisões podem ser tomadas anualmente.

- A decisão de construção ou desenvolvimento, onde a implementação não é imediata, pois depende do tempo de implantação do projeto (como exploração e desenvolvimento de um campo de petróleo e construção de uma plataforma, ou construção de uma refinaria). Tais decisões são tomadas a cada quatro anos.

- A inclusão dos riscos exploratórios de descoberta, ao se considerar campos que ainda não estão em produção.

- A consideração de incertezas nas demandas internas e externas por derivados e petróleo bruto. 


\section{Referências Bibliográficas}

AL-MONEEF, M.A. Vertical Integration Strategies of the National Oil Companies. The Developing Economies, 1998, 203-22.

AL-OBAIDAN, A.M.; SCULLY G.W. The economic efficiency of backward vertical integration in the international petroleum refining industry. Applied Economics, 1993 (Vol 25).

BALLIN, P.R. et al. Quantifying the Impact of Geological Uncertainty on Reservoir Performing Forecasts. SPE 25238, 12th SPE Symposium on Reservoir Simulation held in New Orleans, LA, U.S.A., February 28-March 3, 1993.

BOMFIM, G.A. Modelagem da Data de Entrada em Produção de Poços de Petróleo Utilizando Inferência Fuzzy. Dissertação (mestrado)-Pontifícia Universidade Católica do Rio de Janeiro, Departamento de Engenharia Industrial, março de 2017.

BULAI, V.C.; HOROBET, A. A portfolio optimization model for a large number of hydrocarbon exploration projects. Proceedings of the International Conference on Business Excellence, 2018, 12(1), 171-181.

CAETANI A.P.; FERREIRA, R.; BORENSTEIN, D. Development of an integrated decision-making method for an oil refinery restructuring in Brazil. Energy, 2015, 111, 197-210.

CARLSSON-SZLEZAK, P.; REEVES, M.; SWARTZ, P. What Coronavirus Could Mean for the Global Economy. Harvard Business Review, 3 de março de 2020.

CARNEIRO, M.C.T. Otimização sob incerteza de carteiras de investimentos: aplicação à cadeia integrada de petróleo e derivados. Dissertação (mestrado) - Pontifícia Universidade Católica do Rio de Janeiro, Departamento de Engenharia Industrial, abril de 2008.

CARNEIRO, M.C.T.; RIBAS, G.,P.; HAMACHER, S. Risk Management in the Oil Supply Chain: A CVaR Approach. Ind. Eng. Chem. Res. 2010, 49, 7, 3286-3294.

DA HORA, M.A.B.P. et al. Decision making to book oil reserves for different Brazilian fiscal agreements using dependence structure. Energy Strategy Reviews, 2019, 26. 
DA SILVA, P.S.M. Seleção de portfólio de projetos com restrição de risco: uma aplicação na indústria de exploração e produção de petróleo e gás natural. Dissertação (mestrado)-Pontifícia Universidade Católica do Rio de Janeiro, Departamento de Engenharia Industrial, abril de 2018.

DIAS, M. A. G. Análise de investimentos com opções reais - Teoria e prática com aplicações em petróleo e em outros setores - Volume 2: Processos estocásticos e opções reais em tempo contínuo. Editora Interciência, 2015. 496p.

DIAS, M.,A.,G.; ROCHA, K., M., C. Petroleum Concessions With Extendible Options Using Mean Reversion With Jumps to Model Oil Prices, 3rd Real Options Conference, 1999.

DIXIT, A. K.; PINDYCK, R. S . Investment under uncertainty. Princeton, New Jersey: Princeton University Press, 1994.

DOS SANTOS, J.A.M.; SCHIOZER D.J. Quantifying Production Strategy Impact in Risk Analysis of an E\&P Project Using Reservoir Simulation. SPE Reservoir Simulation Symposium, 2003, 3-5 February, Houston, Texas. FANZERES, B.; STREET, A.; BARROSO, L. A. Contracting Strategies for Renewable Generators: A Hybrid Stochastic and Robust Optimization Approach. IEEE Transactions on Power Systems, vol. 30, no. 4, pp. 18251837, 2015.

FIORENCIO, L. et al. Investment planning in the petroleum downstream infrastructure. International Transactions in Operational Research, 2015, 22, 339-362.

GIBSON, R.; SCHWARTZ, E., S., Stochastic Convenience Yield and the Pricing of Oil Contingent Claims. The Journal of Finance, v. 45, n. 3: 959976, 1990;

GORELL S.; BASSETT, R. Trends in Reservoir Simulation: Big Models, Scalable Models? Will you Please Make up Your Mind? SPE 71596, Annual Technical Conference and Exhibition held in New Orleans, Louisiana, 30 September - 3 October, 2001.

GRANT,R.M; CIBIN, R. Strategy, Structure and Market Turbulence: The International Oil Majors, 1970-1991. Scandinavian Journal of Management, Vol. 12, No. 2, pp. 165-188, 1996.

HAHN, W., J.; DILELLIO, J., A.; DYER, J., S. What do market-calibrated stochastic processes indicate about the long-term price of crude oil? Energy Economics v.44: 212-221, 2014; 
HURST, A.; BROWN, G.C.; SWANSON, R.I. Swanson's 30-40-30 rule. AAPG Bulletin, v. 84, no. 12, December 2000, pp. 1883-1891.

JONQUA, J.P.C.B. Modelo de Programação Matemática Estocástica para - Planejamento Estratégico da Cadeia de Petróleo sob Incerteza. Dissertação (Mestrado). Pontifícia Universidade Católica do Rio de Janeiro, Departamento de Engenharia Industrial, novembro de 2012.

KHOR, C.S. et al. Two-stage stochastic programming with fixed recourse via scenario planning with economic and operational risk management for petroleum refinery planning under uncertainty. Chemical Engineering and Processing, 2017, 47, 1744-1764.

KOROTIN, $V$ et al. A multi-criteria approach to selecting an optimal portfolio of refinery upgrade projects under margin and tax regime uncertainty. Omega, 2017, 72, 50-58.

LOPES, Y.G.; ALMEIDA, A.T. Assessment of synergies for selecting a project portfolio in the petroleum industry based on a multi-attribute utility function. Journal of Petroleum Science and Engineering, 2014, 126, 131-140.

MARKOWITZ, H. Portfolio selection. The Journal of Finance, v. 7, n. 1, p. 77-91, 1952.

MUTAVDZIC, M.; MAYBEE B. An extension of portfolio theory in selecting projects to construct a preferred portfolio of petroleum assets. Journal of Petroleum Science and Engineering, 2015, 133, 518-528.

ORMAN, M.M.; DUGGAN, T.E. Applying modern portfolio theory to upstream investment decision making. Journal of petroleum technology, 1999, 51, 51-53.

ORNSTEIN, G.E.; UHLENBECK, L.S. On the theory of the Brownian motion. Physical review, 1930, 36, 823-841.

PARIKH, J.; PUROHIT, P.; MAITRA, P. Demand projections of petroleum products and natural gas in India. Energy, 2007, 32, 1825-1837.

RIBAS, G.P.; HAMACHER, S.; STREET, A. Optimization under uncertainty of the integrated oil supply chain using stochastic and robust programming. International Transactions in Operational Research, 2010, 17, 777-796.

SALOMÃO, M.C; GRELL, A.P. Uncertainty in Production Profiles on the Basis of Geostatistic Characterization and Flow Simulation. SPE 69477, Latin American and Caribbean Petroleum Engineering Conference held in Buenos Aires, 2001. 
SEFAIR, J.A. et al. Linear solution schemes for Mean-Semi Variance Project portfolio selection problems: An application in the oil and gas industry. Omega, 2017, 68, 39-48.

STEAGALL, D.E.; SCHIOZER, D.J. Uncertainty Analysis In Reservoir Production Forecasts During Appraisal And Pilot Production Phases. SPE 66399 Reservoir Simulation Symposium held in Houston, Texas, 11-14 February 2001.

STEVENS, P.J. Economists and the oil industry: facts versus analysis, the case of vertical integration, in Hunt, L. C. (ed.) (2003), Energy in a Competitive Market.

SUBBEY, S.; MIKE, C.; SAMBRIDGE, M. A Strategy for Rapid Quantification of Uncertainty in Reservoir Performance Prediction. SPE 79678. Reservoir Simulation Symposium, Houston, Texas, 3-5 February 2003.

SUSLICK, S.B.; SCHIOZER, D.J. Risk analysis applied to petroleum exploration and production: an overview. Journal of Petroleum Science and Engineering, 2004, 44, 1-9.

TANG, B.J.; ZHOU, H.L.; CAO, H. Selection of overseas oil and gas projects under low oil price. Journal of Petroleum Science and Engineering, 2017, 156, 160-166.

WALLS, M.R. Combining decision analysis and portfolio management to improve project selection in the exploration and production firm. Journal of Petroleum Science and Engineering, 2004, 44, 55- 65.

YAN, S., \& JI, X. Portfolio selection model of oil projects under uncertain Environment. Soft Comput, 2017, 22, 5725-5734. 
8

\section{Anexo I}

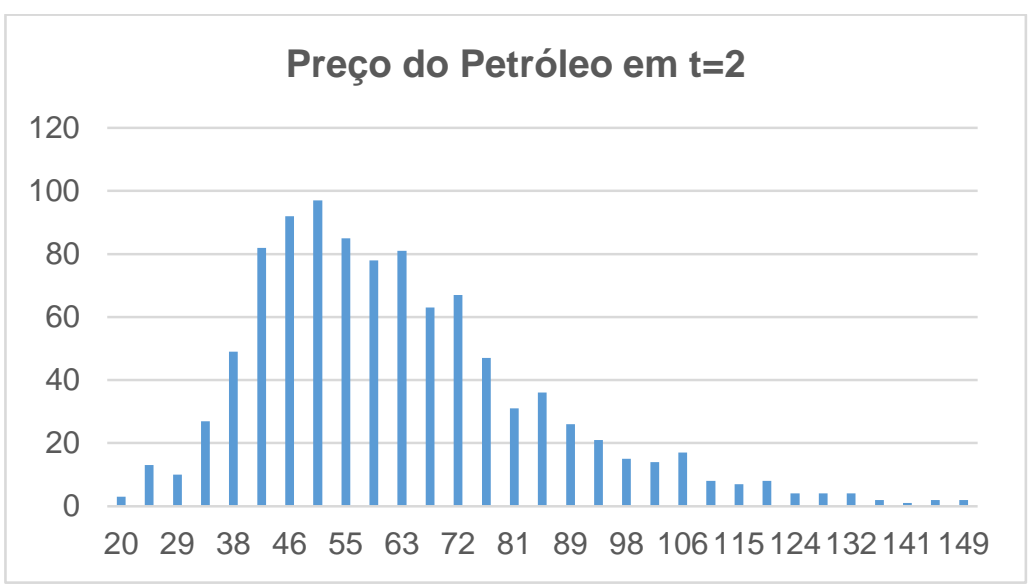

ل)

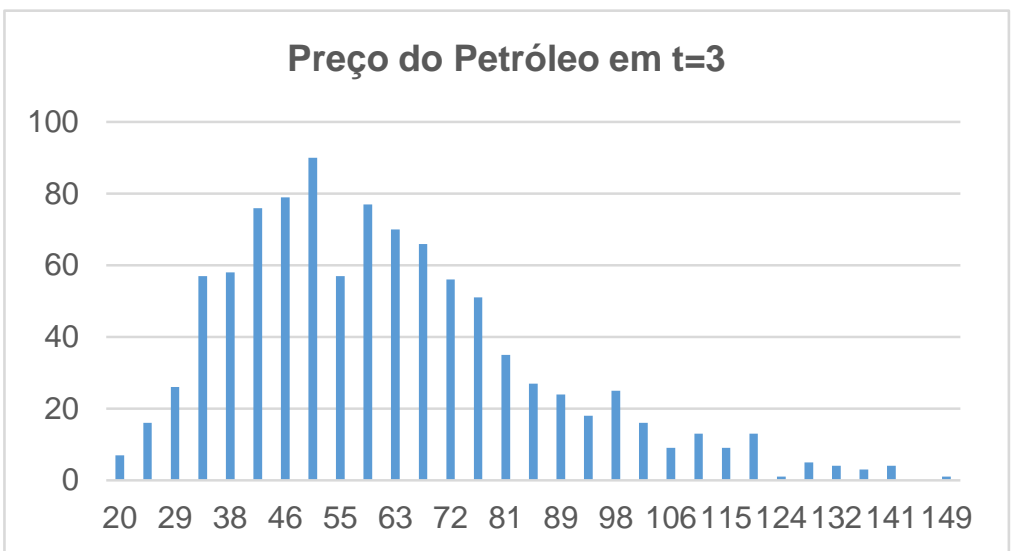




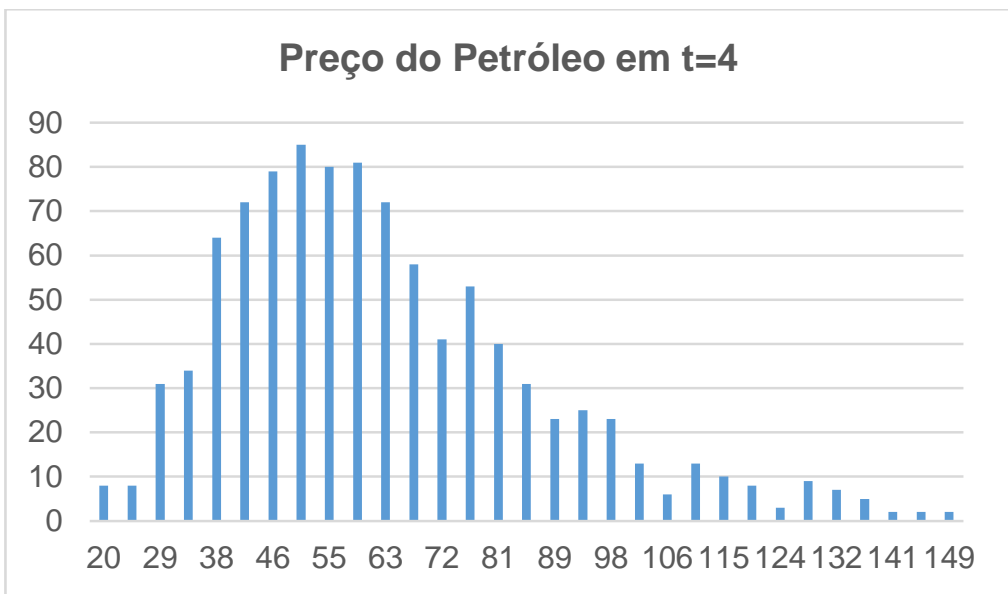

ل)

Preço do Petróleo em $\mathrm{t}=5$

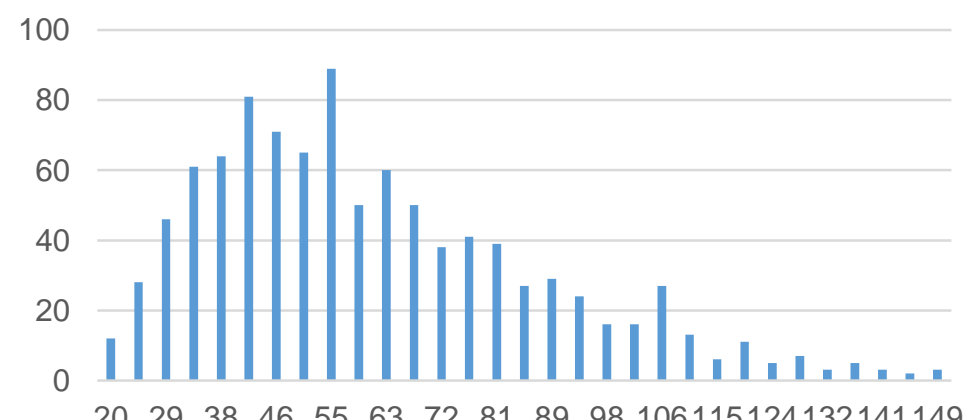

$\begin{array}{lllllllllll}20 & 29 & 38 & 46 & 55 & 63 & 72 & 81 & 89 & 98 & 106115124132141149\end{array}$
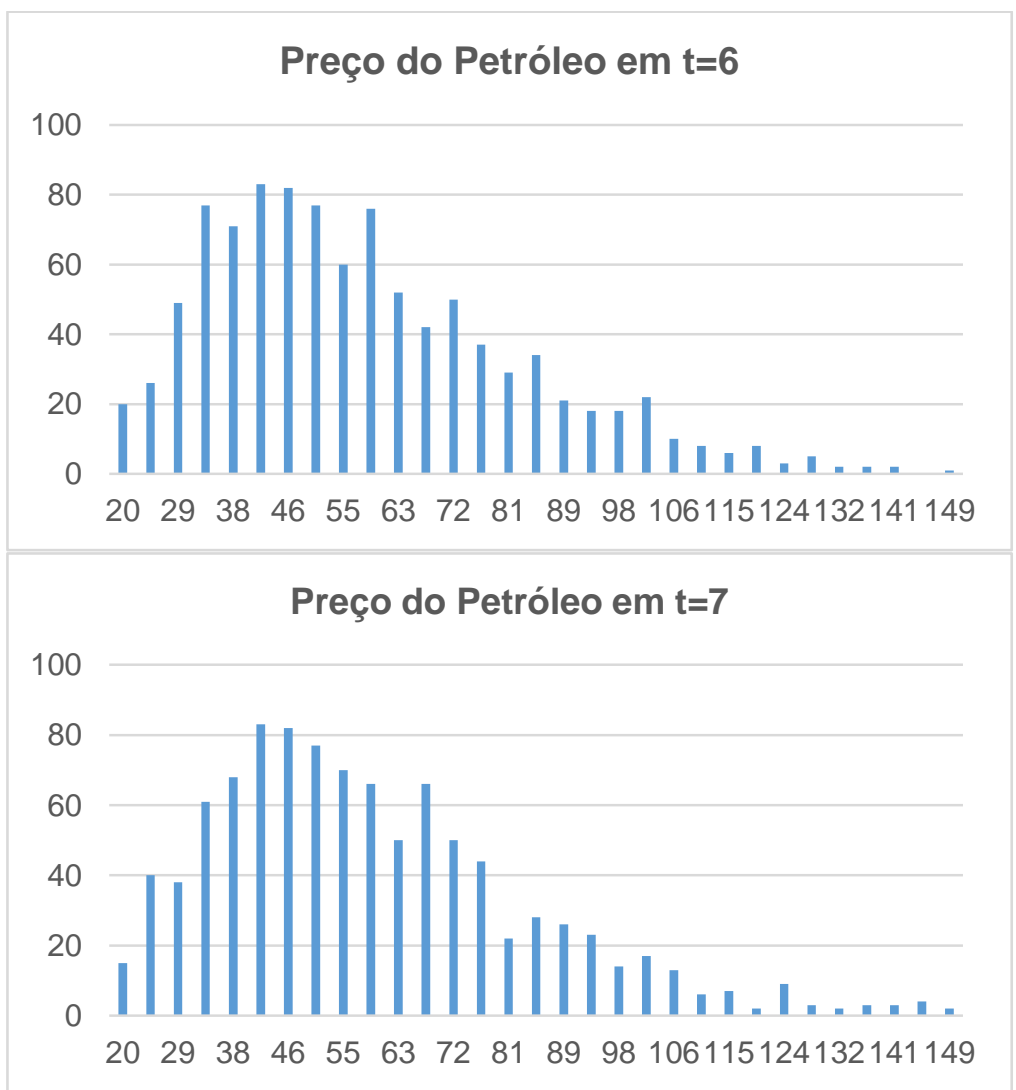

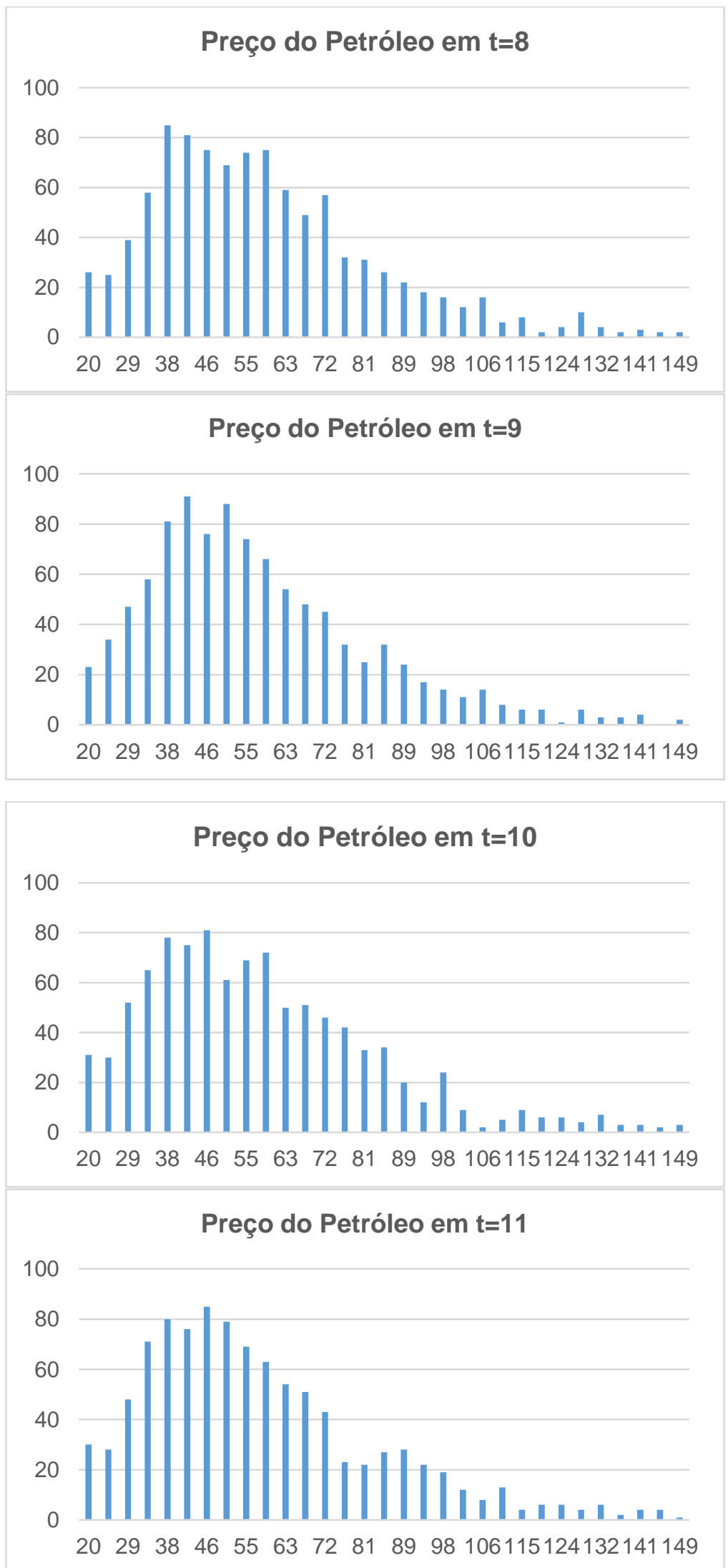